\title{
Um Framework para Desenvolvimento de Interfaces Multimodais em Aplicações de Computação Ubíqua
}

\author{
Valter dos Reis Inácio Júnior \\ Orientadora: Profa. Dra. Maria da Graça Campos Pimentel \\ Dissertação apresentada ao Instituto de Ciências \\ Matemáticas e de Computação - ICMC-USP, como parte \\ dos requisitos para obtenção do título de Mestre em \\ Ciências de Computação e Matemática Computacional.
}



Um Framework para Desenvolvimento de Interfaces Multimodais em Aplicações de Computação Ubíqua 



\section{Dedicatória}

A Deus, pela oportunidade de viver experiências que por vezes nos fazem questionar a Sua razão, mas que sempre se revelam passos necessários $e$ enobrecedores do caráter e da natureza humana. 


\section{Agradecimentos}

Aos meus familiares, Valter, Isabel e Maira, pelo apoio incondicional em todos os momentos.

A minha namorada, Adriana, pelo carinho e compreensão.

A minha orientadora, Graça Pimentel, por toda a ajuda, confiança e liberdade com que me permitiu conduzir a pesquisa. E principalmente, pela amizade nesses anos de convivência.

Aos meus amigos, ex-companheiros do Laboratório Intermídia e atuais companheiros da IBM, pelo incentivo, disposição em colaborar e pelos momentos de descontração.

A FAPESP, pelo apoio financeiro (processo $n^{o}$ 03/11994-5). 


\section{Resumo}

Interfaces multimodais processam vários tipos de entrada do usuário, tais como voz, gestos e interação com caneta, de uma maneira combinada e coordenada com a saída multimídia do sistema. Aplicações que suportam a multimodalidade provêem um modo mais natural e flexível para a execução de tarefas em computadores, uma vez que permitem que usuários com diferentes níveis de habilidades escolham o modo de interação que melhor se adequa às suas necessidades. O uso de interfaces que fogem do estilo convencional de interação baseado em teclado e mouse vai de encontro ao conceito de computação ubíqua, que tem se estabelecido como uma área de pesquisa que estuda os aspectos tecnológicos e sociais decorrentes da integração de sistemas e dispositivos computacionais à ambientes. Nesse contexto, o trabalho aqui reportado visou investigar a implementação de interfaces multimodais em aplicações de computação ubíqua, por meio da construção de um framework de software para integração de modalidades de escrita e voz. 


\section{Abstract}

Multimodal interfaces process several types of user inputs, such as voice, gestures and pen interaction, in a combined and coordinated manner with the system's multimedia output. Applications which support multimodality provide a more natural and flexible way for executing tasks with computers, since they allow users with different levels of abilities to choose the mode of interaction that best fits their needs. The use of interfaces that run away from the conventional style of interaction, based in keyboard and mouse, comes together with the concept of ubiquitous computing, which has been established as a research area that studies the social and technological aspects decurrent from the integration os systems and devices into the environments. In this context, the work reported here aimed to investigate the implementation of multimodal interfaces in ubiquitous computing applications, by means of the building of a software framework used for integrating handwriting and speech modalities. 


\section{Sumário}

\begin{tabular}{lll}
\hline Introdução & 1
\end{tabular}

1.1 Contextualização . . . . . . . . . . . . . . . . . . . 1

1.2 Motivação . . . . . . . . . . . . . . . . . . . . . 2

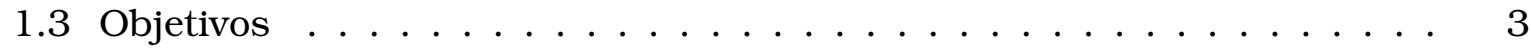

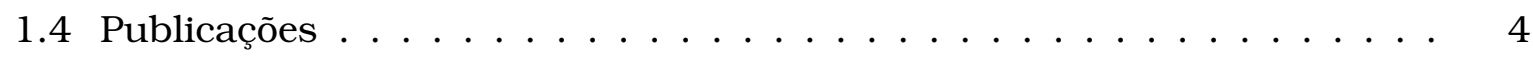

1.5 Estrutura do Documento . . . . . . . . . . . . . . 5

\begin{tabular}{|lll|}
\hline 2 & Interfaces Multimodais e Computação Ubíqua & 7
\end{tabular}

2.1 Considerações Iniciais $\ldots \ldots \ldots \ldots \ldots$. . . . . . . . . . . . . .

2.2 Interfaces Multimodais $\ldots \ldots \ldots \ldots \ldots$

2.3 Interação por Voz e Caneta $\ldots \ldots \ldots \ldots$. . . . . . . . . . 10

2.4 Computação Ubíqua . . . . . . . . . . . . . . . . . . . . . . 12

2.5 Considerações Finais $\ldots \ldots \ldots \ldots \ldots$

3 Conceitos Fundamentais: Reuso de Software 15

3.1 Considerações Iniciais $\ldots \ldots \ldots \ldots \ldots \ldots$

3.2 Bibliotecas . . . . . . . . . . . . . . . . . 15

3.3 APIs - Application Programming Interfaces $\ldots \ldots \ldots \ldots$

3.4 Componentes . . . . . . . . . . . . . . . . . . . . 18

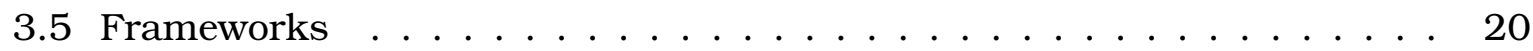

3.6 Patterns . . . . . . . . . . . . . . . . . . . . . . . 23

3.7 Considerações Finais $\ldots \ldots \ldots \ldots \ldots \ldots$ 
4 Infraestruturas de Escrita e Voz: JInk API e JSAPI 27

4.1 Considerações Iniciais $\ldots \ldots \ldots \ldots$. . . . . . . . . . . . . 27

4.2 Modalidade de Escrita $\ldots \ldots \ldots \ldots \ldots \ldots$. . . . . . . . . . . . 27

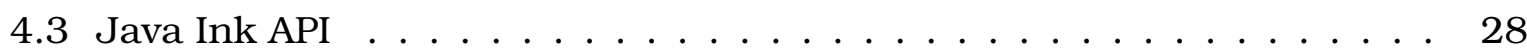

4.3 .1 Método de Reconhecimento . . . . . . . . . . . . . . . . . . 29

4.3 .2 Primitivas Estruturais . . . . . . . . . . . . . . . . 30

4.3 .3 Conjunto de Modelos $\ldots \ldots \ldots \ldots$. . . . . . . . . . 31

4.3 .4 Extração e Reconstrução da Estrutura . . . . . . . . . . . . . . . . 32

4.3 .5 Casamento Estrutural Flexível . . . . . . . . . . . . . . . . . 34

4.3 .6 Pós-Processamento . . . . . . . . . . . . . . . 35

4.3 .7 Especificação de Requisitos . . . . . . . . . . . . . . . . . . . 37

4.3 .8 Modelagem e Implementação . . . . . . . . . . . . . . . . . . 37

4.3 .9 Configuração . . . . . . . . . . . . . . . . . . 39

4.4 Java Speech API $\ldots \ldots \ldots \ldots$

4.4 .1 Arquitetura ........................... 41

4.4 .2 JSGF - Java Speech Grammar Format . . . . . . . . . . . . . . 43

4.4 .3 JSML - Java Speech Markup Language . . . . . . . . . . . . . . . . 44

4.5 Considerações Finais $\ldots \ldots \ldots \ldots \ldots$. . . . . . . . . . . . 45

5 O Projeto Desenvolvido: JMIS Framework 47

5.1 Considerações Iniciais $\ldots \ldots \ldots \ldots$. . . . . . . . . . . . 47

5.2 Fusão de Modalidades . . . . . . . . . . . . . . . . . . . . . 47

5.3 Técnicas de Integração Multimodal Utilizadas $\ldots \ldots \ldots$. . . . . . . . . . 48

5.3 .1 Integração Multimodal baseada em Unificação . . . . . . . . . . . 49

5.3 .2 Gramática Multimodal baseada em Unificação . . . . . . . . . . 50

5.4 Especificação . . . . . . . . . . . . . . . . . . . 53

5.4 .1 Requisitos Não-Funcionais . . . . . . . . . . . . . 53

5.4 .2 Requisitos Funcionais . . . . . . . . . . . . . . . . . 54

5.5 Arquitetura . . . . . . . . . . . . . . . . . . . . 54

5.6 Modelagem e Implementação . . . . . . . . . . . . . . . . 55

5.6 .1 Componente Multimodal $\ldots \ldots \ldots \ldots$ 
5.6 .2 Módulo de Escrita $\ldots \ldots \ldots \ldots$. . . . . . . . . . 56

5.6 .3 Módulo de $\mathrm{Voz} \ldots \ldots \ldots \ldots \ldots$. . . . . . . . . . . 57

5.6 .4 Integrador Multimodal . . . . . . . . . . . . . . . . . 59

5.7 Estrutura de Pacotes $\ldots \ldots \ldots \ldots$. . . . . . . . . . . . 60

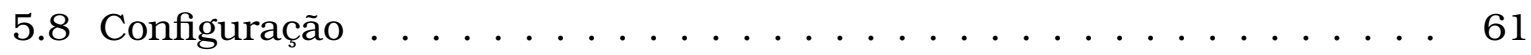

5.9 Avaliação: Aplicações Construídas . . . . . . . . . . . . . . 61

5.9 .1 SpeechBoard . . . . . . . . . . . . . . . . 62

5.9 .2 M4Note . . . . . . . . . . . . . . . . . 64

5.10 Considerações Finais $\ldots \ldots \ldots \ldots \ldots$. . . . . . . . . . . 64

\begin{tabular}{lll}
\hline & Trabalhos Relacionados & 67
\end{tabular}

6.1 Considerações Iniciais $\ldots \ldots \ldots$. . . . . . . . . . . . . 67

6.2 Aplicações Multimodais $\ldots \ldots \ldots$. . . . . . . . . . . . 68

6.2 .1 Put-That-There . . . . . . . . . . . . . . . . 68

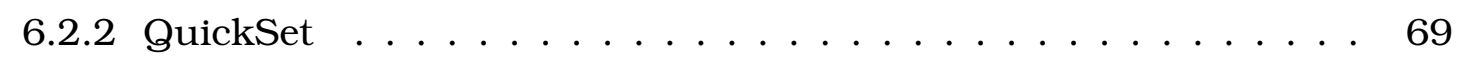

6.2 .3 Field Medic Information System . . . . . . . . . . . . . . 69

6.2 .4 Ford Model U Concept Car . . . . . . . . . . . . . 70

6.2 .5 Multi-Touch Interaction Wall . . . . . . . . . . . . . 71

6.3 Linguagens e Padrões Multimodais . . . . . . . . . . . . . . . . 72

6.3 .1 W3C MMIF - Multimodal Interaction Framework . . . . . . . . 73

6.3 .2 InkML - Ink Markup Language . . . . . . . . . . . . . . . 75

6.3 .3 VoiceXML - Voice Extensible Markup Language . . . . . . . . . . 78

6.3 .4 SALT - Speech Application Language Tags . . . . . . . . . . . . 82

$6.3 .5 \mathrm{X}+\mathrm{V}-\mathrm{XHTML}+$ Voice $\ldots \ldots \ldots . \ldots . \ldots 84$

6.3.6 EMMA - Extensible MultiModal Annotation markup language . . 86

6.4 Considerações Finais $\ldots \ldots \ldots \ldots \ldots$. . . . . . . . . . . . 88

\begin{tabular}{llr}
\hline 7 & Conclusões & 89
\end{tabular}

7.1 Considerações Iniciais $\ldots \ldots \ldots$. . . . . . . . . . . . . . . . 89

7.2 Resultados e Contribuições . . . . . . . . . . . . . . . . . . 90

7.3 Limitações e Problemas Encontrados . . . . . . . . . . . . . . . . . 91

7.4 Trabalhos futuros . . . . . . . . . . . . . . . . 91

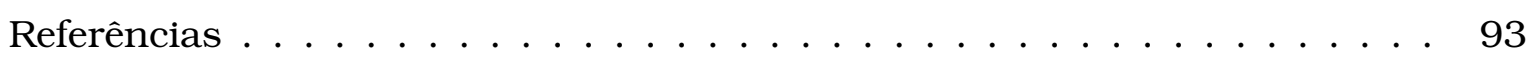




\section{Lista de Figuras}

2.1 Cena do filme Minority Report, em que a personagem interage com o computador por meio de gestos (fonte: http://www.imdb.com/gallery/-

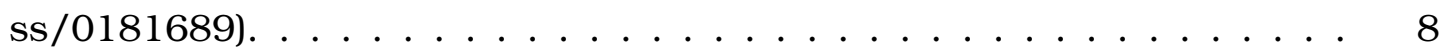

2.2 Exemplos de dispositivos de computação ubíqua: PDA, Tablet PC e lousa

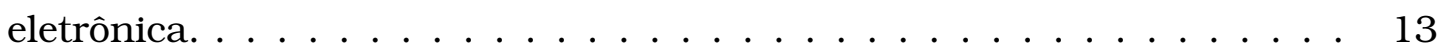

3.1 Inversão de controle: diferença entre bibliotecas, APIs e frameworks (adaptado de [Bachmann et al. 2000|). . . . . . . . . . . . . . . 22

4.1 Visão geral do método de reconhecimento definido por Chan and Yeung

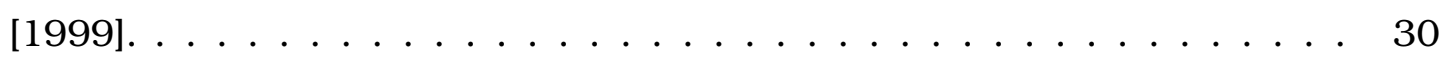

4.2 (a) Direções e valores utilizados na codificação de Freeman| |1974|. (b) Exemplos de caracteres e concatenação de segmentos e traços. (c) Identificação das primitivas e cálculo da direção, onde os pontos representam o início e o fim de cada primitiva. . . . . . . . . . . . . . . 31

4.3 Versões deformadas do caractere "T" resultantes de alteração no tipo (a) e na direção (b) das primitivas (adaptado de |Chan and Yeung, 1999|). . 36

4.4 Diagrama de classes UML referente ao pacote "core" da Java Ink API (por questões de espaço, apenas os principais métodos e atributos são apresentados). ........................ 40

4.5 Interfaces do Painel de Configuração (à esquerda) e do Painel de Controle (à direita) da Java Ink API. . . . . . . . . . . . . . . . . . . . . . 41

4.6 Arquitetura básica de uma aplicação Java utilizando a JSAPI. . . . . . . . . . 42 
5.1 Exemplo de uma árvore de regras com diversos níveis criada a partir de

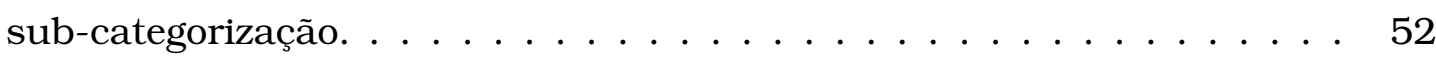

5.2 Arquitetura simplifica do JMIS Framework, ilustrando os quatro módulos principais e seus respectivos níveis. . . . . . . . . . . . . 55

5.3 Diagrama de classes UML para o módulo de escrita. . . . . . . . . . . 58

5.4 Diagrama de classes UML para o módulo de voz. . . . . . . . . . . . . 59

5.5 Diagrama de classes para o módulo relacionado ao Integrador Multimodal, considerado o núcleo do sistema. . . . . . . . . . . . . . . . . 61

5.6 Interface de configuração do JMIS Framework: geração do conjunto de regras e definição de propriedades. . . . . . . . . . . . . . . 63

5.7 Interfaces da SpeechBoard e dos módulos de reconhecimento de voz e

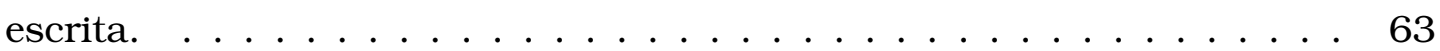

5.8 Interface da ferramenta M4Note: no canto superior esquerdo, o painel para visualização do vídeo; no canto superior direito, a área de edição dos quadros selecionados com tinta eletrônica; na parte inferior, linha do tempo com thumbnails das anotações. . . . . . . . . . . . . . . . . 65

6.1 Put-That-There |Bolt|] $1980 \mid$, um dos primeiros sistemas multimodais. $\mid \ldots \ldots$. . 68

6.2 QuickSet |Cohen et al|, 1997|: Interação multimodal em diversos ambientes. . . . . . . . . . . . . . . . . . 69

6.3 Interfaces multimodais do FMA e do FMC |Holzman, $1999|.| \ldots \ldots$. . . . 70

6.4 Carro-conceito Ford Model U: interior do veículo e interface gráfica com tela sensível ao toque $\mid$ Pieraccini et al., $|2004|$. . . . . . . . . . . . . 71

6.5 Exemplos de aplicações construídas utilizando a tecnologia do Multi-

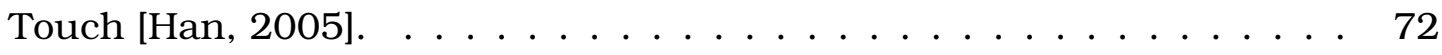

6.6 Fluxo de informação entre os componentes do W3C Multimodal Interaction Framework $|\mathrm{W} 3 \mathrm{C}| ,2002 \mathrm{a} \mid . . \ldots \ldots . \ldots . \ldots 73$

6.7 Exemplo de uma arquitetura cliente-servidor utilizando VoiceXML. . . . 80

6.8 Múltiplos formulários VoiceXML embutidos em um documento XHTML. O resultado é uma aplicação multimodal $\mathrm{X}+\mathrm{V}$ que executa em diferentes

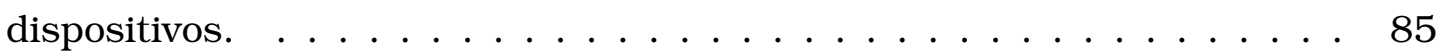




\section{Lista de Tabelas}

4.1 Condições para a combinação de primitivas consecutivas |Chan and Yeung, |1999|, onde $T$ denota os tipos das primitivas e $D$ suas direções. . . 34

4.2 Conjunto de elementos da JSML. . . . . . . . . . . . . . . 46

5.1 Resumo dos pacotes e suas respectivas funções no JMIS Framework. . 62 


\section{Lista de Abreviaturas}

API Application Programming Interface

AHR Automatic Handwriting Recognition

ASR Automatic Speech Recognition

CBSE Component-Based Software Engineering

COM Component Object Model

CORBA Common Object Request Broker Architecture

DLL Dynamic Link Library

DOM Document Object Model

DTMF Dual Tone Multi-Frequential

EMMA Extensible MultiModal Annotation Markup Language

GUI Graphical User Interface

HTML HyperText Markup Language

HPSG Head-driven Phrase Structure Grammar

IDE Integrated Development Environment

IDL Interface Definition Language

IETF Internet Engineering Task Force

InkML Ink Markup Language

IVR Interactive Voice Response

JAR Java Archive

JEE Java Enterprise Edition

JFC Java Foundation Classes

JMF Java Media Framework

JSAPI Java Speech Application Programming Interface

JSDK Java Software Development Kit 
JSGF Java Speech Grammar Format

JSML Java Speech Markup Language

MFC Microsoft Foundation Classes

MVC Model-View-Controller

MMIF Multimodal Interaction Framework

ORB Object Request Broker

SALT Speech Application Language Tags

SDK Software Development Kit

SGML Standard Generalized Markup Language

SMIL Synchronized Multimedia Integration Language

SRGS Speech Recognition Grammar Specification

SSML Speech Synthesis Markup Language

STL Standard Template Library

SVG Scalable Vector Graphics

TIS Text-To-Speech

VoiceXML Voice Extensible Markup Language

W3C World Wide Web Consortium

WML Wireless Markup Language

WWW World-Wide Web

X+V XHTML+Voice

XHTML Extensible HyperText Markup Language

XML Extensible Markup Language 


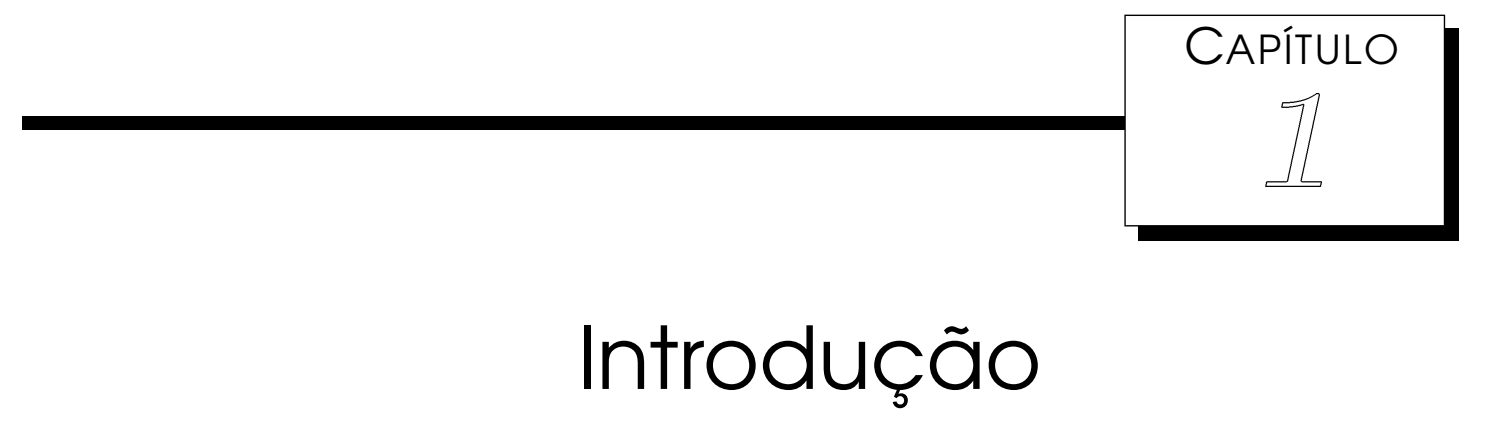

\subsection{Contextualização}

O progresso atual no desenvolvimento de tecnologias de hardware tem levado a um crescente aumento nas capacidades dos computadores, tornando-os menores, mais rápidos e baratos. Isso vem possibilitando uma ampla difusão desses equipamentos pelos mais diversos ambientes, atingindo um número cada vez maior de usuários. Dispositivos como telefones celulares, handhelds, laptops e superfícies eletrônicas em geral já se tornaram parte do cotidiano das pessoas, sendo considerados indispensáveis para a manutenção do estilo de vida moderno.

Entretanto, um problema inerente ao uso dos computadores é que muitas vezes os usuários são obrigados a mudar seus hábitos e métodos de trabalho para adaptarem-se a eles. Embora a evolução dos softwares tenha acompanhado de perto o desenvolvimento dos hardwares, há uma enorme demanda por sistemas que sejam fáceis de usar (alta usabilidade) e que não interfiram muito na maneira das pessoas realizarem suas tarefas (pouco intrusivos). As interfaces gráficas baseadas no paradigma WIMP (Windows, Icons, Menus and Pointers), por exemplo, apesar de representarem uma evolução em relação às interfaces textuais, requerem ainda um aprendizado específico significativo, sobretudo para as pessoas que não utilizam o computador no seu dia-a-dia. 
Nesse sentido, os contínuos esforços empregados em pesquisas na área de Interação Humano-Computador (IHC) nas últimas décadas resultaram no desenvolvimento de interfaces computacionais que suportam formas mais naturais de comunicação, por meio da fala, visão, toque, gestos manuais, etc. As chamadas interfaces multimodais surgiram para tomar vantagem dessas novas modalidades de interação, possibilitando uma maior comunicação com o sistema multi-sensorial humano através do processamento simultâneo de diferentes tipos de entrada [Dix et al., 1998].

O objetivo das interfaces multimodais é suportar múltiplas modalidades de interação, como por exemplo reconhecimento de voz, gestos e escrita manual, de uma maneira integrada e sincronizada com a saída multimídia do sistema Oviatt and Cohen, 2000. Essa nova classe de interfaces representa uma perspectiva de interação que pode influenciar enormemente a produtividade dos usuários, além de permitir uma maior expressividade na comunicação homem-máquina.

\subsection{Motivação}

Aplicações baseadas em interfaces multimodais provêem uma maneira mais natural e flexível para a execução de tarefas em computadores, uma vez que permitem que usuários com diferentes níveis de habilidades escolham o modo de interação que melhor se adequa às suas necessidades e preferências. Essas características têm despertado o interesse da comunidade científica na construção de sistemas que suportem o uso de interfaces multimodais, principalmente nas áreas ligadas a acessibilidade e a utilização de computadores por pessoas portadoras de deficiências.

Entretanto, apesar da evolução de softwares para processamento isolado de modalidades, como por exemplo reconhecedores de voz e escrita cada vez mais precisos, e da disponibilidade de equipamentos para manipulação de diferentes tipos de entrada, como telas sensíveis ao toque e dispositivos baseados em caneta, poucas aplicações têm explorado as vantagens dessas tecnologias. Uma razão para isso é que o tempo gasto para se implementar uma interface multimodal é proibitivo: sistemas que envolvem esse tipo de interface são mais complexos do que os baseados em interação unimodal, o que torna o seu projeto e implementação uma tarefa demorada e dispendiosa.

Sobretudo, interpretadores para várias modalidades são difíceis de desenvolver devido à necessidade de conhecimento especializado sobre os domínios dessas aplicações |Flippo et al., 2003|. Alguém que deseja equipar uma aplicação com tais interfaces deve partir do zero, implementando acesso a sensores externos, desenvolvendo algoritmos para a integração/desambigüação de modalidades e fazendo chamadas a APIs (Application Programming Interfaces) de baixo-nível [Flippo et al., 2003|. Mesmo 
para modalidades isoladas, como o caso do reconhecimento de escrita, ainda existem poucas opções de ferramentas de desenvolvimento que possibilitem integrá-las facilmente às aplicações, sendo a maioria composta de softwares proprietários.

Além disso, os sistemas multimodais atuais fazem uso de regras rígidas e sintaxes específicas sobre as modalidades envolvidas, tornando necessário a adaptação do usuário e aumentando a curva de aprendizado [Oviatt and Cohen, 2000|. O fato de não poder interagir com esses sistemas de uma maneira flexível, utilizando comandos e semânticas definidas por ele próprio, desestimula o usuário.

Investigações relativas a prover apoio para o desenvolvimento de interfaces multimodais tem sido reportadas, entre outros, no contexto de aplicações Web (por exemplo [Honkala and Pohja, 2006; Taib and Ruiz, 2006), dispositivos moveis (por exemplo SSerrano et al., 2006; Paterno; and Giammarino, 2006; Taib and Ruiz, 2005; Hanheide et al., 2005]) e ambientes de realidade virtual (por exemplo Latoschik [2005]; Irawati et al. [2006]).

Honkala and Pohja [2006] estendem a proposta padrão do W3C para especificação de formulários XForms, em um modelo que combina para XForms com folhas de estilo e controle de interação multimodais. Já Taib and Ruiz [2006] investigam o uso de interação multimodal para a personalização de navegação.

Serrano et al. [2006] propõem uma abordagem baseada em componentes para desenvolvimento e avaliação de interfaces multimodais para telefones moveis, baseada em um trabalho prévio do grupo relativo a componentes de software para prototipação rápida de aplicações Bouchet et al. [2004]. Paterno; and Giammarino [2006] apresentam um modelo e uma ferramenta para a criação de aplicações que combinam ambientes baseados em voz e interfaces gráficas. Hanheide et al. [2005] combinam informação do ambiente e gestos na interação com dispositivos móveis do tipo "wearable device" - o trabalho combina reconhecimento de voz com visão para reconhecimento de gestos.

\subsection{Objetivos}

A computação ubíqua tem se estabelecido como uma área de pesquisa que estuda os aspectos tecnológicos e sociais decorrentes da integração de sistemas e dispositivos computacionais à ambientes. A premissa básica para as aplicações ubíquas é mudar o foco de interação para fora do paradigma tradicional de "computação no desktop", fugindo do modelo de interação baseado em teclado, mouse e display |Abowd and Mynatt, 2000. 
Este projeto teve como objetivo geral investigar os problemas associados à integração de interfaces multimodais, especificamente as que envolvem interação por caneta e voz, a aplicações de computação ubíqua. Para tanto, foi proposta a construção de um conjunto de componentes de software que agregassem as funcionalidades de reconhecimento de escrita manual, interpretação de gestos, símbolos e formas desenhados manualmente, verificação de assinaturas, reconhecimento e síntese de voz. A idéia era que esses componentes fossem estruturados sob a forma de um framework, denominado Java Multimodal Ink and Speech (JMIS Framework), de maneira a facilitar a sua utilização por outros programadores.

As atividades desenvolveram-se no contexto de dois projetos de pesquisa: o Projeto InCA-SERVE1, que consiste de uma cooperação internacional entre o ICMC-USP, no Brasil, e o Georgia Institute of Technology (GaTech), nos EUA, e tem como objetivo a construção de aplicações de computação ubíqua que enfatizam os processos de captura e acesso de informação em ambientes tais como salas de aulas e reuniões; e o Projeto Applied Mobile Technology Solutions in Learning Environments2, que é o resultado de uma parceria entre a Hewlett-Packard Company e a USP, e tem por objetivo explorar a utilização de infraestruturas de computação móvel em atividades de ensino e aprendizagem em ambientes universitários. Esses projetos serviram de base para a implementação de aplicações prova-de-conceito, de modo a testar o framework desenvolvido.

\subsection{Publicações}

As publicações obtidas até o momento no contexto deste trabalho foram:

- Cattelan, R. G., Inácio Jr, v. R., Pimentel, M. G. C. (2005). Pervasive Imaging: a Capture and Access Perspective. In: Proceedings of the 2005 Workshop of Pervasive Image Capture and Sharing, 2005, Tokio, Japan.

- Macedo, A. A., Bulcão Neto, R. F., Camacho-Guerrero, J. A., Jardim, C. H., Cattelan, R. G., Inácio Jr, V. R., Pimentel, M. G. C. (2005). Linking Everyday Presentations through Context Information.In: Proceedings of the 3rd IW3C2 Latin American Web Congress, 2005, Buenos Aires, pp. 1-8.

- Goularte, R., Camacho-Guerrero, J. A., Inácio Jr, V. R., Cattelan, R. G. Pimentel, M. G. C. (2005). M4Note: a Multimodal Tool for Multimedia Annotation. In: Cadernos de Computação do ICMC-USP, São Carlos, May 2005, Vol. 6, No. 01, pp. 113-131.

\footnotetext{
${ }^{1}$ http://coweb.icmc.usp.br/incaserve

${ }^{2}$ http://coweb.icmc.usp.br/coweb/mostra.php?ident $=167$
} 
- Pimentel, M. G. C., Cattelan, R. G., Inácio Jr, V. R., Baldochi Jr, L. A., CamachoGuerrero, J. A., Botero, P., Fortes, R. P. M., Pratschke, A., Farah, J. P. S., Goularte, R. (2004). Exploiting mobility to document the learning experience. In: Proceedings of the 1st TIDIA Workshop: E-learning Project, 2004, São Paulo, pp. 57-62.

- Goularte, R., Camacho-Guerrero, J. A., Inácio Jr, V. R., Cattelan, R. G. Pimentel, M. G. C. (2004). M4Note: a Multimodal Tool for Multimedia Annotation. In: Proceedings of the 10th WebMedia/2nd IW3C2 LA-Web Joint Conference, Ribeirão Preto, October 2004, IEEE CS Press, pp.142-149.

- Macedo, A. A., Camacho-Guerrero, J. A., Cattelan, R. G., Inácio Jr, V. R., Pimentel, M. G. C. (2004). Interaction Alternatives for Linking Everyday Presentations. Technical Report, Instituto de Ciências Matemáticas e de Computação, Universidade de São Paulo. São Carlos, 2004.

- Goularte, R., Camacho-Guerrero, J. A., Inacio Jr, V. R., Cattelan, R. G. (2004). Interactive Multimedia Annotations: Enriching and Extending Content. In: Proceedings of the 2004 ACM Symposium on Document Engineering, Milwaukee-USA, October 2004, pp. 84-86.

- Macedo, A. A., Camacho-Guerrero, J. A., Cattelan, R. G., Inácio Jr, V. R., Pimentel, M. G. C. (2004). Interaction Alternatives for Linking Everyday Presentations. In: Proceedings of the 15th ACM Conference on Hypertext and Hypermedia, Santa Cruz-CA-USA, August 2004, ACM Press, pp. 112-113.

\subsection{Estrutura do Documento}

O restante deste documento está organizado da seguinte maneira: o Capítulo 2 resume alguns fundamentos sobre as áreas de pesquisa de interfaces multimodais e computação ubíqua; o Capítulo 3 discute conceitos básicos sobre reuso de software; o Capítulo 4 detalha as duas infraestruturas envolvidas na implementação do framework multimodal; o Capítulo 5 descreve o projeto desenvolvido e os resultados obtidos; o Capítulo 6 apresenta alguns dos trabalhos relacionados; e o Capítulo 7 apresenta as conclusão do trabalho, contribuições e trabalhos futuros. 


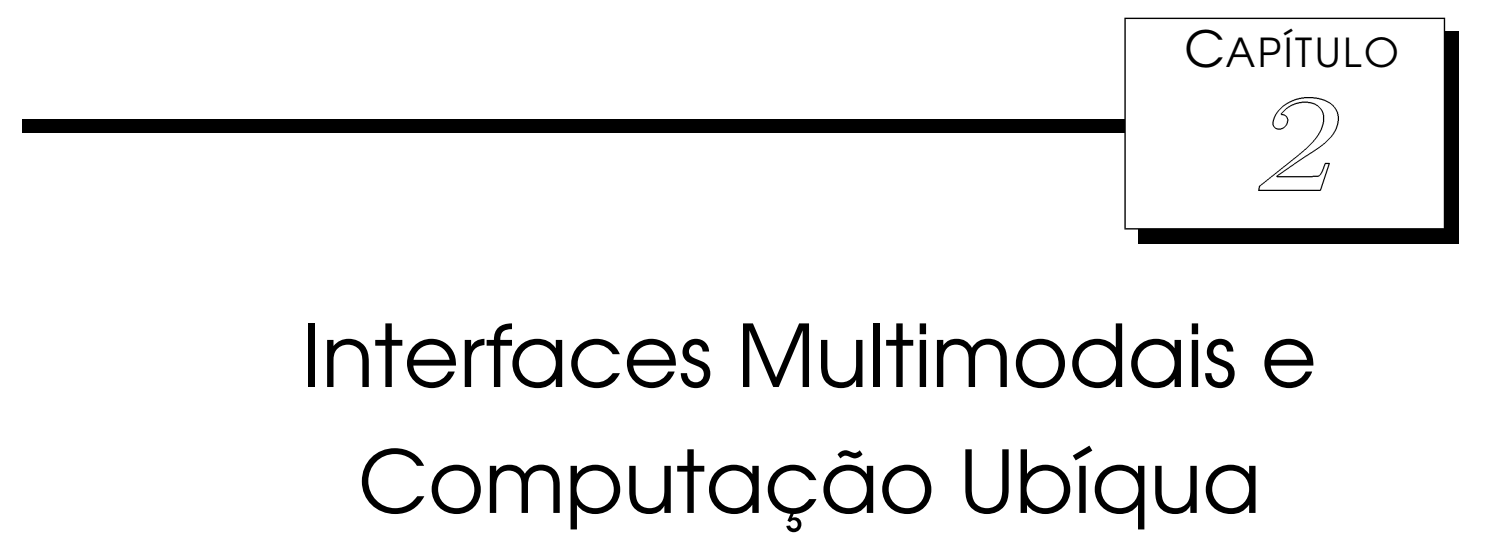

\subsection{Considerações Iniciais}

Neste capítulo são apresentados conceitos fundamentais sobre Interfaces Multimodais e Computação Ubíqua, alguns dos trabalhos mais relevantes em cada área e noções sobre o Estado da Arte. Devido a ampla abrangência desses temas, os mesmos serão abordados sob uma perspectiva mais diretamente relacionada ao trabalho exposto nesta dissertação.

\subsection{Interfaces Multimodais}

A percepção dos humanos de seu ambiente dá-se por meio dos cinco sentidos: visão, audição, tato, paladar e olfato. Esses sentidos, utilizados de maneira isolada ou combinada, constituem uma rede sensorial que permite ao cérebro obter todo tipo de informação necessária para a interação com o mundo exterior. Da mesma forma, a comunicação entre humanos vale-se desses mecanismos para capturar, processar e trocar informação, seja ela por meio da fala, gestos, expressões faciais, etc. Esse tipo de comunicação é naturalmente multimodal, já que os humanos durante uma conversa, por exemplo, gesticulam, apontam para objetos, demonstram emoções e sentimentos, tudo ao mesmo tempo. A interação envolve não apenas componentes 
lingüísticos ou provenientes de um único canal sensorial, mas sim de múltiplos, simultaneamente. Seria ideal, portanto, que pudéssemos fazer uso de todo esse aparato físico/biológico e do caráter multi-canal da comunicação humana também para nos comunicar com as máquinas.

Entretanto, no estágio atual da tecnologia, existe ainda uma enorme distância entre a interação humano-computador e a interação humano-humano, sendo que um dos grandes desafios de áreas como IHC e IA (Inteligência Artificial) é tornar essa comunicação o mais próxima possível da comunicação humano-humano. Até poucos anos atrás, o computador era visto como uma ferramenta passiva que realizava tarefas e cujo objetivo aparentemente era ser um "escravo" sob o comando humano. Porém, com a evolução de softwares baseados em IA, capazes de interpretar ordens e tomar decisões, e de dispositivos eletrônicos capazes de perceber e reagir a estímulos do ambiente, o conceito de computador tem mudado drasticamente: ele não é mais apenas uma ferramenta que simplesmente executa determinadas tarefas, mas sim um participante que interage e se comunica de volta com o usuário, inclusive explicitando suas necessidades |Jokinen and Raike, 2003|.

Nesse contexto, o termo multimodal pode ser entendido como "vários modos" ou "múltiplas modalidades" de interação, onde cada qual pode corresponder a um dos cinco sentidos físicos utilizados na comunicação. Assim como no filme Minority Report [20th Century Fox, 2002], em que as personagens interagem através de gestos manuais com a interface de um computador (Figura 2.1), o objetivo das chamadas interfaces multimodais é tornar a interação humano-computador mais parecida com a forma segundo a qual os humanos interagem entre si e com o ambiente [Dix et al., 1998.
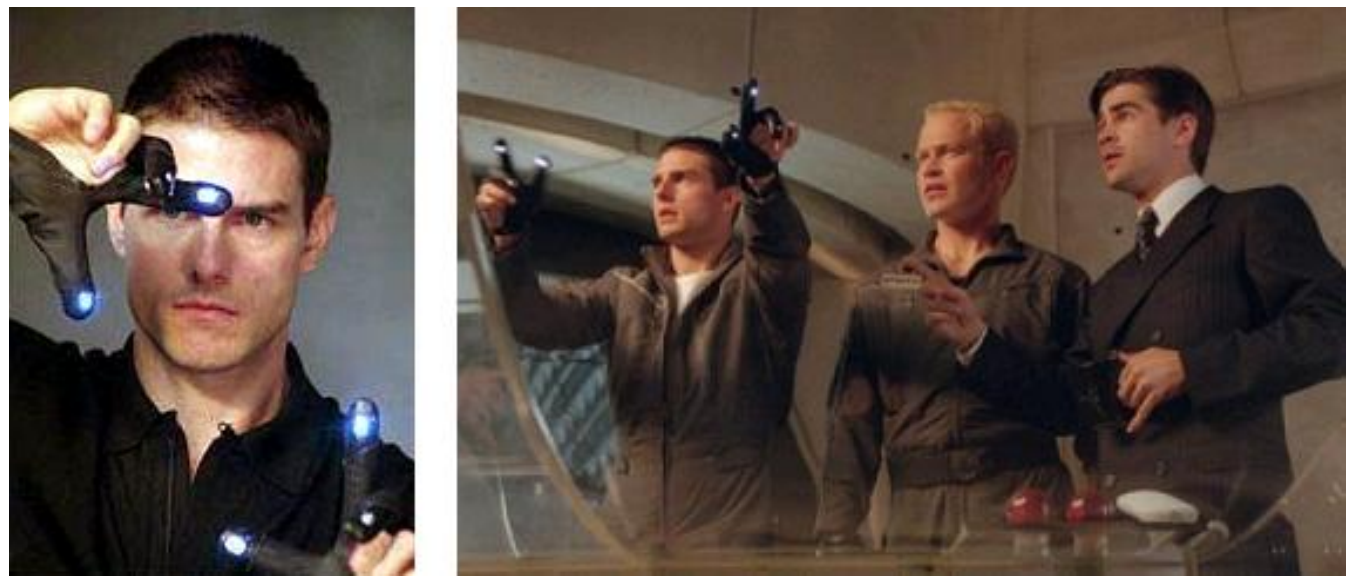

Figura 2.1: Cena do filme Minority Report, em que a personagem interage com o computador por meio de gestos (fonte: http://www.imdb.com/gallery/ss/0181689). 
Geralmente, quando utilizamos uma interface de computador, fazemos uso de um dispositivo de entrada por vez, seja digitando, clicando o mouse, falando ou apontando com uma caneta magnética (como por exemplo, em tablets e lousas eletrônicas). Essa maneira unimodal de expressar nossa intenção é longe de ser satisfatória: alguns exemplos onde essa afirmação se torna evidente são quando pressionamos uma tecla errada ou quando temos que navegar por uma série de menus apenas para mudar a cor de um objeto. A seguir são discutidas algumas razões práticas, biológicas e até mesmo matemáticas que justificam o uso da interação multimodal em IHC |Sharma et al., 1998]:

Razões Práticas: Os sistemas de IHC atuais apresentam várias desvantagens do ponto de vista de eficiência. Embora estejamos habituados a utilizá-los, dispositivos como o teclado e o mouse são desajeitados e inconvenientes para uso em certos aplicações como, por exemplo, em ambientes de realidade virtual imersiva. Diversos estudos confirmam que as pessoas preferem utilizar múltiplas modalidades para a manipulação de objetos virtuais Hauptmann and McAvinney, 1993| |Oviatt et al., 1997|. Hauptmann and McAvinney [1993| concluíram que $71 \%$ dos indivíduos pesquisados preferem utilizar as mãos e a voz para controlar esses objetos do que uma única modalidade isolada. Oviatt et al. [1997] também demonstrou que $95 \%$ das pessoas tendem a utilizar gestos junto com a voz para a tarefa de manipulação de mapas. Cohen et al. [1989] mostrou que as modalidades também podem se complementar: gestos manuais são considerados ideais para manipulação direta de objetos, ao passo que a linguagem natural é mais bem aplicada em tarefas descritivas.

Razões Biológicas: Uma argumentação racional para o uso de múltiplas modalidades pode ser encontrada na natureza: seres humanos bem como outros animais integram múltiplos sentidos para interagir com o ambiente. Estudos revelam que os diferentes sinais sensoriais são inicialmente capturados em áreas distintas do cérebro, convergindo então para uma única área no colículo superior e gerando um sinal resultante |R. R. Murphy, 1996]. A grande maioria (cerca de $75 \%$ ) dos neurônios dessa região do cérebro são multi-sensoriais. Isso sugere fortemente que o uso da multimodalidade em IHC seria desejável, especialmente se o objetivo for incorporar naturalidade de comunicação.

Razões Matemáticas: Outras razões para a integração de modalidades tem origem do campo da Fusão de Dados. O objetivo da Fusão de Dados é pesquisar maneiras de otimizar a integração de diferentes sinais sensoriais (como por exemplo, radar, infra-vermelho, etc.) para a detecção de alvos. A combinação de múltiplos sensores provém da análise estatística de dados, que estabelece 
que a desvantagem em se utilizar um único sensor se dá pela inadequação desse sensor em reduzir a incerteza para a tomada de decisão. Essa incerteza surge quando alguma característica está ausente, ou o sensor não mede corretamente todos os atributos necessários ou quando as observações são ambíguas. Por outro lado, é estatisticamente vantajoso combinar múltiplas observações de uma mesma fonte, pois a redundância melhora as estimativas e aumentam a precisão do sistema [D. L. Hall and J. Llinas, 1997].

A utilização simultânea de vários canais sensoriais, ou modos de comunicação, tais como visão e audição, aumenta a capacidade humana de absorção e troca de informação e evita que apenas um canal seja sobrecarregado [Dix et al., 1998]. A idéia é que interfaces multimodais suportem de maneira flexível a comunicação humanocomputador, permitindo assim que usuários com diferentes preferências e níveis de habilidades escolham o modo como irão interagir. Por exemplo, usuários com deficiências visuais ou motoras podem sentir-se mais confortáveis ao utilizar uma interface baseada em voz, ao passo que usuários com problemas na fala ou audição podem achar a interação por caneta ou gestos mais eficiente. A flexibilidade de interação inclui tanto a escolha de qual modalidade usar como também a possibilidade de combinar diferentes tipos de entradas ou alternar entre os modos a qualquer momento. Isso vai de encontro ao conceito de computação ubíqua (Seção 2.4) segundo o qual os sistemas computacionais é que devem se adaptar às pessoas, ao contrário do que acontece atualmente na maioria das aplicações.

Há ainda um crescente interesse no projeto de interfaces multimodais que explorem tecnologias baseadas em visão computacional, tais como reconhecimento de faces |Zhao et al., 2003|, gestos manuais |Westeyn et al., 2003| e rastreamento de olhar |Morimoto et al., 1999]. Em contraste aos modos de entrada ativos como a fala ou a escrita, nos quais o usuário interage explicitamente com o sistema, as tecnologias baseadas em visão permitem modos de entrada passivos, exigindo o mínimo de interferência e não desviando a atenção do usuário na execução de suas tarefas Oviatt, 2002.

\subsection{Interação por Voz e Caneta}

Atualmente, sistemas envolvendo interação com voz e caneta constituem um campo de pesquisa bastante em evidência na área de interfaces multimodais. Isso se deve a uma série de fatores, descritos a seguir. 


\section{Disponibilidade de tecnologias}

A implementação de interfaces que explorem várias modalidades é uma tarefa complexa e ainda em fase de amadurecimento, dependendo em grande parte do avanço nas pesquisas individuais de cada modalidade. Apenas recentemente ferramentas para programação de aplicações com, por exemplo, reconhecimento de voz, se tornaram disponíveis.

Apesar disso, tecnologias como o reconhecimento de escrita já se tornaram comuns em tablets e palmtops, e estão agora começando a aparecer em telefones móveis, na forma de agendas, gerenciadores de contatos e ferramentas para anotações pessoais.

\section{Suporte à mobilidade}

As interfaces baseadas em entrada por voz e/ou caneta são particularmente efetivas no suporte a mobilidade. As conhecidas limitações dos dispositivos móveis, como o tamanho reduzido do display e a ausência de teclado, podem ser "amenizadas" pelo uso de interação multimodal. Além disso, diferentemente do teclado e mouse, as interfaces físicas dos dispositivos que suportam essas modalidades são compactas e portáteis.

Um outro ponto é que, com a atual difusão das redes sem fio e da computação distribuída, os sistemas de reconhecimento de voz e escrita, que demandam grande quantidade de processamento e memória, podem ser executados como serviços remotos.

\section{Modalidades complementares}

A combinação de entradas de voz e de caneta provê uma maior flexibilidade de interação, na medida em que cada modalidade individualmente se adapta melhor a um determinado tipo de tarefa ou situação.

A modalidade voz, por exemplo, oferece velocidade na entrada de informações e facilidade de uso. Além disso, libera o usuário do contato direto, permitindo que seus olhos e mãos fiquem livres para a execução de outras atividades. Segundo Oviatt et al. [2000], os usuários tendem a preferir a fala para descrever objetos e fatos, relacionar informações, como também comandar ações do sistema.

Já a modalidade caneta é preferida na entrada de símbolos e sinais (por exemplo, dígitos e abreviações), gestos, desenhos, rascunhos e para seleção de objetos na tela Oviatt et al. 2000|. A entrada por caneta em domínios como arquitetura e engenharia, onde há necessidade de gráficos e informação espacial precisa de pontos, 
linhas e áreas, é uma capacidade importante. Essa modalidade também suporta melhor a privacidade do usuário e funciona como uma alternativa à voz em ambientes com alto nível de ruído.

\section{Tratamento de erros}

Uma das vantagens da integração de modalidades é o aumento de eficiência no tratamento de erros, tanto em relação a erros provenientes do usuário como do sistema. Algumas das razões para isso são |Oviatt et al., 2000|: (a) de acordo com o tipo de tarefa, o próprio usuário irá escolher o modo de interação menos propenso a erros; (b) o usuário tem a tendência de trocar de modo de interação após erros, facilitando a recuperação do sistema; (c) a linguagem do usuário é simplificada quando este interage de maneira multimodal, o que reduz a complexidade do processamento de linguagem natural e portanto diminui erros de reconhecimento; (d) arquiteturas multimodais bem desenvolvidas suportam a desambiguação mútua das entradas, em que a informação semântica de uma modalidade funciona como entrada parcial para a desambiguação da outra.

\subsection{Computação Ubíqua}

O conceito de computação ubíqua surgiu em 1991, quando Mark Weiser, pesquisador do Xerox Palo Alto Research Center, introduziu uma nova maneira de fazer uso dos computadores na vida das pessoas. Segundo ele, facilidades computacionais deveriam ser incorporadas aos ambientes para auxiliar as tarefas humanas de uma forma transparente e pouco intrusiva [Weiser, 1991]. Nesse contexto, os computadores não só estariam em todos os lugares, como também se comunicando de maneira autônoma sobre uma rede. Eles se utilizariam de múltiplos sensores para obter dados do ambiente, atuando de modo inteligente de acordo com informações pessoais de cada usuário.

Weiser também descrevia uma proliferação de dispositivos computacionais ubíquos de vários tamanhos, desde pequenos e pessoais (inch-scale), até grandes e de uso coletivo (yard-scale). Isso de fato já ocorreu, com a popularização de dispositivos pessoais como PDAs, tablets e laptops, e dispositivos maiores, como lousas eletrônicas (Figura 2.2).

Outro aspecto da visão de Weiser era que novas aplicações surgiriam para explorar o uso destes dispositivos. Basicamente, o desenvolvimento de tais aplicações está relacionado a três temas: 

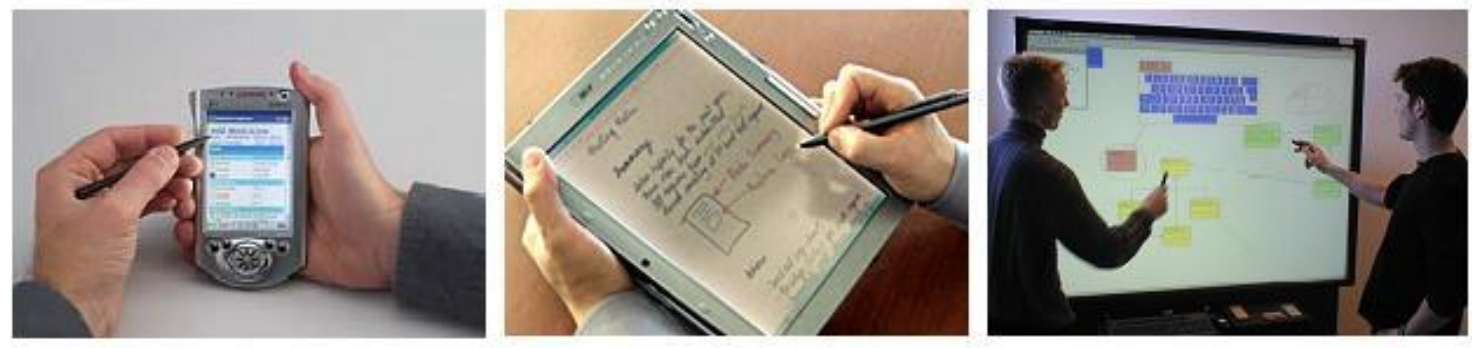

Figura 2.2: Exemplos de dispositivos de computação ubíqua: PDA, Tablet PC e lousa eletrônica.

Captura e acesso de experiências: Aplicações de computação ubíqua que tentam automatizar a captura de experiências e prover acesso flexível à informação capturada são de muita utilidade. Nos últimos anos, sobretudo em função da difusão da multimídia nos ambientes computacionais, o homem passou a utilizar o computador como forma de capturar e armazenar memórias, por meio de documentos tradicionais, hiperdocumentos ou arquivos de áudio e vídeo. Esse tipo de aplicação apresenta um amplo espaço de pesquisa para a integração de interfaces multimodais, uma vez que as atividades de captura poderiam ser manipuladas e controladas de diferentes formas, provendo uma ubiqüidade ainda maior. $\mathrm{O}$ acesso às informações armazenadas também seria facilitado, incluindo a possibilidade de manipulação da informação multimídia por meio de interação multimodal |Laverty and Defee, 1997|.

Computação ciente de contexto: Aplicações de computação ubíqua precisam ser cientes de contexto, isto é, ser capazes de adaptar seu comportamento de acordo com informações obtidas do ambiente físico e computacional. Muitas aplicações ainda têm procurado obter informações simples de contexto, tais como informações de localização e identificação, mas numerosos desafios ainda impedem a representação de contexto de forma reusável e bem definida Abowd and Mynatt, 2000. Pesquisas recentes reportam o uso de interfaces multimodais com o intuito de fornecer mecanismos para obtenção de informações de contexto Nock et al., 2004.

Interfaces naturais: As pessoas desejam interfaces que possibilitem diferentes formas de interação entre seres humanos e computadores. Similarmente às interfaces multimodais, o objetivo das interfaces naturais é suportar as formas comuns de expressão humana, porém de uma maneira transparente, tal como as pessoas interagem com o mundo físico. Alguns trabalhos tentam explorar o uso de objetos concretos com o intuito de manipular artefatos computacionais, criando o conceito de interfaces tangiveis [Ishii and Ullmer, 1997]. Há ainda 
pesquisas relacionadas ao uso de sensores em dispositivos computacionais, de modo a permitir que a manipulação física desses dispositivos seja corretamente interpretada pelas aplicações que os controlam [Harrison et al., 1998].

\subsection{Considerações Finais}

O advento de interfaces multimodais baseadas em reconhecimento de voz, gestos e outros comportamentos naturais, representa apenas o início da pesquisa em direção a interfaces com uma percepção sensorial próxima (ou mesmo superior) à humana. Tais interfaces irão eventualmente interpretar entradas contínuas de um grande número de entradas visuais, auditivas e táteis, as quais serão reconhecidas conforme os usuários desempenham suas atividades [Oviatt, 2002]. O mesmo sistema poderá incorporar e processar informações relativas à ambientes físicos, de modo a suportar adaptação inteligente aos usuários. Pesquisas recentes reportam inclusive o desenvolvimento de interfaces baseadas no reconhecimento de padrões de ondas cerebrais: sistemas inteligentes, conectados por meio eletrodos a regiões específicas do cérebro, captam a atividade cerebral e identificam a intenção do usuário, executando movimentos com o mouse [Costa and Cabral Jr., 2000].

A computação ubíqua, por sua vez, inspira o desenvolvimento de aplicações não centradas no paradigma de interação baseado em teclado-mouse-display. De maneira oposta ao conceito de realidade virtual, cujo objetivo é simular fielmente o mundo real dentro do computador, em computação ubíqua são as aplicações e objetos computacionais que "se projetam" para o mundo exterior, ampliando a perspectiva humana de interação. 


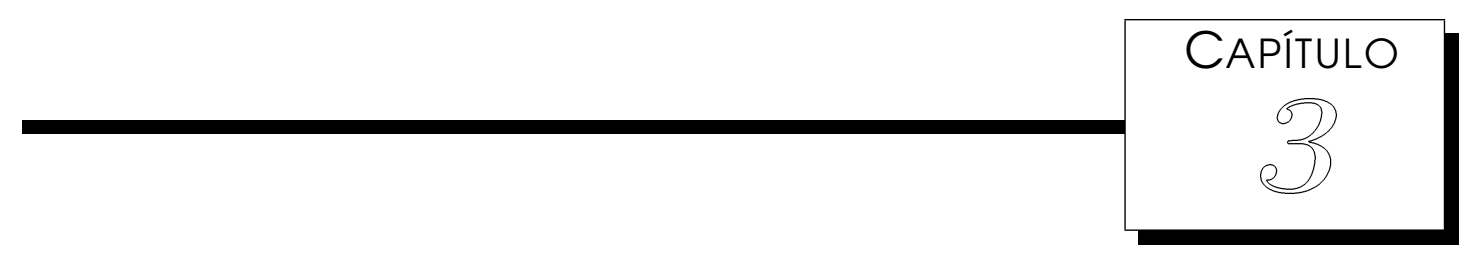

\section{Conceitos Fundamentais: Reuso de Software}

\subsection{Considerações Iniciais}

O reuso de software tem sido um dos principais objetivos da Engenharia de Software desde o surgimento dessa área. Seus potenciais benefícios, como aumento da qualidade, redução do custo e do tempo de desenvolvimento, tornaram esse tema de vital interesse tanto para a comunidade científica como para a indústria.

Desde o início da década de 70 com o aparecimento da programação modular, passando pelos anos 80 com a emergência das linguagens orientadas a objetos, até os dias de hoje com o modelo de desenvolvimento baseado em componentes, as técnicas de reuso de software evoluíram continuamente |Bosch et al., 1997|. Nesse contexto, o capítulo ora apresentado aborda os conceitos fundamentais por trás de algumas das principais técnicas de reuso, evidenciando similaridades e diferenças entre elas, e visando fornecer um conhecimento básico sobre alguns dos termos empregados neste trabalho.

\subsection{Bibliotecas}

Uma das primeiras técnicas de reuso de código foi a utilização de bibliotecas. Operações comuns, tais como ordenações, funções numéricas e de manipulação de 
cadeias de caracteres, ao invés de terem que ser reimplementadas a cada nova aplicação, passaram a ser reunidas em porções modulares de software e compartilhadas por diferentes tipos de programas. Isso proporcionou um grande aumento de produtividade no desenvolvimento de software, uma vez que os programadores poderiam então focar na construção da aplicação em si, deixando de lado a implementação de rotinas auxiliares e a involuntária "reinvenção da roda".

Basicamente, a integração de bibliotecas pode ser feita de modo estático, incluindo-se o código objeto (pré-compilado) no programa em tempo de compilação, ou de modo dinâmico, durante a execução do programa. Esse processo, conhecido como ligação (do Inglês, linking), permite que as bibliotecas sejam referenciadas a partir de arquivos separados no disco, sendo muitas vezes não incluídas no executável do aplicativo. As bibliotecas ligadas dinamicamente, também conhecidas como Dynamic Link Libraries (DLLs) no ambiente Windows, podem ser carregadas em memória durante a inicialização ou posteriormente, quando da chamada de uma função específica. Usualmente o código de uma DLL ocupa um único espaço em memória que é compartilhado por diferentes programas, os quais executam a mesma página física de RAM mapeada em diferentes espaços de endereços [Wikipedia, 2006].

Além de bibliotecas providas por linguagens de programação, como a C Library ou a Standard Template Library (STL), incluídas nas linguagens $\mathrm{C}$ e $\mathrm{C}++$, respectivamente, a maioria dos sistemas operacionais modernos também fornecem bibliotecas para chamadas aos serviços do sistema. Essas bibliotecas oferecem ainda suporte à maioria dos serviços que uma aplicação moderna espera de um sistema operacional, como: modelo de compartilhamento de objetos, bibliotecas para integração com interfaces gráficas nativas, funções de acesso ao sistemas de arquivos, etc.

Com a difusão das linguagens orientadas a objetos no final dos anos 80 e a introdução de novos paradigmas de programação, as técnicas de reuso de software atingiram um nível ainda mais alto. A modelagem de características essenciais de um problema em classes de objetos e a possibilidade de mais tarde recombiná-los para construir diferentes tipos de sistemas trouxe uma grande facilidade ao desenvolvimento das chamadas bibliotecas de classes.

Uma biblioteca de classes é um conjunto de classes projetado para prover funcionalidades reusáveis com um propósito genérico [Bachmann et al., 2000]. Um exemplo seria um conjunto de classes para manipulação de coleções de objetos, tais como listas, pilhas e filas. As bibliotecas de classes não impõem nenhum modelo de arquitetura particular à aplicação; elas apenas provêem as funcionalidades que podem ajudá-la a executar uma tarefa. Tais funcionalidades são fornecidas em baixonível e o desenvolvedor é o responsável pela interconexão entre a biblioteca e aplicação. As bibliotecas de classes se tornaram mais comuns quando do surgimento de 
plataformas como a Java [Sun Microsystems, [1996], contendo um rico conjunto de bibliotecas embutidas na própria linguagem e mecanismos bem definidos de extensão, providos por meio de interfaces e pacotes (JARs - Java Archives).

\subsection{APIs - Application Programming Interfaces}

A habilidade para reutilizar módulos de software e montar aplicações a partir de peças independentes baseia-se fundamentalmente no conceito de interface. Essa abstração provê um mecanismo que permite controlar as dependências que surgem entre os diferentes módulos de um sistema. Uma interface de programação de aplicação (do Inglês, Application Programming Interface - API) é basicamente uma especificação em linguagem de programação das propriedades de um módulo que outros módulos clientes podem ou não depender [Bachmann et al., 2000].

Em outras palavras, uma API determina como um conjunto de funcionalidades de um componente de software pode ser programaticamente utilizado por outros softwares. Ela define um ponto de acesso que permite que diferentes desses elementos façam requisições, executem tarefas e troquem dados entre si. Dentre as principais características das APIs, podemos citar:

Ocultamento de informação: Corresponde à capacidade de uma API em "esconder" o código, restringindo o acesso à lógica interna de programação. Isso vai de encontro aos princípios de baixo acoplamento e alta coesão da Engenharia de Software, na medida em que essa característica diminui a dependência entre dois módulos e reforça os limites de cada parte do sistema. Além disso, o ocultamento de código libera o programador usuário da API de compreender detalhes complexos do seu funcionamento interno de Souza et al., 2004.

Separação especificação/implementação: Consiste da separação da interface da API propriamente dita, com seus métodos e propriedades visíveis externamente, da maneira como os mesmos são implementados e manipulados internamente. Uma vez definido o conjunto de serviços a serem disponibilizados, uma mesma API pode ter diferentes implementações, inclusive desenvolvidas por provedores independentes. Além disso, essa separação possui um importante papel ao ajudar a coordenar a construção de componentes de um sistema: se os projetistas concordam com uma interface, então a implementação interna de dois componentes também pode ser feita de maneira relativamente independente, desde que sejam respeitados os contratos sobre como estes irão se comportar em conjunto [Fowler, 2002]. 
Interoperabilidade: Uma API também pode servir como ponto de ligação entre dois sistemas distintos, integrando inclusive softwares escritos em diferentes linguagens. Exemplos disso são a Windows API |Microsoft, 2006], que permite que quaisquer programas acessem e utilizem recursos do sistema operacional (tais como sistema de arquivos, escalonamento de processos, etc.) e a Java Speech API |Sun Microsystems, 1998c|, que funciona como um discreto intermediário entre uma aplicação cliente Java e as várias engines de reconhecimento e síntese de voz disponíveis no mercado.

Estabilidade: APIs são desenvolvidas para mudarem pouco, de forma a manter a compatibilidade com sistemas que as utilizam e reforçar a independência entre provedores e clientes de APIs. As especificações tendem a ser o mais bem projetadas possivel, definindo formalmente assinaturas de métodos, parâmetros de entrada e dados de saída, de modo que sejam evitadas futuras modificações. Entretanto, essa estabilidade não se aplica a implementação interna da API, que pode mudar conforme a necessidade sem trazer conseqüências aos clientes, graças à separação da interface da implementação.

Muitas vezes uma API é provida como parte de um SDK (Software Development Kit) de uma linguagem de programação, um software ou até mesmo de um hardware. Algumas companhias protegem suas APIs do acesso público, como é o caso da Sony e sua API para o video-game PlayStation 2. Essa API é disponibilizada apenas para desenvolvedores licenciados, possibilitando que a empresa mantenha um certo controle de qualidade sobre os jogos criados para o console. Outras companhias divulgam suas APIs livremente, como é o caso da Microsoft com suas APIs para o Windows e da Sun com a plataforma Java. Essas companhias utilizam o largo alcance de suas APIs para propagar seus produtos e aumentar a sua fatia no mercado.

\subsection{Componentes}

Atualmente não existe um consenso sobre a definição do termo componente na literatura. Muitos autores tentam definí-lo utilizando elementos que os permitem caracterizá-lo sob diferentes óticas. Meijler and Nierstrasz [1997], por exemplo, sustentam que um componente é uma abstração de uma estrutura de software utilizada para construir sistemas maiores que esconde os detalhes de implementação da estrutura menor. Tais estruturas ou peças de software são como "caixas-pretas", possuindo um conjunto limitado de regras que funcionam como "plugues", especificando como elas podem ser combinadas. Assim, ao invés de ter que modificar a implementação interna de um componente para adaptar suas funcionalidades, o usuário 
(cliente) apenas altera o comportamento do mesmo por meio de parâmetros de configuração.

Brown and Short 1997, por sua vez, caracterizam um componente como um “conjunto de serviços reusáveis disponibilizados independentemente”. Por "conjunto de serviços reusáveis" entenda-se como o conjunto de capacidades que um componente provê e que outros componentes podem utilizar. No entanto, para que isso seja possivel, o componente deve fornecer uma especificação completa e precisa dos serviços que ele oferece e de sua interface, de forma que uma implementação desenvolvida baseada em tal especificação se adeqüe perfeitamente. Isso também possibilita que a implementação dos serviços seja modificada sem afetar a utilização do componente, permitindo que os clientes continuem utilizando a mesma interface.

A outra parte da definição, "disponibilizados independentemente", refere-se ao fato de que em geral um componente é desenvolvido sem conhecimento sobre o contexto onde será utilizado. Isso enfatiza a noção de que componentes são construídos para colaborar entre si para realizar uma tarefa, mas não para interferir um no outro. Em particular, dois componentes não podem ter dependências entre si, podendo ser inclusive desenvolvidos em linguagens e plataformas distintas, ou ainda, serem passíveis de substituição sem que gerem algum efeito colateral no sistema como um todo.

Atualmente, devido a grande concorrência no setor de software, sistemas complexos precisam ser construídos em curtos períodos de tempo, com ênfase na qualidade e no baixo custo de desenvolvimento. Tais requisitos fizeram com que surgisse uma abordagem mais organizada de reuso, conhecida como Engenharia de Software Baseada em Componentes (do Inglês, Component-Based Software Engineering - CBSE) |Pressman, 2002]. O objetivo da CBSE é tornar o processo de desenvolvimento mais simples e ágil, através da utilização de componentes pré-construídos, padronizados e que podem ser integrados a diferentes aplicações. As aplicações são projetadas utilizando-se padrões arquiteturais específicos para cada domínio e montadas a partir de componentes, resultando em um software de qualidade e em um curto período de desenvolvimento.

Essa abordagem levou ao surgimento dos chamados produtos COTS (commercial off-the-shelf): componentes especialmente desenvolvidos para comercialização e prontos para o uso, os quais geralmente implementam interfaces padronizadas. Assim, um sistema baseado em componentes pode envolver produtos de múltiplos fornecedores e ao mesmo tempo não depender de nenhum em específico. Outro motivador é que o uso de componentes de terceiros não depende de ferramentas ou conhecimento sobre o funcionamento interno do componente que só o fabricante possui Bachmann et al., 2000. 
Com o impacto do CBSE, várias companhias importantes e consórcios da indústria têm proposto padrões para o desenvolvimento de componentes, dentre os quais podemos citar [Pressman, 2002]:

OMG CORBA: Especificado pelo OMG (Object Management Group), o padrão CORBA (Common Object Request Broker Architecture) define uma arquitetura comum para negociação entre objetos distribuídos. Ela se baseia na utilização de um intermediador de requisição de objetos (do Inglês, Object Request Broker - ORB), que fornece diversos serviços para permitir que componentes troquem informação entre si independentemente de sua localização. A integração dos componentes CORBA é garantida por meio do uso de uma linguagem de interface denominada IDL (Interface Definition Language) e os objetos se comunicam enviando solicitações de serviços ao ORB, usando o paradigma cliente/servidor.

Microsoft COM: O Modelo de Objetos de Componentes (Component Object Model COM) desenvolvido pela Microsoft fornece uma especificação para a integração de componentes reusáveis produzidos por diferentes fornecedores em uma aplicação rodando sob o sistema operacional Windows. O COM é constituído basicamente por dois elementos: interfaces COM (implementadas pelos objetos) e um conjunto de mecanismos para efetuar o registro e a troca de mensagens entre esses componentes. O COM também é largamente usado em produtos como o Microsoft Office para permitir, por exemplo, que um documento Word referencie dinamicamente dados em uma planilha Excel.

Sun JavaBeans: O sistema de componentes reutilizáveis JavaBeans é uma infraestrutura CBSE portátil, independente de plataforma, desenvolvida pela Sun Microsystems para a linguagem de programação Java. O objetivo quando da sua criação era que os componentes JavaBeans fossem utilizados como blocos simples de construção de aplicações, podendo ser compostos, conectados e customizados visualmente através de uma IDE (Integrated Development Environment). Para que uma classe seja considerada um JavaBean ela deve obedecer certas convenções de nomes, propriedades e comportamentos, de modo a garantir a intercambialidade e padronizar o acesso às funcionalidades do componente.

\subsection{Frameworks}

Assim como o conceito de componentes, o termo framework de software encontra diversas definições na literatura. Dentre elas, a mais comumente citada é a de Johnson and Foote 1988: "um framework é um conjunto de classes que incorpora um projeto (design) abstrato de soluções para uma família de problemas 
relacionados". Em outras palavras, um framework é uma arquitetura de software semi-completa, reutilizável, e que pode ser adaptada para produzir aplicações personalizadas dentro de um domínio específico.

Os frameworks são principalmente uma forma de reuso de projeto, além de código |Johnson, 1997b]. O projeto de um sistema normalmente é descrito em termos de componentes, de como estes interagem e colaboram entre si, quais as responsabilidades de cada um, a lógica de controle e o fluxo de informação. Um framework define esses elementos de tal forma que não apenas componentes individuais são utilizados, mas toda a estrutura de relacionamentos, decisões de projeto e padrões identificados em um domínio de aplicação.

De acordo com Fayad and Schmidt 1997, os principais benefícios dos frameworks orientados a objetos tem origem na modularidade, reusabilidade e extensibilidade que eles provêem aos desenvolvedores, como descrito a seguir:

Modularidade: Frameworks aumentam a modularidade por meio do encapsulamento de implementações voláteis atrás de interfaces estáveis. A modularidade de um framework ajuda a aprimorar a qualidade do software devido ao impacto localizado de mudanças no projeto ou na implementação. Isso reduz o esforço necessário para a compreensão e manutenção do software existente.

Reusabilidade: As interfaces estáveis oferecidas pelos frameworks aumentam a reusabilidade através da definição de componentes genéricos que podem ser reaplicados para criar novas aplicações. Essa reusabilidade se aproveita do conhecimento de domínio e do esforço empregado por desenvolvedores experientes na construção do framework, de modo a evitar recriar e revalidar soluções para requisitos comuns de aplicações e desafios de projeto que sejam recorrentes.

Extensibilidade: Um framework aumenta a extensibilidade por meio de ganchos (hooks) e gabaritos (templates), que consistem de pontos adaptáveis da arquitetura providos explicitamente e que permitem às aplicações especializarem suas classes e agregarem novas características e serviços. Os ganchos podem ser vistos como "espaços reservados" ou pontos flexíveis nos quais as aplicações acoplam seus comportamentos particulares ao framework, sendo normalmente oferecidos como métodos abstratos sem implementação. Um gabarito, por sua vez, define um comportamento abstrato ou um fluxo genérico de controle que implementa a lógica de interação dos objetos internos do framework e realiza chamadas a métodos-gancho [Pree, 1999].

Uma das características dos frameworks é a chamada "inversão de controle" Johnson, 1997a). Tradicionalmente, um desenvolvedor usa uma biblioteca ou com- 
ponente escrevendo um programa que chama as suas funções ou métodos quando necessário. O desenvolvedor é responsável pela estrutura e pelo controle de fluxo do programa, decidindo quando e como utilizar tais recursos. Em um framework, a estrutura principal é reutilizada e o código do programa é plugado nela, sendo que as classes definidas pelo desenvolvedor é que são chamadas pelo framework. O framework é que determina a estrutura e o fluxo de controle do programa, se comunicando por meio de mensagens enviadas a classes abstratas e interfaces num processo conhecido como callback. Tais classes e interfaces são especializadas e implementadas, provendo o comportamento específico da aplicação. Assim, quando um evento ocorre, o framework chama um método pré-definido em um componente registrado como ouvinte (listener), que por sua vez realiza o processamento definido pela aplicação em resposta ao evento. A Figura 3.1 ilustra essa diferença no fluxo de controle.
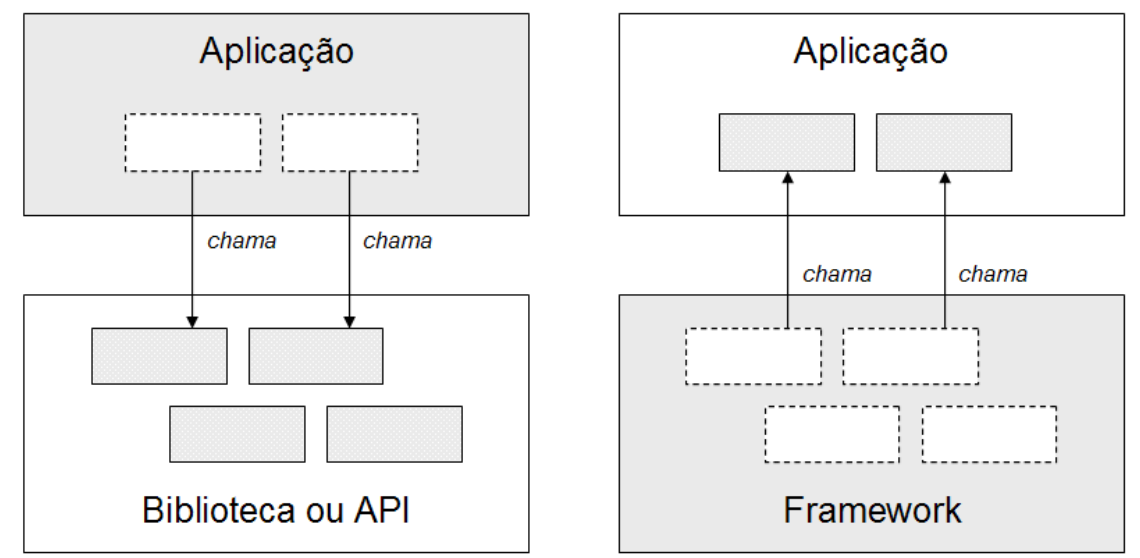

Figura 3.1: Inversão de controle: diferença entre bibliotecas, APIs e frameworks (adaptado de (Bachmann et al., 2000|).

Os frameworks podem ser classificados de acordo com a sua forma de reuso em caixa-branca ou caixa-preta |Fayad and Schmidt, 1997|. Nos frameworks caixabranca (white-box) as aplicações recorrem a técnicas como herança e ligação dinâmica para estender o framework. Assim, as funcionalidades são customizadas especializandose classes e sobrecarregando-se métodos-gancho pré-definidos. Essa abordagem requer dos desenvolvedores de aplicação maior conhecimento sobre a estrutura do framework e detalhes de seu funcionamento interno, tornando-os, portanto, mais difíceis de utilizar. Nos frameworks caixa-preta (black-box), o reuso ocorre por meio de composição. As funcionalidades são configuradas e customizadas por meio de componentes parametrizáveis e pela integração destes às aplicações. Como resultado, os frameworks caixa-preta são mais fáceis de utilizar que os frameworks caixa-branca, porém mais difíceis de construir, já que os desenvolvedores necessitam prever interfaces e ganchos que atinjam um conjunto mais amplo de casos de uso. 
A especialização de um framework ocorre em pontos pré-definidos denominados hot-spots [Pree, 1999]. Estes pontos, também conhecidos como "pontos-variáveis", representam as partes específicas das aplicações cujo comportamento pode ser modificado ou adaptado e são considerados lugares ideais para a inserção de ganchos. Em contraste, os "pontos-fixos" (frozen spots) representam os aspectos comuns do framework que são compartilhados pelas aplicações, incluindo componentes básicos e o relacionamento entre eles. Eles são implementados por completo e usados sem alteração em todas as instâncias do framework [Froehlich et al., 1998].

O conceito de frameworks vem sendo utilizado há décadas e nos mais diversos domínios. Entretanto, os exemplos mais populares têm sua origem no domínio das interfaces gráficas de usuário. Frameworks como MacApp e X-windows, criados na década de 80, tiveram um importante papel no desenvolvimento de interfaces para os ambientes Macintosh e Unix, respectivamente. Posteriormente, o MFC (Microsoft Foundation Classes), o JFC (Java Foundation Classes) surgiram para disponibilizar esses recursos para plataformas PC. Atualmente, alguns frameworks bastante conhecidos são o Struts Apache Software Foundation, 2000 e o JSF (Java Server Faces) [Sun Microsystems, 2004], que implementam o padrão MVC (Model-View-Controller) para aplicações Web desenvolvidas sob a plataforma JEE (Java Enterprise Edition).

\subsection{Patterns}

Frameworks estão intimamente ligados a outras técnicas de reuso, tais como padrões (patterns). Os padrões representam um conjunto de soluções recorrentes para problemas de projeto de software dentro de contextos específicos Fayad and Schmidt, 1997|. Padrões e frameworks facilitam o reuso pela captura de estratégias bem sucedidas de desenvolvimento. A principal diferença entre eles é que os frameworks focam no reuso de projetos concretos, algoritmos e componentes codificados em uma linguagem de programação particular, ao passo que os patterns têm seu foco no reuso de projetos abstratos, modelos conceituais e micro-arquiteturas de software independentes de implementações específicas.

Nas últimas décadas, programadores e arquitetos de software experientes têm contribuído para a criação de uma literatura que documente esses padrões, de modo a possibilitar não apenas o reuso de software em si, mas também o reuso de conhecimento. Assim, desenvolvedores com menos experiência podem se valer de soluções comprovadamente eficazes para resolver problemas conhecidos, causando um aumento de produtividade e na qualidade do produto final. De acordo com Schmidt and Buschmann 2003, os padrões podem ser classificados em três tipos: 
Padrões de projeto: provêem um esquema para refinar os elementos internos de um software e o relacionamento entre eles, descrevendo uma estrutura comum que resolva um problema genérico de projeto dentro de um contexto particular Gamma et al., 1995.

Padrões arquiteturais: expressam a estrutura organizacional de um sistema de software como um todo, definindo um conjunto de sub-sistemas e guidelines para o relacionamento entre eles, além de especificar suas responsabilidades Buschmann et al., 1996.

Linguagens de padrões: reúnem um conjunto de padrões relacionados para definir um vocabulário comum sobre problemas de desenvolvimento de software e provêem um processo para a resolução sistemática desses problemas Alexander et al., 1977.

Dentre estes tipos, os mais comumente utilizados são os padrões de projeto. Um padrão de projeto é descrito essencialmente por meio das seguintes informações |Gamma et al., 1995|: um nome, que seja sugestivo e exprima a idéia principal do padrão; um contexto, apontando as situações mais freqüentes nas quais o problema costuma ocorrer; o problema que ele resolve, indicando quando o padrão deve ser aplicado; e uma solução, descrevendo os elementos que compõem o projeto, seus relacionamentos e responsabilidades.

Um exemplo de padrão de projeto é o padrão MVC (do Inglês, Model-ViewController). Esse padrão endereça o problema da construção de interfaces para interação com o usuário [Froehlich et al., 1997]. Normalmente tais interfaces são alvos de constantes modificações, de acordo com a adição de novas funcionalidades ao software, e sofrem com a necessidade de prover diferentes métodos de acesso (por exemplo, através de um botão, teclado, menu, etc.) e formas de visualização (por exemplo, através de uma janela de aplicação, página Web, arquivo, etc.).

Esses problemas sugeriram a criação do padrão MVC, que desvincula a interface da aplicação de suas funcionalidades separando-a em três áreas: processamento (modelo), saída (visão) e entrada (controlador). O modelo encapsula os dados e as funcionalidades da aplicação em si; a visão apresenta os dados manipulados pelo modelo, sendo que múltiplas visões podem ser acopladas a um único modelo para apresentar os dados de diferentes maneiras; e o controlador, que recebe a entrada do usuário e invoca métodos do modelo para executar a tarefa desejada. Cada visão tem seu próprio controlador e os mesmos podem ser alterados para prover diferentes métodos de entrada.

Os padrões de projeto além de fornecerem exemplos a serem seguidos e modelos que podem ser adaptados a aplicações com diferentes necessidades, garantem a 
uniformidade na estrutura do software, aumentando assim a produtividade no desenvolvimento e a facilidade na manutenção. Por esse motivo, os padrões são utilizados com eficiência na construção de frameworks. Um único framework geralmente contém muitos padrões, o que coloca os frameworks em um nível de abstração diferente dos padrões. Padrões de projetos são os elementos micro-arquiteturais dos frameworks, e esses, por sua vez, correspondem à implementação concreta de vários padrões Johnson, 1997b.

\subsection{Considerações Finais}

Conforme apresentado ao longo deste capítulo, o reuso é uma maneira eficiente de se aprimorar a produtividade e a qualidade do software. Nos dias atuais, em que o desenvolvimento de novos produtos é orientado por fatores como tempo e custos, a reutilização de modelos bem definidos, padrões maduros e implementações largamente testadas, pode ser uma condição determinante para o sucesso ou o fracasso de um produto de software [Schmidt and Buschmann, 2003].

Inicialmente, a maioria dos softwares focava no reuso de código apenas, reaproveitando partes de programas existentes ou criando bibliotecas para um escopo genérico de aplicações. Com a disseminação das técnicas de programação orientada a objetos na década de 90, uma nova abordagem foi concebida. Sistemas complexos e de grande porte passaram a ser construídos a partir de infra-estruturas semi-prontas, como componentes e frameworks. Os componentes enfatizam a modularidade e o baixo acoplamento às aplicações, atendendo a um requisito específico e podendo ser substituídos por outros que realizem as mesmas tarefas. Já os frameworks fornecem uma arquitetura pré-definida em que a aplicação deve se adaptar, provendo funcionalidades mais genéricas, porém dentro de um determinado domínio.

Assim, baseando-se nos conceitos aqui apresentados, foi proposta uma arquitetura de um framework multimodal que integrasse as modalidades de voz e escrita, como mencionado no Capítulo 1. O resultado dessa arquitetura, detalhes de projeto e implementação são apresentados no próximo capítulo. 


\section{- \\ Infraestruturas de Escrita e Voz: JInk API e JSAPI}

\section{1 Considerações Iniciais}

Este capítulo provê informações detalhadas sobre as infraestruturas utilizadas na implementação do framework multimodal proposto. A Java Ink é uma API de reconhecimento de escrita desenvolvida pelo aluno e que foi estendida para se adequar aos requisitos desse projeto. Grande parte do esforço de implementação se deu na modificação dessa API e na sua integração ao framework. A JSAPI, por sua vez, é uma interface definida pela Sun Microsystems |1998c que possibilita a construção de interfaces de voz em aplicações Java. Ela foi integrada ao framework como parte do módulo de voz, e sua arquitetura é discutida neste capítulo.

\subsection{Modalidade de Escrita}

Com a popularização de dispositivos de computação móvel, tais como Tablet PCs, PDAs e smartphones, as interfaces baseadas em entrada por caneta estão se tornando cada vez mais comuns. Conforme o uso dessa modalidade se expande, as aplicações passam a não apenas oferecer funcionalidades básicas de agenda e telefone, como também programas de e-mail, editores de textos e acesso a WorldWide Web (WWW). Para suportar essas atividades, além de um mini-teclado (que pode 
ser físico ou projetado em uma tela sensivel ao toque), normalmente os aparelhos provêem algum sistema para reconhecimento de escrita manual.

O reconhecimento de escrita, isto é, a transcrição das entradas manuais em caracteres manipuláveis por computadores (tais como o ASCII), é um tema em pesquisa a mais de trinta anos. Diferentes abordagens têm sido propostas na tentativa de se obter sistemas de reconhecimento mais precisos, as quais incluem desde o uso de modelos matemático-estatísticos, métodos baseados em análise estrutural, até técnicas envolvendo inteligência artificial [Plamondon and Srihari, 2000].

Basicamente, o reconhecimento de caracteres pode ser classificado em dois tipos: off-line e on-line. O reconhecimento off-line foca no processamento de imagens previamente obtidas, nas quais são analisadas as disposições e níveis de cores dos pixels, sem levar em conta informações de tempo ou de direção de escrita dos traços. Já no reconhecimento on-line, o processamento ocorre durante a escrita, sendo fornecida a seqüência exata dos pontos que compõem os traços, possibilitando assim calcular sua direção.

Algumas estratégias são utilizadas para facilitar o processo de reconhecimento, como a demarcação de áreas de escrita, a definição de conjuntos de caracteres permitidos ou a restrição da maneira como os mesmo devem ser escritos. Em alguns casos os reconhecedores são específicos para algum domínio, como caracteres música |Forsberg et al., 1998| ou associados ao projeto de interfaces [Lin et al., 2000].

Atualmente, existem sistemas comerciais que fazem uso de alfabetos próprios, como o Graffiti [Palm, 1997], que possui um conjunto de caracteres similar ao alfabeto Romano. Embora possua taxa de precisão acima de 99\%, esse sistema restringe a escrita do usuário a um estilo pré-definido, aumentando a curva de aprendizado e tornando a interação com o dispositivo menos natural.

\subsection{Java Ink API}

Durante sua pesquisa de iniciação científica realizada no período de Julho de 2002 a Dezembro de 2003, o autor desta dissertação esteve investigando o problema do reconhecimento on-line de caracteres de escrita manual. Esse trabalho resultou no desenvolvimento de um serviço denominado Java Ink (JInk), que consistia de um conjunto de classes Java que implementavam as funcionalidades básicas de um reconhecedor de caracteres [Inácio Jr., 2003].

Em vista da indisponibilidade de um software de reconhecimento não-proprietário, de código aberto e que se adequasse aos requisitos funcionais do framework multimodal aqui proposto, optou-se por integrar o serviço JInk ao projeto. Outro 
ponto que influenciou nessa escolha foi o fato de o serviço ter sido implementado pelo próprio aluno, o que facilitaria a modificação e a adaptação do código. A idéia era que o serviço JInk fosse estendido para suportar não apenas caracteres, como também gestos, marcas, formas e símbolos provenientes de interação com caneta.

No entanto, durante a fase de análise de requisitos observou-se que as modalidades de reconhecimento a serem incorporadas ao serviço tinham em comum a definição de novos tipos de caracteres. Assim, ao invés de estender o conjunto de caracteres suportados apenas para os especificados no projeto, optou-se por generalizar o mecanismo de reconhecimento, de modo que ele pudesse ser configurado para outros tipos de caracteres. O serviço poderia então ser utilizado em aplicações de diferentes domínios, possibilitando ao programador definir os tipos de caracteres a serem reconhecidos de acordo com a necessidade.

Essa abordagem, além de aumentar a complexidade do serviço, sugeriu que o mesmo deveria ser implementado de uma forma mais modular e menos acoplada às aplicações, de maneira a facilitar o reuso. Sendo assim, o serviço foi remodelado e reimplementado na forma de uma API, denominada Java Ink API (JInk API), cuja implementação é detalhada nas seções seguintes.

\subsubsection{Método de Reconhecimento}

O propósito desta seção é descrever de maneira detalhada o funcionamento do método de reconhecimento utilizado pela JInk API, que baseia-se no algoritmo de Casamento Estrutural Flexível [Chan and Yeung, 1999], bem como fornecer uma visão da complexidade de sua implementação.

Esse método foi escolhido após a realização de uma ampla revisão bibliográfica, onde foram analisadas características como: eficiência e precisão no reconhecimento, dificuldade de implementação e capacidade de extensão. Contudo, é necessário ressaltar que o foco deste trabalho não está na avaliação ou comparação de técnicas de reconhecimento, mas sim na disponibilização de uma infra-estrutura básica para a construção de interfaces multimodais envolvendo interação por escrita manual.

O método de reconhecimento proposto por Chan and Yeung 1999] é dividido em três estágios principais: Extração e Reconstrução da Estrutura, Casamento Estrutural Flexível e Pós-Processamento, como representado na Figura 4.1.

Basicamente, o que existe após a escrita do caractere é apenas uma seqüência de pontos, representados por suas respectivas coordenadas. O primeiro passo é identificar as primitivas que compõem cada caractere, através da extração da estrutura, sendo que neste estágio algumas formas de reconstrução podem ser empregadas. 


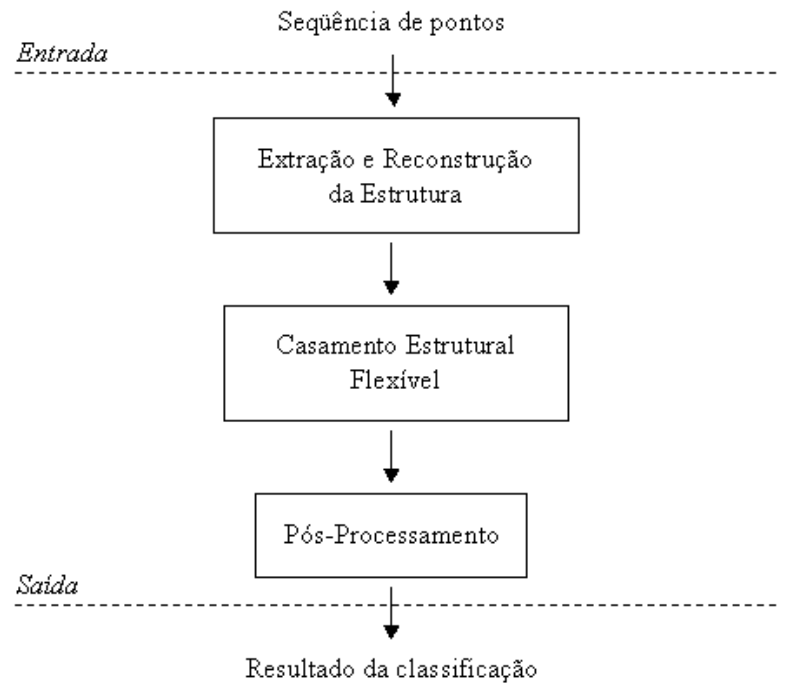

Figura 4.1: Visão geral do método de reconhecimento definido por Chan and Yeung [1999].

Com a estrutura obtida, os caracteres podem então ser comparados com os modelos pré-fornecidos, na tentativa de encontrar alguma equivalência. É então aplicado o algoritmo de Casamento Estrutural Flexível, que executa uma série de transformações na estrutura do caractere de modo a facilitar o reconhecimento. Finalmente, no último passo do reconhecimento, operações de pós-processamento são realizadas, para que ambigüidades ou possiveis erros de classificação sejam corrigidos. Todos os estágios aqui descritos serão melhor detalhados nas seções seguintes.

\subsubsection{Primitivas Estruturais}

O método de reconhecimento proposto por Chan and Yeung [1999] considera cada caractere como sendo um conjunto de linhas e curvas, organizadas sobre uma estrutura bi-dimensional. Os elementos que formam esse conjunto são denominados primitivas estruturais, e são identificados a partir da seqüência de segmentos que compõem cada traço do caractere. São definidos cinco tipos de primitivas: linha, curva acima (sentido anti-horário), curva abaixo (sentido horário), loop e ponto.

Os segmentos são fragmentos de reta que interpolam os pontos gerados pela discretização do traço, sendo que cada segmento possui uma direção de escrita (facilmente obtida no reconhecimento on-line). Essa direção segue o modelo de codificação

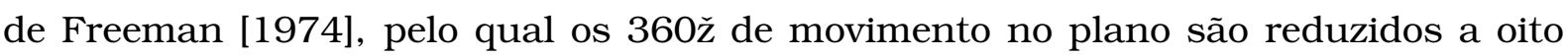
direções, representadas por valores inteiros de 0 a 7, como mostrado na Figura $4.2 \mathrm{a}$. Assim, um valor inteiro é associado para cada segmento do traço, representando a direção aproximada na qual este se enquadra. Os valores obtidos são concatenados em uma string, sendo que segmentos consecutivos com direções iguais são unidos 
em um só segmento (Figura 4.2p). Uma direção também é associada a cada primitiva identificada, sendo calculada através do segmento obtido entre os pontos inicial e final da primitiva (Figura 4.2 c).

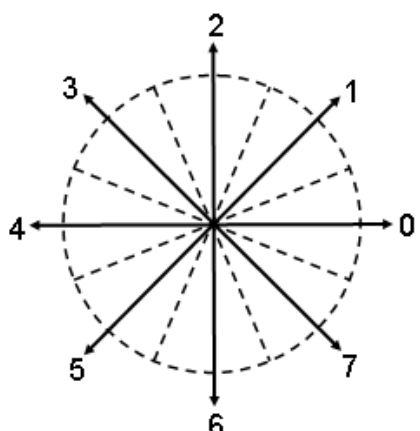

(a)

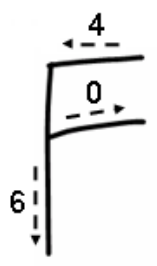

460

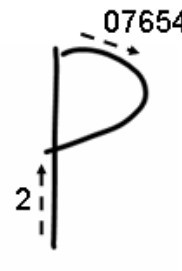

207654

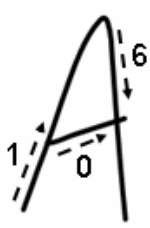

160

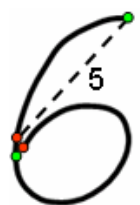

\{CurvaAcima, 5\}, \{CurvaAcima, 7 \}, \{Loop, -1$\} \quad\{$ Linha, 6$\}$

(b)

(c)

Figura 4.2: (a) Direções e valores utilizados na codificação de Freeman [1974]. (b) Exemplos de caracteres e concatenação de segmentos e traços. (c) Identificação das primitivas e cálculo da direção, onde os pontos representam o início e o fim de cada primitiva.

Essas estruturas podem ser expressas por uma gramática $G=\left(V_{T}, V_{N}, P, S\right)$, onde:

- $V_{T}=\{$ Linha, CurvaAcima, CurvaAbaixo, Loop, Ponto, 0, 1, 2, 3, 4, 5, 6, 7\} representa o conjunto de símbolos terminais;

- $V_{N}=\{$ Caractere, ConjuntoDeTraços, Traço, ConjuntoDeSegmentos, Segmento, ConjuntoDePrimitivas, Primitiva, TipoPrimitiva, Direção\} são os símbolos nãoterminais;

- $P=\{$ Caractere $\rightarrow$ ConjuntoDeTraços;

ConjuntoDeTraços $\rightarrow$ Traço| (Traço, ConjuntoDeTraços);

Traço $\rightarrow$ (ConjuntoDeSegmentos, ConjuntoDePrimitivas);

ConjuntoDeSegmentos $\rightarrow$ Segmento | (Segmento, ConjuntoDeSegmentos);

ConjuntoDePrimitivas $\rightarrow$ Primitiva | Primitiva,ConjuntoDePrimitivas);

Segmento $\rightarrow$ Direção;

Primitiva $\rightarrow$ (TipoPrimitiva, Direção);

TipoPrimitiva $\rightarrow$ Linha | CurvaAcima | CurvaAbaixo | Loop | Ponto;

Direção $\rightarrow 0|1| 2|3| 4|5| 6 \mid 7\}$

são as regras de produção;

- $S$ é o símbolo inicial (um Caractere).

\subsubsection{Conjunto de Modelos}

Antes do reconhecimento é necessário definir um conjunto básico de modelos para cada classe de caractere. Esses modelos serão posteriormente utilizadas para o 
teste de casamento, no qual o caractere apresentado será comparado com os modelos pré-definidos.

Os modelos devem ser distintos, isto é, não podem possuir o mesmo número de primitivas com os mesmos tipos e direções. Diferentes classes de caracteres também podem ter diferentes números de modelos, dependendo da complexidade da estrutura.

Na implementação da JInk API são fornecidos métodos que permitem que cada usuário especifique seu próprio conjunto de modelos, melhorando a precisão do algoritmo pela personalização do reconhecedor. Em alguns casos é possível também fazer combinações com os traços dos caracteres e reduzir o número de modelos.

\subsubsection{Extração e Reconstrução da Estrutura}

Neste estágio, as primitivas estruturais que compõem o caractere são identificadas por meio de uma série de operações realizadas sobre os segmentos que formam cada traço do caractere.

\section{Identificação de Primitivas}

Como explicado na Seção 4.3.2, cada segmento possui uma direção de escrita, codificada em um valor inteiro de 0 a 7 . Essas direções são armazenadas seqüencialmente em uma string, partindo do ponto inicial ao ponto final de cada traço do caractere.

A extração da estrutura de um traço começa pela identificação de conjuntos de segmentos que correspondem a uma mesma primitiva. Pequenas variações de direção entre segmentos consecutivos são mantidas e representadas em um único traço, ao passo que variações bruscas de direção implicam na quebra do traço. Posteriormente, cada traço dará origem a uma primitiva. Além disso, segmentos consecutivos com direções iguais são agrupados em um único segmento, reduzindo o tamanho da string. Esses casos podem ser resumidos da seguinte forma:

Dados $s_{i}$ e $s_{i+1}$ dois segmentos consecutivos, com $1 \leq i \leq N-1$ e $N$ igual ao número de segmentos no traço, e $d\left(s_{k}\right)$ a direção do $k$-ésimo segmento, temos:

$$
\begin{cases}\left|d\left(s_{i}\right)-d\left(s_{i+1}\right)\right|=1, & \text { manter os segmentos e o traço; } \\ \left|d\left(s_{i}\right)-d\left(s_{i+1}\right)\right|>1, & \text { manter os segmentos e quebrar o traço; } \\ \left|d\left(s_{i}\right)-d\left(s_{i+1}\right)\right|<1, & \text { unir os segmentos e manter o traço. }\end{cases}
$$




\section{Remoção de Zig-Zag}

Uma outra operação realizada durante a extração da estrutura é a remoção de zig-zag. Esse tipo de problema ocorre geralmente devido à baixa qualidade do dispositivo de captura ou à estilos ruins de escrita. Para resolvê-lo pode-se simplesmente extrair os pontos médios de cada segmento e conectá-los novamente, de modo a "suavizar" a trajetória do traço, reduzindo o conjunto de pontos de sua estrutura. Entretanto, isso pode fazer com que a posição dos pontos mude e, dependendo de quantas vezes essa operação for executada, pode deformar o caractere e prejudicar o reconhecimento.

\section{Identificação de Loops}

Depois de obter a estrutura preliminar é necessário verificar a ocorrência de determinadas sub-estruturas, tais como loops, e testar a possibilidade de combinação entre primitivas.

Uma das maneiras de se identificar loops é por meio da análise da distância dos pontos do traço em relação a um ponto fixo. Sempre que esta distância for menor que um limitante e os pontos não pertençam ao mesmo segmento, é retornado um valor -1 indicando que um loop foi encontrado.

Em geral, um loop pode se localizar em três diferentes posições no traço: no começo, no meio e no fim. Quando o loop está no começo, o ponto inicial é fixado e o método acima pode ser utilizado para detectar sua ocorrência. O mesmo pode ser utilizado quando o loop está no fim, com a diferença que o ponto a ser fixado é o final. Já quando o loop está no meio, são utilizadas as duas extremidades do traço. Estas vão sendo deslocadas uma em direção à outra e o teste vai sendo executado conforme a distância entre elas diminui.

\section{Combinação de primitivas}

Algumas vezes um traço pode ser quebrado devido à baixa qualidade da escrita ou do dispositivo de captura. Desse modo, faz-se necessário checar cada par de primitivas consecutivas no conjunto de primitivas do caractere. Se algumas condições forem satisfeitas, é possível combiná-las em uma única nova primitiva. A Tabela apresenta algumas dessas condições e primitivas resultantes das combinações.

De acordo com a tabela, para combinar duas linhas é necessário que elas possuam a mesma direção. Para combinar duas curvas é preciso inicialmente determinar o TipoUniao, que descreve como elas estão conectadas. Esse tipo nada mais é do que a primitiva resultante da união do último segmento da primeira primitiva e 


\begin{tabular}{|c|c|c|c|}
\hline $\begin{array}{c}\text { Primitiva 1: } \\
\left\{T_{1}, D_{1}\right\}\end{array}$ & $\begin{array}{c}\text { Primitiva 2: } \\
\left\{T_{2}, D_{2}\right\}\end{array}$ & Condição & $\begin{array}{c}\text { Nova Primitiva: } \\
\left\{T_{N}, D_{N}\right\}\end{array}$ \\
\hline \hline$\left\{\right.$ Linha, $\left.D_{1}\right\}$ & $\left\{\right.$ Linha, $\left.D_{2}\right\}$ & $D_{1}=D_{2}$ & $\left\{\mathrm{Linha}, D_{1}\right\}$ \\
\hline $\begin{array}{c}\left\{\text { CurvaAcima, } D_{1}\right\} \text { ou } \\
\left.\text { CurvaAbaixo, } D_{1}\right\}\end{array}$ & $\begin{array}{c}\left.\text { CurvaAcima, } D_{2}\right\} \text { ou } \\
\left.\text { CurvaAbaixo, } D_{2}\right\}\end{array}$ & $T_{1}=T_{2}=$ TipoUniao & $\left\{T_{1}, D_{N}\right\}$ \\
\hline
\end{tabular}

Tabela 4.1: Condições para a combinação de primitivas consecutivas Chan and Yeung, 1999|, onde $T$ denota os tipos das primitivas e $D$ suas direções.

do primeiro segmento da segunda primitiva. Comparando o TipoUniao obtido com os tipos de ambas as curvas é possivel determinar se essas devem ou não ser combinadas.

\subsubsection{Casamento Estrutural Flexível}

Após extrair a estrutura final do caractere é possivel então compará-lo ao conjunto de modelos. Entretanto, devido aos diferentes estilos e à variabilidade natural que ocorre durante a escrita, a probabilidade do caractere apresentado ser exatamente igual à algum dos modelos pré-fornecidos é baixa. O método de Casamento Estrutural Flexível tenta resolver esse problema executando uma série de deformações na estrutura do caractere, por meio de alterações na sua forma e direção, garantindo assim robustez e eficácia no reconhecimento.

O algoritmo em alto nível do método de Casamento Estrutural Flexível desenvolvido por Chan and Yeung 1999], corresponde a:

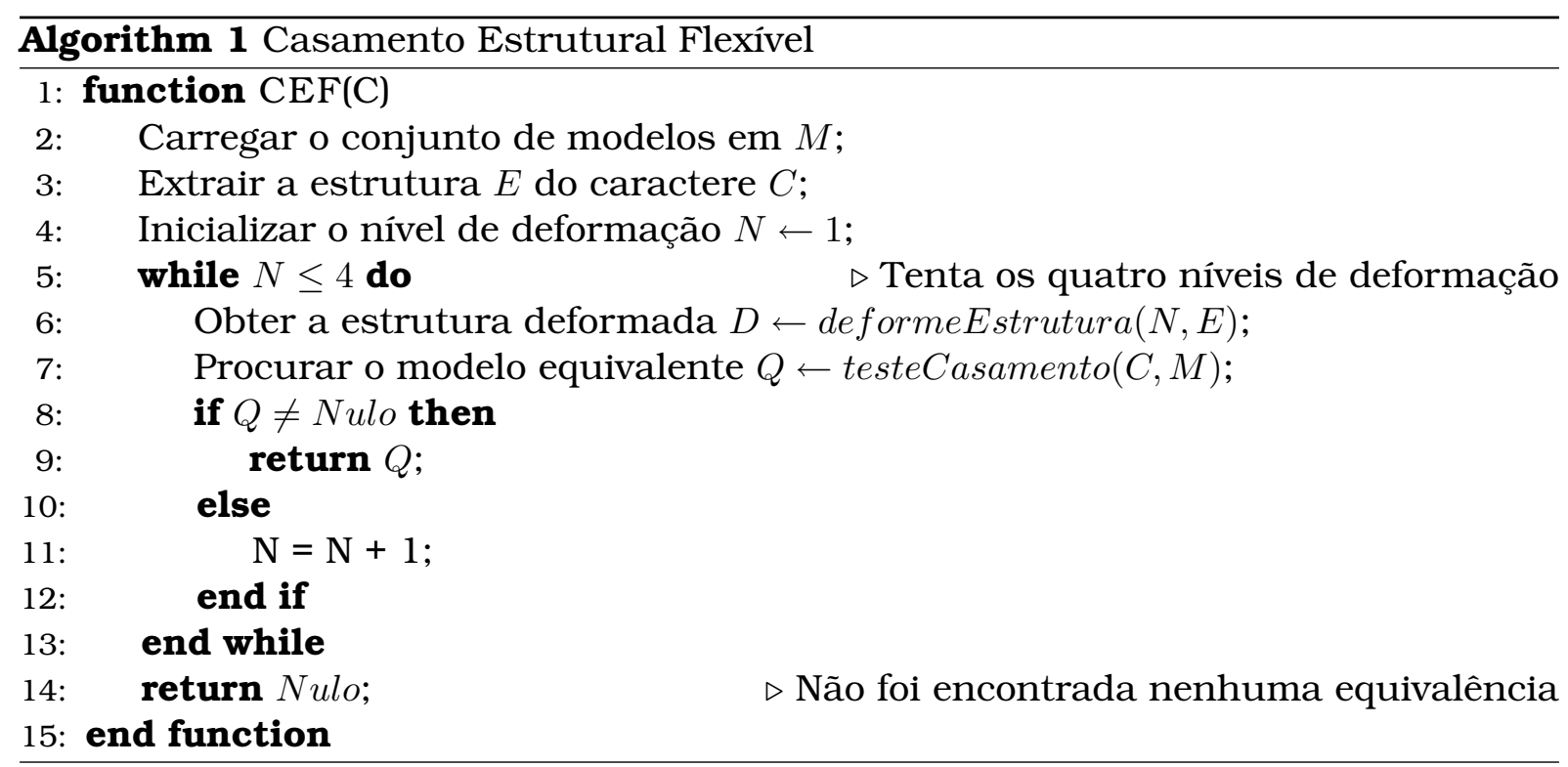




\section{Níveis de Deformação}

Há quatro níveis de deformação, sendo que o processo termina assim que um modelo equivalente (resultante de deformação ou não) é encontrado ou terminam os níveis e o caractere é rejeitado. A seguir é apresentada uma descrição sobre esses níveis.

Nivel 1: Nenhuma deformação. A estrutura do caractere não é modificada, sendo que para uma equivalência ser encontrada o caractere deve ter estrutura idêntica à de um dos modelos.

Nível 2: Deformação no tipo das primitivas. A estrutura do caractere sofre alterações no tipo de suas primitivas. Por exemplo, uma Linha se torna um de seus tipos vizinhos, isto é, uma CurvaAcima ou CurvaAbaixo, já que o tipo Linha é o meio-termo entre eles. Os tipos CurvaAcima e CurvaAbaixo podem apenas se transformar numa Linha, pois esses tipos não são vizinhos. A direção de cada primitiva é mantida sem alterações. Um exemplo é apresentado na Figura 4.3 a, no qual são geradas oito variações distintas do caractere "T".

Nível 3: Deformação na direção das primitivas. Nesse caso, cada primitiva tem sua direção alterada para suas direções vizinhas, de acordo com o esquema de codificação descrito na Seção 4.3.2. Assim, uma primitiva $\{$ Linha, 5$\}$ pode se tornar $\{$ Linha, 4$\}$ ou $\{$ Linha, 6\}. Como exemplo, o mesmo caractere "T" é apresentado na Figura 4.3b ao lado de suas oito variações. Primitivas como Loop e Ponto, cuja direção é inválida, não sofrem o efeito dessas deformações.

Nivel 4: Deformação simultânea no tipo e direção. Quando nenhum modelo é encontrado nos passos anteriores, é então utilizada a deformação simultânea no tipo e na direção de cada primitiva do caractere. Como resultado, um número muito maior de variações é gerado. O mesmo "T", nesse passo, gera 80 variações, sendo que cada uma será testada com o conjunto de modelos.

\subsubsection{Pós-Processamento}

Utilizando o Casamento Estrutural Flexível, caracteres que não encontrariam equivalência direta com os modelos pré-definidos podem ser reconhecidos. Entretanto, ao mesmo tempo que o método diminui a taxa de rejeição ele pode gerar muitos resultados equivocados, já que a flexibilidade dada ao caractere é cada vez maior conforme aumenta o nível de deformação. 


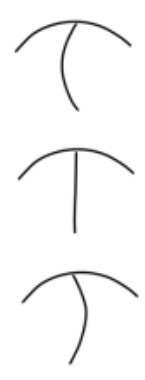

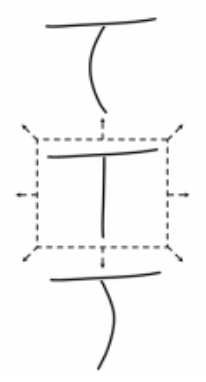

(a)

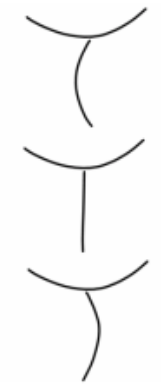

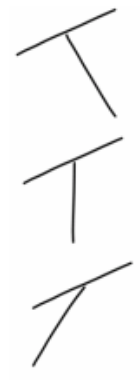
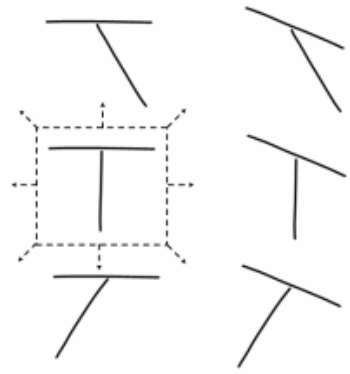

(b)

Figura 4.3: Versões deformadas do caractere " $T$ " resultantes de alteração no tipo (a) e na direção (b) das primitivas (adaptado de [Chan and Yeung, 1999|).

Assim, torna-se necessário executar passos adicionais para verificar a adequação do resultado e desfazer ambigüidades. De modo geral, há dois tipos principais de ambigüidades:

Caracteres distintos representados pela mesma estrutura. Por exemplo, os caracteres "L" e "T" podem ser classificados com a mesma estrutura $\{\{$ Linha, 6\}, $\{$ Linha, 0$\}\}$. Para resolver essa ambigüidade, deve-se considerar a posição relativa dos traços vertical e horizontal: se o traço horizontal estiver acima do ponto médio do traço vertical, este é classificado como "T"; caso contrário, é classificado como um "L".

Similaridades entre caracteres. Devido ao fato de alguns caracteres serem muito parecidos, resultados equivocados são bastante comuns. Como exemplo, temos o caso de caracteres como "1" e "7", "9" e "g", "u” e "y", etc. O algoritmo que possibilita distinguir " $u$ " de "y" por exemplo, que são definidos pelas primitivas $\{\{$ CurvaAcima, 0$\},\{$ Linha, 6\}\}, resolve essa ambigüidade através da comparação da altura das duas primitivas.

A desvantagem do pós-processamento é que para cada grupo de caracteres suscetível à erro de reconhecimento é necessário escrever uma rotina específica para tratá-lo. Na versão atual da JInk API a operação de pós-processamento é definida por meio de uma interface, na qual a aplicação que a implementa cuida de executar sua verificação de erros após receber o callback. Para o caso de reconhecimento de letras e dígitos, é fornecida uma implementação default.

Em uma avaliação realizada por Chan and Yeung [1999], o método foi testado com dados obtidos de 150 usuários, e as taxas de reconhecimento foram de 98.60\% para dígitos, $98.49 \%$ para letras maiúsculas e $97.44 \%$ para letras minúsculas. Quando os casos de rejeição foram excluídos do cálculo, as taxas subiram para 99.93\%, 99.53\% e 98.07\%, respectivamente. 


\subsubsection{Especificação de Requisitos}

Durante a fase de reformulação do serviço de reconhecimento JInk, foi definido que a API deveria atender aos seguintes requisitos:

1. Deve suportar o reconhecimento on-line de caracteres de escrita manual nãocursiva (os caracteres devem estar separados);

2. Deve permitir a extensão dos tipos de caracteres suportados. Ex: um programador pode definir os tipos "Gestos", "Formas Geométricas", "Alfabeto Japonês Hiragana”, "Letras Gregas”, etc.;

3. Deve possibilitar que o programador especifique o conjunto de símbolos para cada tipo de caracteres suportado. Ex: para o tipo "Letras Gregas”, os símbolos podem ser “ $\alpha$ ", “ $\beta$ ”, “ $\gamma$ ", “ $\delta$ ", “ $\epsilon ”$, etc.;

4. Deve permitir que cada usuário treine seu próprio conjunto de modelos de caracteres, de forma a aumentar a precisão do reconhecedor;

5. Deve prover interfaces de programação responsáveis por notificar a ocorrência de eventos relacionados ao reconhecimento;

6. Deve possibilitar que o método de reconhecimento utilizado, baseado no algoritmo de Casamento Estrutural Flexivel [Chan and Yeung, 1999], tenha seus parâmetros e restrições configuráveis;

7. Deve suportar diferentes formas de unificação/segmentação dos caracteres. Ex: algumas aplicações exigem que os traços sejam agrupados de acordo com sua posição relativa, enquanto outras demandam que esse processo seja feito de acordo com o tempo de escrita de cada traço;

8. O reconhecimento deve poder ser executado de maneira concorrente à aplicação, como um processo independente;

9. Deve suportar a manipulação de arquivos XML com informação de tipos, símbolos, modelos e outras configurações do usuário;

10. A configuração da API deve poder ser feita via uma interface gráfica, por meio de um painel de controle que efetue a geração automática dos arquivos XML;

\subsubsection{Modelagem e Implementação}

A estrutura da API é composta por três pacotes: core, util e demo. O primeiro, core, contém as classes e interfaces correspondentes ao núcleo da API, responsáveis 
pelo reconhecimento e pelo suporte ao tratamento de eventos. O segundo, util, possui as classes utilitárias responsáveis pela configuração da API, gerenciamento de usuários e manipulação de arquivos XML. Por fim, o pacote demo contém as aplicações desenvolvidas com a API e utilizadas como prova de conceito. Nesta seção são descritos as funcionalidades e os relacionamentos das classes e interfaces do pacote core e apresentada a sua modelagem UML.

Do ponto de vista arquitetural, a principal classe da Java Ink API é a InkRecognizer, por servir de ponto de ligação entre a API e a aplicação que a utiliza. Essa classe engloba as duas classes responsáveis pelo reconhecimento de fato dos caracteres: InkStructureExtractor e InkStructureMatcher. A primeira efetua a extração da estrutura dos traços, sendo encarregada da identificação das primitivas que formam cada traço. Ela faz uso de outra classe, InkGeometric, que implementa uma série de algoritmos geométricos para a identificação de interseções entre segmentos, cálculo de distância entre pontos e linhas, etc. Valendo-se desses métodos a classe InkstructureExtractor realiza operações de suavização, elimina distorções, identifica loops e junções nos traços e obtém as primitivas estruturais. Após isso, a classe InkStructureMat cher, que contém os métodos relativos ao algoritmo de Casamento Estrutural Flexível (CEF), efetua o reconhecimento do caractere, baseando-se nas primitivas obtidas no processo anterior.

A classe InkType, por sua vez, representa os tipos de caracteres suportados pelo reconhecedor, que podem ser definidos pelo programador. Cada tipo é composto por um conjunto de símbolos e modelos, e define determinadas propriedades relacionadas ao seu reconhecimento. Os modelos, implementados pela classe InkModel, representam algumas das variações de cada caractere, que devem ser fornecidas pelo usuário para que seja construída uma "base de exemplos" e o reconhecedor (mais especificamente, um objeto da classe InkStructureMatcher) possa compará-los com os caracteres de entrada. A busca por um modelo semelhante não é linear, sendo efetuada em vários níveis e com o caractere de entrada sofrendo múltiplas deformações em sua estrutura, de acordo com o algoritmo de CEF. Assim, cada instância da classe InkModel possui um símbolo, definido pela classe InkSymbol, e um caractere, representado pela classe InkCharacter.

Os objetos da classe InkSymbol correspondem aos possíveis elementos que podem ser associados aos modelos. Como exemplo, os símbolos do tipo "Dígito", seriam: “0”, “1”, “2”, “3”, “4”, “5”, “6”, “7”, “8” e “9”. As propriedades, descritas pela classe InkProperties, servem para informar, por exemplo, que os traços não podem ser invertidos ou ter sua ordem de escrita permutada, características necessárias quando do reconhecimento de assinaturas. Já os objetos da classe InkCharacter são constituídos por um conjunto de traços, representados por instâncias da classe Inkstroke, 
e sua função é identificar quais traços pertencem a um mesmo agrupamento, executando para isso operações de unificação e segmentação. Essa classe também possui um objeto da classe InkPositionMask, que especifica a posição relativa entre os traços que compõem cada caractere através de uma máscara.

A classe InkStroke é composta por objetos InkSegment e InkPrimitive. O primeiro se refere aos segmentos de reta que interpolam os pontos obtidos pela discretização da escrita no dispositivo, e correspondem às unidades básicas que formam cada traço. Já o segundo, corresponde aos elementos primitivos que definem a estrutura do caractere, identificados pelo InkStructureExtractor, e que são utilizados pelo InkStructureMatcher durante a execução do algoritmo de CEF.

Por fim, a interface InkResultListener é responsável pela notificação dos eventos resultantes do reconhecimento, representados pela classe InkResultEvent. Uma aplicação que deseja receber callbacks desses eventos deve registrar-se no objeto InkRecognizer e prover a implementação da interface InkResultListener, possibilitando-a manipular os resultados da maneira mais apropriada ou mesmo realizar um pós-processamento do caractere reconhecido (para remoção de ambigüidades, por exemplo). A Figura 4.4 apresenta o diagrama de classes do pacote descrito nesta seção.

\subsubsection{Configuração}

A aplicação responsável pela customização e controle da Java Ink era de difícil entendimento, englobando numa mesma interface informação relacionada à configuração/programação da API (de interesse apenas do desenvolvedor) e controles do reconhecedor em tempo de execução (de interesse do usuário). Assim, foram criadas duas aplicações independentes: o Painel de Configuração, responsável pelo gerenciamento de tipos de caracteres, propriedades e símbolos permitidos, e o Painel de Controle, que possibilita a seleção de usuários, monitoramento do reconhecedor, adição e remoção de modelos, etc. Essas ferramentas são mostradas na Figura 4.5.

\subsection{Java Speech API}

A Java Speech API, desenvolvida pela Sun Microsystems [1998c em cooperação com outras companhias como IBM, Apple, AT\&T e Philips, define uma interface de software que permite aos desenvolvedores utilizar as vantagens da tecnologia de reconhecimento e síntese de voz em aplicações Java ${ }^{1}$.

\footnotetext{
${ }^{1}$ http://java.sun.com
} 


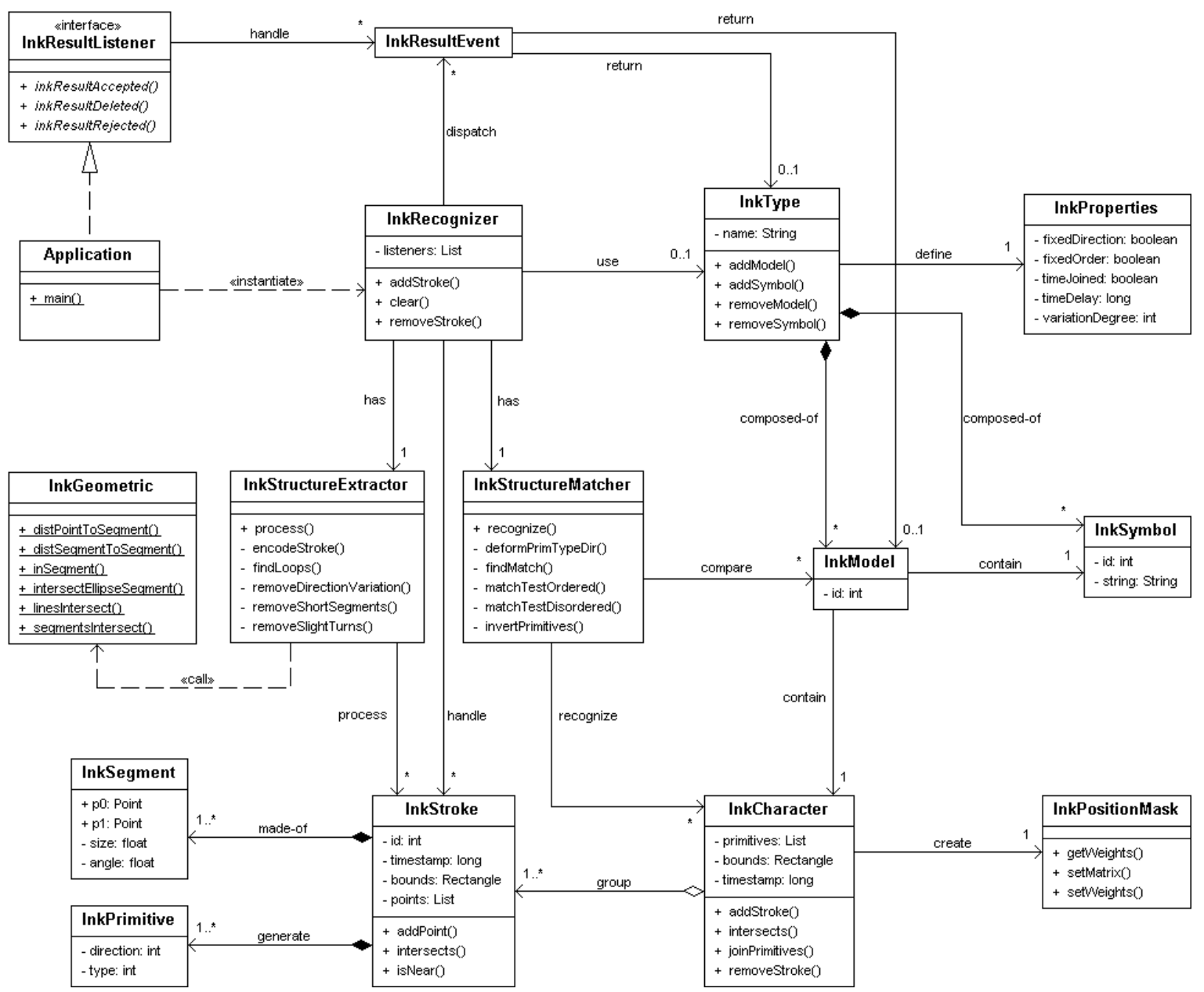

Figura 4.4: Diagrama de classes UML referente ao pacote "core" da Java Ink API (por questões de espaço, apenas os principais métodos e atributos são apresentados).

A Java Speech API (JSAPI) é dividida em dois núcleos: o reconhecimento, que permite processar a entrada de voz do usuário e determinar o que foi o falado; e a síntese, que permite que uma saída de voz seja sintetizada a partir do texto gerado por uma aplicação ou usuário. O processamento da voz propriamente dito não é realizado pelo software Java, uma vez que a API constitui-se apenas de uma especificação padrão que possibilita às aplicações acessarem os recursos de reconhecedores e sintetizadores específicos (engines).

O reconhecimento de voz é realizado com base em gramáticas, definidas pelo programador durante a fase de implementação. Elas são classificadas em dois tipos:

Gramática de Regras: Faz uso de regras pré-estabelecidas, que especificam o que pode ser dito, restringindo o conjunto de possiveis entradas por parte do usuário. Por meio de um arquivo texto escrito em um formato especial de definição de gramáticas, o JSGF (Java Speech Grammar Format) [Sun Microsystems, 1998b], 

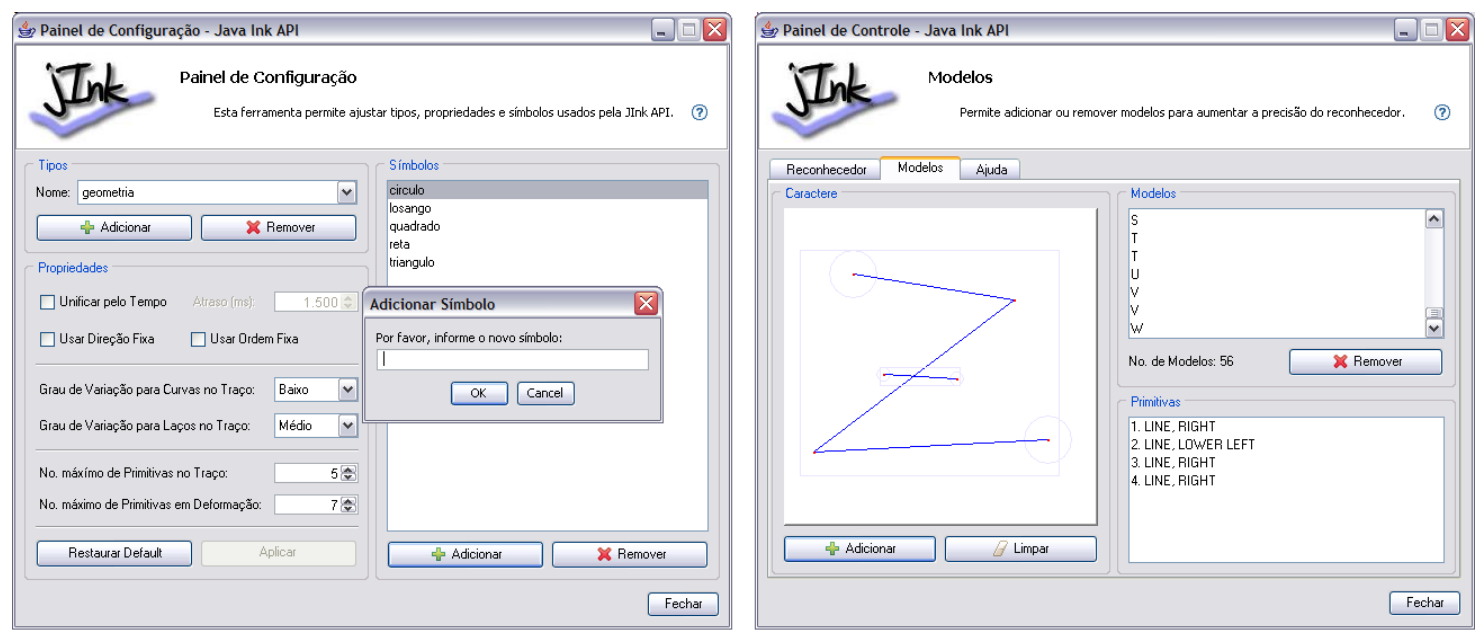

Figura 4.5: Interfaces do Painel de Configuração (à esquerda) e do Painel de Controle (à direita) da Java Ink API.

são determinadas exatamente todas as possiveis palavras ou frases que podem ser pronunciadas. Cada regra pode ser associada a um evento específico, que será gerado toda vez que uma ocorrência da regra for identificada. Uma explicação mais detalhada sobre a JSGF é apresentada na Seção 4.4.2.

Gramática de Ditado: É utilizada no reconhecimento de discurso contínuo, em que o usuário pronuncia as palavras em seqüência, porém sem uma ordem prédeterminada. Este tipo de gramática é mais complexo, devido ao maior tamanho do vocabulário e à ausência de regras, exigindo um processamento computacional mais elaborado. De modo a aumentar a precisão deste tipo de gramática é possível utilizar gramáticas voltadas para áreas específicas de conhecimento, tais como direito e medicina, que serão usadas para o reconhecimento de palavras técnicas ou comuns em um determinado domínio.

A síntese de voz é realizada com base em uma linguagem de marcação denominada JSML (Java Speech Markup Language) [Sun Microsystems, 1999], que segue o padrão XML. Desse modo, palavras ou mesmo frases inteiras podem ser facilmente sintetizadas pela transformação de cadeias de caracteres em voz digitalizada (text-tospeech). A JSML também especifica o modo como o som deverá ser gerado, permitindo alterar propriedades como tom de voz, ritmo e volume. Esses e outros recursos serão explicados mais detalhadamente na Seção 4.4.3.

\subsubsection{Arquitetura}

A arquitetura básica de uma aplicação desenvolvida sobre a JSAPI é composta por vários itens, estruturados em camadas. Conforme apresentado na Figura 4.6, a 
aplicação Java, em um nível mais alto, utiliza os recursos de reconhecimento e/ou síntese de voz de uma engine através de uma implementação da API. Essa implementação funciona como um driver, cuidando das peculiaridades de acesso de cada engine que ela se propõe a tornar compativel, de modo que as suas funcionalidades sejam providas seguindo as especificações e padrões descritos pela API.

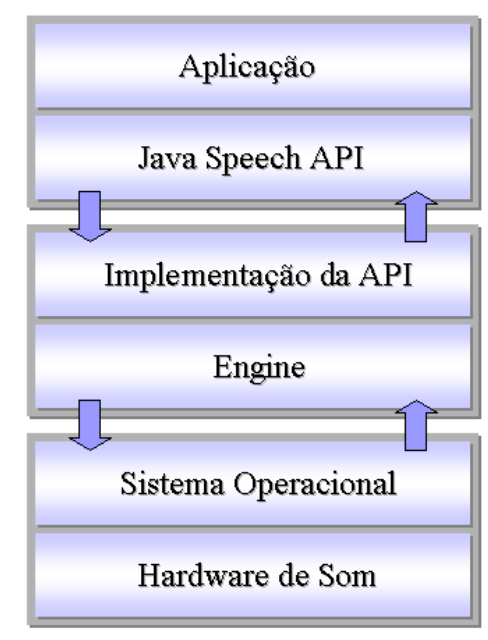

Figura 4.6: Arquitetura básica de uma aplicação Java utilizando a JSAPI.

Em um nível mais baixo, a engine acessa os recursos de hardware da máquina, por meio do sistema operacional. Assim, os eventos de E/S como o áudio captado pelo microfone ou emitido pelos auto-falantes são tratados pelo sistema operacional e re-direcionados à engine ou ao hardware de som, de acordo com a direção do fluxo.

\section{Engines}

A arquitetura da JSAPI é baseada em um conjunto de classes abstratas e interfaces que representam a visão do programador da engine, porém, sem fazer referência a um produto específico. Essa engine pode ser tanto uma solução implementada em hardware quanto em software (ou um híbrido das duas), executando localmente ou em um servidor. Ela também pode ser escrita em Java ou em qualquer outra linguagem, desde que seja possível o acesso às funções da engine a partir de um programa Java.

Diferentes implementações de engines possuem diferentes funcionalidades. Algumas possuem capacidade para assimilar padrões de fala, utilizar dicionários para contextos específicos ou fazer uso de diferentes tipos de sintetizadores, enquanto outras não implementam nenhuma dessas funcionalidades. Alguns exemplos de engines mais conhecidos são os softwares ViaVoice [IBM, 1998b], Microsoft Agent |Microsoft, 1999] e o Sphinx, desenvolvido pela Carnegie Mellon University [2004]. 


\section{Implementações da JSAPI}

A JSAPI é um pouco diferente das demais extensões Java, uma vez que a Sun Microsystems não provê nenhuma implementação de referência para ela. Ao contrário, a Sun disponibiliza uma lista de terceiros que possuem produtos que implementam a interface. O website oficial da Java Speech ${ }^{2}$ lista várias companhias como provedoras de produtos compatíveis, sendo que algumas estão descritas a seguir:

FreeTTS [Sun Microsystems, 2001]: Consiste de uma implementação open source, escrita totalmente em Java. É baseada na Flite 1.1, uma engine para síntese de voz desenvolvida na Carnegie Mellon University. A última versão da FreeTTS inclui suporte parcial a JSAPI, oferecendo somente o recurso de síntese de voz.

Speech for Java |IBM, 1998a|: Essa implementação é baseada no produto comercial da IBM para reconhecimento e síntese de voz, o ViaVoice. A tecnologia do ViaVoice suporta o reconhecimento de discurso contínuo e permite o treinamento do reconhecedor, de maneira a ajustá-lo à voz do usuário e aumentar sua precisão.

TalkingJava SDK |Cloudgarden, 2001|: É uma implementação completa da API, compatível com vários engines de reconhecimento e síntese de voz. Também inclui pacotes para redirecionamento de áudio, permitindo, por exemplo, que o stream de áudio seja gravado/lido em arquivos ou enviado/recebido através de uma rede. Ela faz uso de outra implementação da Sun, o Java Media Framework Sun Microsystems, 1998a.

\subsubsection{JSGF - Java Speech Grammar Format}

Os sistemas de reconhecimento provêem aos computadores a habilidade para ouvir a voz de um usuário e determinar o que foi dito. Entretanto, as tecnologias atuais ainda não suportam o reconhecimento de voz irrestrito, que é a habilidade para ouvir qualquer fala em qualquer contexto e transcrevê-la corretamente. Assim, para alcançar uma maior precisão e um tempo de resposta razoável, os atuais reconhecedores de voz restringem o que pode ser ouvido utilizando gramáticas.

A Java Speech Grammar Format (JSGF) [Sun Microsystems, 1998b define uma maneira de descrever tais gramáticas, conhecidas como gramáticas de comando $e$ controle ou gramáticas regulares, de um modo independente de plataforma e do tipo de engine utilizada. A JSGF utiliza uma representação textual que é legivel e editável por desenvolvedores e computadores, e que pode ser incluída no código da aplicação.

\footnotetext{
${ }^{2}$ http://java.sun.com/products/java-media/speech
} 
Basicamente, uma gramática é composta por um conjunto de regras que juntas especificam os tipos de construções verbais que um usuário pode dizer. Por exemplo, uma gramática simples para controle de programas deve ouvir por "abra o arquivo" ou "feche a janela", como exemplificado a seguir. As regras, por sua vez, podem conter combinações de texto (tokens) ou referências à outras regras.

A maioria dos reconhecedores possui um vocabulário para cada linguagem suportada. Entretanto, não é possível incluir 100\% de uma linguagem, como por exemplo, nomes, termos técnicos e palavras estrangeiras. Para problemas como esse, uma aplicação ou um usuário podem incluir o token inexistente, junto com a sua pronúncia, de modo a assegurar o reconhecimento.

\section{Exemplo de uma Gramática}

Este exemplo é derivado da listagem abaixo, sendo explicado a seguir.

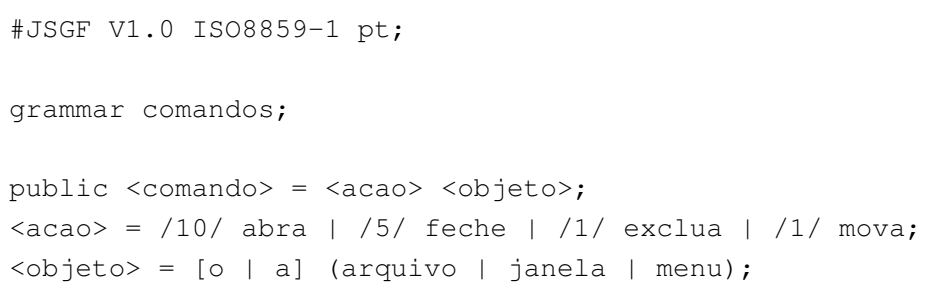

A primeira linha de código indica a versão da JSGF usada, o esquema de codificação dos caracteres e a linguagem utilizada. Em seguida, é definido o nome da gramática e o conjunto de regras. Neste exemplo, a gramática comandos possui uma única regra do tipo public, a regra $\langle$ comando $\rangle$, que é considerada o ponto inicial para o reconhecedor. Essa regra é definida pela concatenação de duas regras privadas, $\langle$ acao $\rangle$ e $\langle o b j e t o\rangle$. A regra $\langle$ acao $\rangle$ possui uma lista de ações e seus respectivos pesos, indicando, por exemplo, que a ação "abra" é mais propensa a ocorrer do que as outras. Já a regra <objeto>, é definida pelos artigos opcionais "o" ou "a”, e obrigatoriamente uma das alternativas entre "arquivo", "janela” e "menu”.

\subsubsection{JSML - Java Speech Markup Language}

Um sintetizador de voz provê ao computador a habilidade para reproduzir a voz humana, possibilitando que usuários e aplicações forneçam textos que serão convertidos em áudio. Os sintetizadores são desenvolvidos para produzir um som de voz o mais natural possivel, de modo semelhante aos seres humanos. Entretanto, a fala humana é um processo complexo, e a habilidade dos sintetizadores em reproduzir esta capacidade é limitada. Uma vez que os sintetizadores não compreendem o que 
dizem, não é possível esperar que eles utilizem o estilo ou a entonação corretos para cada frase.

Nesse sentido, a Java Speech Markup Language (JSML) [Sun Microsystems, 1999] permite às aplicações fornecer informações adicionais sobre como um texto deve ser convertido em som, aumentando a qualidade e a naturalidade da fala. Os documentos JSML podem incluir informação estrutural sobre parágrafos e sentenças, permitindo controlar a reprodução de palavras, enfatizar partes do texto e definir características como o ritmo e a velocidade da fala.

A JSML pode ser usada em uma grande variedade de aplicações para reproduzir texto das mais variadas fontes, incluindo e-mail, informações de bases de dados, páginas Web, palavras de processadores de documentos, etc. A aplicação é responsável por converter o conteúdo de informação e formatá-lo para texto JSML, usando para isso conhecimento sobre como a saída deve ser produzida.

Apesar da JSML possuir similaridades com o formato HTML, os papéis de ambas são diferentes, pois a linguagem HTML é especializada na apresentação visual da informação, enquanto que a JSML é especializada na apresentação sonora do conteúdo da fala. A JSML também é um subconjunto da linguagem XML, sendo portanto um padrão aberto, independente de plataforma e de fácil extensão.

\section{Elementos da JSML}

Os elementos da JSML podem ser containers, que possuem sub-elementos e/ou texto a ser falado, ou elementos vazios. Alguns tipos de elementos podem conter um ou mais atributos, que são usados para fornecer informação adicional sobre o elemento. Uma lista dos elementos da sintaxe JSML é apresentada na Tabela 4.2 , junto de alguns exemplos.

\subsection{Considerações Finais}

O propósito deste capítulo foi descrever as duas infraestruturas utilizadas no contexto deste projeto, fornecendo uma visão detalhada sobre suas arquiteturas. A JInk API é uma biblioteca de classes Java que possibilita a construção de interfaces baseadas em interação por caneta. Um dos objetivos com a implementação da JInk é que ela tivesse um método de reconhecimento genérico, que possibilitasse o reconhecimento não apenas caracteres, como também gestos, formas e traços específicos de um determinado domínio. Desse modo a API pode ser configurada para diferentes tipos de aplicações, podendo um caractere ser reconhecido e associado a um 


\begin{tabular}{|c|c|c|}
\hline Elementos & Descrição & Exemplo \\
\hline PARA & $\begin{array}{l}\text { Especifica que o texto contido é um } \\
\text { parágrafo. }\end{array}$ & $\begin{array}{l}\text { PARA }>\text { Este é um curto } \\
\text { parágrafo. </PARA }><\text { PARA }>0 \\
\text { assunto mudou, então este é um } \\
\text { novo parágrafo. </PARA }>\end{array}$ \\
\hline SENT & $\begin{array}{l}\text { Especifica que o texto contido é uma } \\
\text { sentença. }\end{array}$ & $\begin{array}{l}\text { SENT }>\text { Ela disse: } \quad<\text { SENT }>\text { "Vou } \\
\text { embora amanhã..." }</ \text { SENT }></ \text { SENT }>\end{array}$ \\
\hline SAYAS & $\begin{array}{l}\text { Especifica como o texto deve ser pro- } \\
\text { nunciado. }\end{array}$ & $\begin{array}{l}<\text { SAYAS SUB="i três e" > IEEE } \\
</ \text { SAYAS }>\end{array}$ \\
\hline EMP & $\begin{array}{l}\text { Especifica que o texto deve ser pronun- } \\
\text { ciado com ênfase. }\end{array}$ & $\begin{array}{l}<\text { <EMP LEVEL=" reduced" > Silêncio! } \\
\text { O bebê está dormindo! } \quad</ \text { EMP }>\end{array}$ \\
\hline BREAK & Especifica uma parada durante a fala. & $<$ BREAK SIZE="small"/> \\
\hline PROS & $\begin{array}{l}\text { Especifica propriedades da fala, tais } \\
\text { como volume, ritmo, freqüência. }\end{array}$ & $\begin{array}{l}\text { <PROS RATE="50"VOL="+100\%" }> \\
\text { Querem fazer O favor de ficar } \\
\text { quietos! </PROS }>\end{array}$ \\
\hline MARKER & $\begin{array}{l}\text { Requisita uma notificação quando a } \\
\text { fala alcança este marcador. }\end{array}$ & $\begin{array}{l}\text { Responda: <MARKER } \\
\text { MARK="sim_ou_nao"/> Sim ou não? }\end{array}$ \\
\hline ENGINE & $\begin{array}{l}\text { Fornece instruções para um sinteti- } \\
\text { zador específico. }\end{array}$ & $\begin{array}{l}\text { O cachorro faz <ENGINE } \\
\text { ENGID="AnimalSinth1.0" } \\
\text { DATA="dog" > </ENGINE }>\end{array}$ \\
\hline
\end{tabular}

Tabela 4.2: Conjunto de elementos da JSML.

elemento gráfico, comando a ser executado, ou qualquer outro objeto definido pelo programador.

A JSAPI fornece uma interface de alto nível para a implementação de interfaces de voz. A arquitetura coerente da API, junto de sua padronização de classes e interfaces, além de extensa documentação, foram fundamentais para a sua integração ao JMIS Framework. Além disso, a JSAPI prove uma camada de abstração sobre as engine de voz utilizada, de forma que o framework multimodal não fica dependente de um produto em específico, podendo usar diferentes implementações da API. Isso também garante um aumento na portabilidade das aplicações desenvolvidas. 


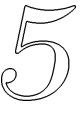 \\ O Projeto Desenvolvido: JMIS Framework}

CAPÍTULO

\subsection{Consideraçōes Iniciais}

O JMIS Framework (Java Multimodal Ink and Speech Framework) consiste de uma infraestrutura reusável para integração de interfaces de escrita e voz cujo foco é facilitar a prototipação rápida de aplicações multimodais. Este capítulo tem por objetivo descrever o projeto e a implementação dessa infraestrutura.

\subsection{Fusão de Modalidades}

A principal característica de um sistema multimodal é a sua capacidade em combinar diferentes tipos de entrada individuais, processá-las utilizando uma técnica de integração e retornar um resultado contendo algum significado específico para a aplicação. Essa funcionalidade, também conhecida como fusão multimodal, é responsável por resolver ambigüidades entre as modalidades de entrada, detectando preferências do usuário ou possíveis estilos de interação, de modo a aumentar a precisão do sistema. Normalmente isso é feito por meio de regras ou informações de contexto fornecidas pela aplicação. A entrada de informação redundante também é considerada de grande utilidade para a redução da incerteza e aumento da confiabilidade da fusão multimodal, por exemplo, quando há ruído em uma das entradas ou 
informação incompleta é provida pelo usuário.

Os sinais de entrada provenientes das várias modalidades podem ser combinados em diversos níveis, sendo que a literatura aponta duas abordagens principais, conhecidas como fusão em nível característico (feature level) e fusão em nível semântico (semantic level) |Corradini et al., 2003|:

Fusão em Nivel Característico: Também conhecido como "fusão cedo", esse tipo de integração é geralmente utilizado para modalidades de entrada fortemente acopladas ou sincronizadas, tais como fala e movimento dos lábios. Nesse processo, o reconhecimento de uma modalidade influencia o curso do reconhecimento do outro. A fusão cedo não é recomendada para modalidades que diferem substancialmente no conteúdo de informação e tempo de entrada, como voz e gestos por caneta, além de requerer uma grande quantidade de dados para treinamento e possuir um alto custo computacional.

Fusão em Nivel Semântico: Essa segunda abordagem, também conhecida como " $f u$ são tarde", é mais aplicada para modalidades pouco acopladas e que diferem na sua escala de tempo (assíncronas). As informações provenientes dos reconhecedores individuais são normalmente representadas por estruturas de características na forma de pares atributo-valor e combinadas depois. Geralmente as entradas possuem timestamps que são integrados em conformidade com funções de vizinhança temporal e algoritmos de casamento recursivo de estruturas de características.

De acordo com Corradini et al. [2003], a fusão em nível semântico oferece uma série de vantagens sobre a fusão em nível característico. Primeiramente, os reconhecedores para cada modalidade podem ser treinados separadamente e integrados sem necessidade de serem retreinados no caso da inserção de uma nova modalidade. Além disso, produtos comerciais (off-the-shelf) podem ser utilizados para modalidades padrão como, por exemplo, reconhecimento de voz. Uma vantagem adicional é a simplicidade, uma vez que a integração não adiciona nenhum parâmetro extra além dos utilizados pelos reconhecedores de cada modalidade permitindo uma certa generalização sobre o número e os tipos de modalidades envolvidas. O framework multimodal implementado neste trabalho utiliza a abordagem da fusão em nível semântico.

\subsection{Técnicas de Integração Multimodal Utilizadas}

Duas técnicas foram utilizadas na implementação do JMIS Framework: a Integração Multimodal baseada em Unificação JJohnston et al., 1997 e a Gramática 
Multimodal baseada em Unificação |Johnston, 1998|. Embora seja apenas um aprimoramento da primeira, a segunda técnica suporta um nível mais completo de integração e possui características mais complexas para representação das entradas. Essas duas abordagens serão discutidas nesta seção.

\subsubsection{Integração Multimodal baseada em Unificação}

Uma das técnicas de integração multimodal mais citadas na literatura é a desenvolvida por Johnston et al. [1997]. Eles propõem uma arquitetura baseada no conceito de estruturas de características tipadas (do Inglês, typed feature structures) para representar a contribuição semântica das diferentes entradas. Assim, para cada interação é gerada uma estrutura de características contendo informações sobre a interpretação da entrada, como tipo, timestamp, probabilidade e outros dados específicos de cada modalidade.

A unificação é uma operação que determina a compatibilidade de duas peças de informação; caso elas sejam compatíveis, é gerado um único resultado que pode ser interpretado pelo sistema. Essa compatibilidade é especificada por meio de características que funcionam como restrições, indicando quais entradas são ou não aceitas. Por exemplo, se uma dada entrada de voz pode ser unificada com um gesto de linha, uma estrutura pode ser associada à essa entrada com uma característica denominada localização cujo valor requerido seja um objeto do tipo linha. Baseando-se nessas informações, o integrador então identifica a melhor combinação em potencial e gera uma estrutura final que represente a interpretação.

Cohen et al. 1997] descrevem uma implementação dessa técnica no sistema QuickSet, que possui uma interface multimodal baseada em reconhecimento de voz e gestos com caneta para interação com mapas e simulações militares. Nesse exemplo, se o usuário diz "criar trincheira aqui”, a seguinte estrutura de características é gerada:

$$
\left[\begin{array}{ll}
\text { objeto }: & {[\text { palavras }: \text { criar trincheira aqui }]_{\text {trincheira }}} \\
\text { modalidade }: & \text { voz } \\
\text { timestamp }: & 131621738 \\
\text { probabilidade }: & 0.85 \\
\text { localizacao: } & {[]_{\text {linha }}}
\end{array}\right]_{\text {comando }}
$$

Enquanto fala, se o usuário faz um gesto de "linha" com a caneta, uma segunda estrutura representando essa interação também é gerada: 


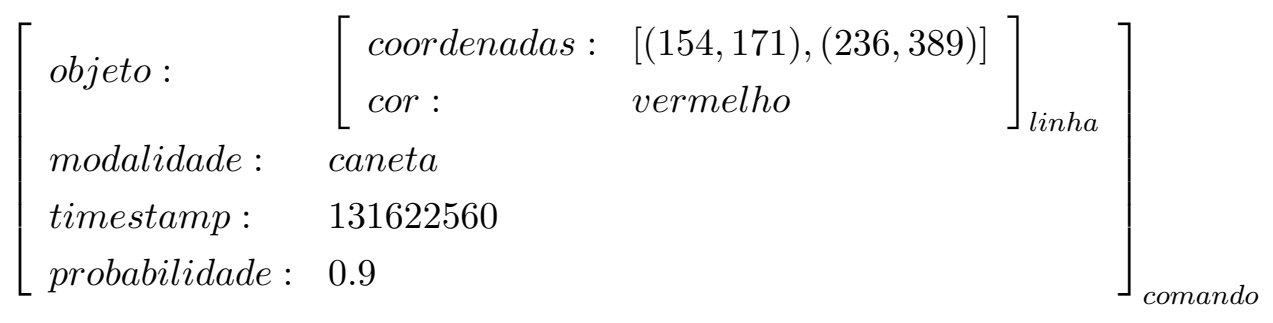

Por fim, se o integrador multimodal identifica essas estruturas como complementares, um resultado com um maior nível semântico é criado, e a probabilidade desse resultado corresponde à multiplicação das probabilidades das estruturas de entrada:

$$
\left[\begin{array}{lll}
\text { objeto: } & {\left[\begin{array}{ll}
\text { coordenadas }: & {[(154,171),(236,389)]} \\
\text { cor }: & \text { vermelho }
\end{array}\right]_{\text {linha }}} \\
\text { probabilidade }: & 0.76 & \\
\text { acao }: & \text { criar_trincheira }
\end{array}\right]_{\text {resultado }}
$$

A integração é então guiada pela definição de restrições que especifiquem quais tipos de entrada são complementares e cujos timestamps das estruturas se sobreponham ou estejam dentro de um intervalo de tempo determinado. Nesse caso, a frase dita é complementada por um gesto que identifica a localização do objeto a ser criado. Para um dado instante no tempo, todas as possiveis combinações de voz e gestos são analisadas (utilizando a consistência de tipos) e a estrutura de mais alta probabilidade é selecionada pelo algoritmo.

\subsubsection{Gramática Multimodal baseada em Unificação}

Embora a técnica descrita na seção anterior seja uma solução eficiente para uma ampla gama de aplicações, o integrador proposto por Johnston et al. 1997] permite somente estruturas que podem ser árvores unárias ou binárias de um nível de profundidade. Isso limita a combinação a um único comando de voz e um único gesto, não sendo possível a integração de entradas mais complexas. Para sobrepor essa deficiência, Johnston 1998 propôs uma evolução da sua técnica, desenvolvendo um formalismo completo para uma gramática multimodal.

Nessa técnica, a representação de expressões multimodais segue o modelo sintático de gramáticas como a HPSG (Head-Driven Phrase Structure Grammar) |Pollard and Sag, 1994]. Frases e gestos passam a ser vistos como elementos terminais no processo de parsing, sendo também referenciados como bordas léxicas. Os componentes de interpretação atribuem representações gramaticais à essas entradas na forma de 
estruturas de características, de maneira similar à técnica anterior. A integração multimodal é realizada a partir de um algoritmo de parsing que testa a combinação das bordas léxicas, utilizando para isso um conjunto de regras e restrições pré-definidas.

As regras da gramática multimodal são produções na forma $L H S \Rightarrow D T R_{1} D T R_{2}$ onde $L H S, D T R_{1}$ e $D T R_{2}$ são estruturas de características. Esse esquema de regras é organizado hierarquicamente, permitindo que sub-regras específicas herdem restrições de regras mais genéricas. Assim, a estratégia básica de integração definida por Johnston et al. 1997] se torna apenas mais uma regra em um dos múltiplos níveis da árvore de regras, como exemplificado no esquema abaixo:

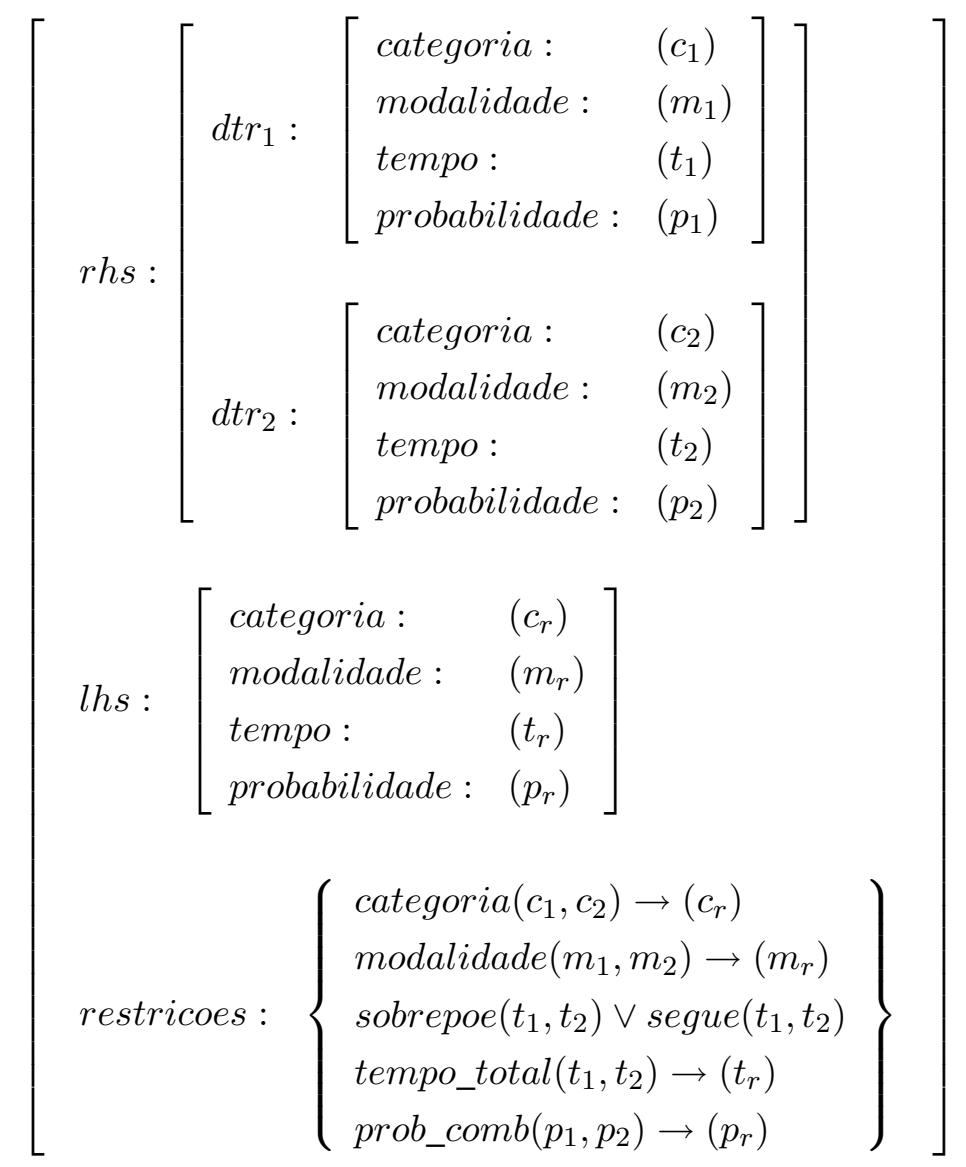

Nesse esquema, a característica restrições indica uma série de condições que devem ser satisfeitas para que a regra seja aplicada. A unificação de duas bordas candidatas envolve compará-las com as sub-regras $d t r_{1}$ e $d t r_{2}$; se as bordas combinam com as sub-regras, então as restrições são checadas. Por fim, se todas restrições são satisfeitas, uma nova borda léxica lhs é criada. As regras são indexadas internamente por um atributo categoria para evitar comparações desnecessárias, só sendo processadas se a entrada possuir a mesma categoria. 
As restrições determinam relacionamentos entre as bordas léxicas, podendo inclusive formar condições complexas usando operadores lógicos como $\vee$ (ou), $\wedge$ (e), $\mathrm{e} \neg$ (negação). Por exemplo, a restrição temporal sobrepoe $\left(t_{1}, t_{2}\right) \vee \operatorname{segue}\left(t_{1}, t_{2}\right)$ estabelece que a borda $d t r_{1}$ deve sobrepor ou preceder a borda $d t r_{2}$. Já a restrição modalidade $\left(m_{1}, m_{2}\right) \rightarrow\left(m_{r}\right)$ indica que a modalidade resultante da união de duas bordas com modalidades $m_{1}$ e $m_{2}$ deve ser $m_{r}$. Características auxiliares e restrições não relevantes à explicação do método foram omitidas.

Uma vez que as regras da gramática multimodal têm que ser binárias, a solução para a definição de comandos que envolvam mais de dois elementos ou que possuam interpretações complexas é feita a partir de sub-categorização. Uma regra pode ser formada pela combinação de outras sub-regras, de uma maneira recursiva. Desse modo, uma interação envolvendo três bordas léxicas, por exemplo, pode ser representada por duas regras: uma regra $A$ formada pela composição de duas sub-regras $a_{1}$ e $a_{2}$, e uma segunda regra composta pelo resultado de A e B. Essa sub-categorização de regras é demonstrada na Figura 5.1 .

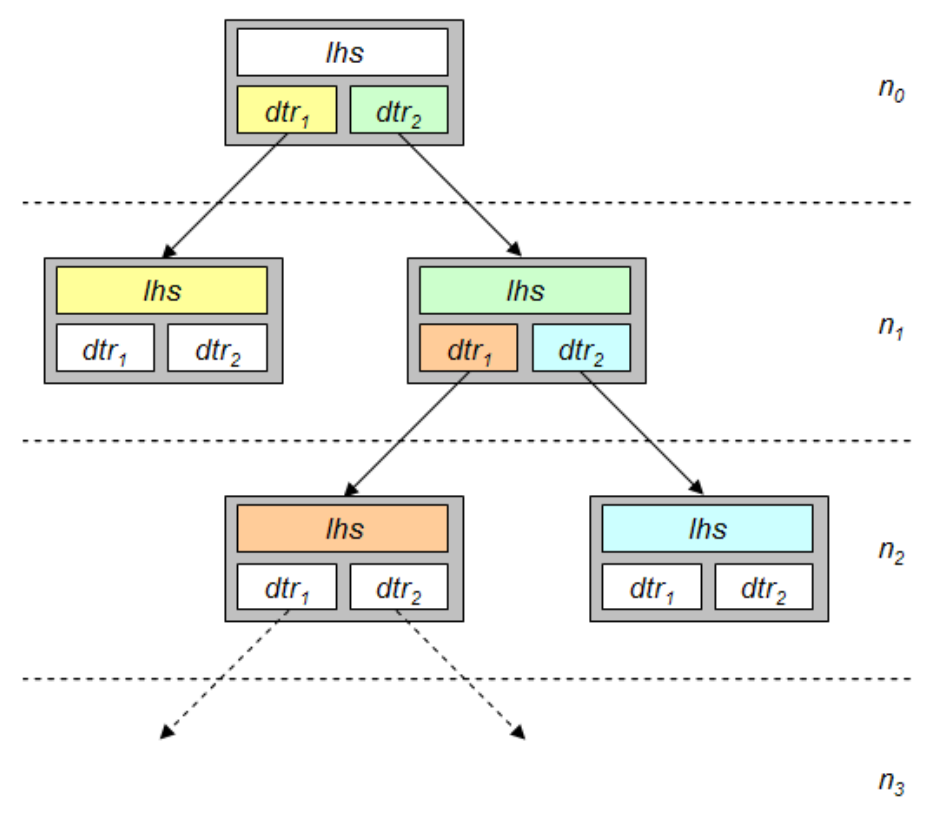

Figura 5.1: Exemplo de uma árvore de regras com diversos níveis criada a partir de sub-categorização.

Por meio dessa técnica, um amplo escopo de entradas multimodais pode ser representado, incluindo a combinação de múltiplas interações de voz e gestos em um único comando. A utilização do esquema de regras e restrições permite que essas combinações sejam descritas da maneira que for considerada mais conveniente, além de suportar a generalização da arquitetura para possibilitar a adição de outras 
modalidades. O aspecto declarativo da gramática também facilita a modificação do conjunto de regras e a prototipação rápida de sistemas multimodais [Johnston, 1998.

\subsection{Especificação}

Nesta seção são apresentados os requisitos funcionais e não-funcionais identificados para

\subsubsection{Requisitos Não-Funcionais}

Como requisitos comuns a quaisquer frameworks orientados a objetos, o JMIS Framework também deve objetivar as seguintes características:

Reusável: O framework deve ser suficientemente genérico para suportar a sua reutilização em diferentes tipos de aplicações. Além disso, ele deve ser de fácil configuração e possibilitar sua personalização pelo próprio usuário, por meio de interfaces gráficas e arquivos de propriedades.

Extensivel: O framework deve possuir uma arquitetura extensivel, permitindo que suas classes sejam especializadas, estendidas e customizadas para suportar aplicações com diferentes características e necessidades.

Adaptável: O framework deve exigir mínima modificação no código existente e ser de fácil utilização. A implementação dependente de domínio deve poder ser feita separadamente, por meio de classes abstratas, interfaces e mecanismos de tratamento de eventos.

Modular: O framework deve ser estruturado sob uma arquitetura modular, com suas classes organizadas de maneira lógica em pacotes, possuindo um baixo acoplamento entre si e um alto grau de coesão.

Eficiente: Por se tratar de um framework para interação com usuário, espera-se que o mesmo seja eficiente, tanto em termos de desempenho como de precisão dos sistemas de reconhecimento e de integração de modalidades. Além disso, o framework deve executar de maneira transparente, realizando o mínimo possível de intromissões no ambiente do usuário.

Documentado: Além da documentação interna existente em todo o código e externa no formato Javadoc, o framework deve fornecer informação de alto nível sobre sua instalação, utilização e customização. Deve ainda possuir códigos-exemplo, demonstrando a sua integração à diferentes aplicações. 


\subsubsection{Requisitos Funcionais}

Foram identificados os seguintes requisitos funcionais para o JMIS Framework:

1. Deve suportar duas modalidades de entrada, por caneta e voz;

2. Os fluxos provenientes das modalidades de interação devem ser processados por reconhecedores individuais. Neste caso, serão utilizadas as infra-estruturas providas pelas APIs Java Ink e Java Speech, detalhadas no Capítulo 4;

3. Deve permitir a utilização independente de modalidades, quando da ausência de uma ou por escolha do usuário;

4. Deve suportar a fusão de modalidades em nivel semântico, isto é, após o processamento independente das entradas;

5. Deve possibilitar que o algoritmo de fusão de modalidades utilizado, baseado método proposto por Johnston [1998], tenha seus parâmetros e restrições configuráveis;

6. Deve permitir a definição estruturas de características (empregadas pelo método de fusão para descrever as possíveis combinações de interação);

7. Deve possibilitar que tais estruturas sejam descritas por meio de uma interface gráfica e armazenadas em arquivos XML;

8. O framework deve ser independente de língua, permitindo sua adaptação para diferentes idiomas por meio de arquivos de propriedades;

9. Deve prover interfaces de programação responsáveis por notificar a ocorrência de eventos relacionados à identificação de estruturas;

10. Deve fornecer informação sobre tempo e localização espacial (no caso da escrita) das interações, para processamento posterior pela aplicação.

\subsection{Arquitetura}

A arquitetura do JMIS Framework pode ser decomposta em quatro módulos principais: o Componente Multimodal, o Módulo de Escrita (implementado pela Java Ink API), o Módulo de Voz (representado pela Java Speech API) e o Integrador Multimodal. Esses quatro elementos operando em conjunto devem prover uma infraestrutura completa para a construção de aplicações multimodais envolvendo escrita e voz.

Para facilitar a compreensão, os módulos do framework multimodal foram distribuídos em três níveis, como ilustrado na Figura 5.2: 
Aplicação: No nível de aplicação encontra-se o Componente Multimodal, responsável por instanciar os módulos de escrita e voz, capturar as entradas e manipular as respostas processadas pelo módulo do nível inferior.

Fusão Multimodal: No nível intermediário encontra-se o Integrador Multimodal, responsável por unificar os fluxos de eventos gerados independentemente pelos módulos de escrita e voz, interpretá-los e despachar a respectiva resposta para o nível acima.

Processamento Unimodal: No nível mais baixo estão os módulos de escrita e voz, utilizadas como infraestrutura para o processamento individual das entradas.

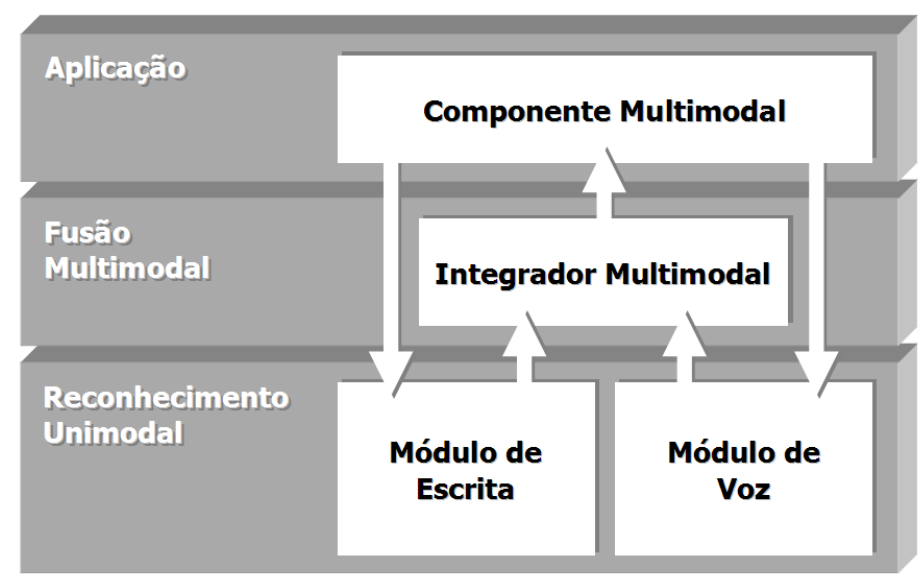

Figura 5.2: Arquitetura simplifica do JMIS Framework, ilustrando os quatro módulos principais e seus respectivos níveis.

\subsection{Modelagem e Implementação}

A arquitetura definida para o JMIS Framework utiliza como base duas APIs para o processamento individual das modalidades: a Java Ink API, implementada pelo aluno no contexto de seu trabalho de iniciação científica e utilizada no reconhecimento de escrita; e a Java Speech API, desenvolvida pela Sun Microsystems 1998c e responsável pelo reconhecimento e síntese de voz. Essas duas infra-estruturas são detalhadas no Capítulo 4 .

Embora essas APIs forneçam um conjunto bastante rico de classes e interfaces, a conversão dos resultados específicos de cada modalidade em uma representação comum para unificação é um processo relativamente complicado. A integração de componentes desenvolvidos separadamente, com propósitos e arquiteturas totalmente distintos, é uma tarefa complexa. Assim, grande parte do esforço de implementação 
do framework se deu na criação e na adaptação de componentes auxiliares que realizassem a "ligação" das APIs com o Integrador Multimodal e, posteriormente, do Componente Multimodal com a aplicação cliente.

Tendo essas dificuldades em vista, esta seção expõe alguns detalhes da lógica de programação dos componentes do JMIS, a modelagem de classes UML e o funcionamento de cada módulo.

\subsubsection{Componente Multimodal}

O Componente Multimodal é a principal interface entre a aplicação cliente e o JMIS Framework. Ele é responsável pelo tratamento da entrada proveniente da aplicação, pelo controle do fluxo interno de dados e pela notificação de eventos de integração. Assim, ele funciona tanto como um "porta de entrada" de interação unimodal, como também como uma "porta de saída" de interação multimodal.

O Componente Multimodal é formado por uma única classe abstrata de nome MultimodalComponent, e cuja intenção dessa é esconder os detalhes de configuração dos módulos do framework da aplicação cliente. Essa classe implementa o padrão de projeto Client Facade e é utilizada para gerenciar os objetos responsáveis pelos módulos de escrita e voz, alocar reconhecedores, configurar listeners de eventos, carregar gramáticas e arquivos de propriedades. Se essa sequência de tarefas fosse implementada pela aplicação, além de tornar complexa a integração, criaria dependências entre as camadas de apresentação e a lógica interna do framework. Assim, ao invés de gerenciar múltiplos componentes não-relacionados a lógica da aplicação e explicitamente definir o relacionamento entre eles, o desenvolvedor simplesmente chama os métodos de fachada dessa classe, a qual por sua vez executa o processamento.

Para que a MultimodalComponent funcione adequadamente são necessários três passos: (1) que a aplicação adicione essa classe como listener de eventos do mouse, de modo que o módulo de processamento de escrita possa receber os dados de entrada; (2) que as gramáticas de regras relacionados ao reconhecimento de voz sejam definidas; (3) que a classe seja estendida e tenha seus métodos abstratos implementados. Este último passo é um gancho que possibilita que a aplicação implemente seu próprio tratamento em resposta aos eventos de integração multimodal.

\subsubsection{Módulo de Escrita}

O módulo de escrita, composto pela JInk API e suas classes adaptadoras, tem como principal ponto de entrada a classe InkController. Ela implementa o padrão Controller e é utilizada pelo Componente Multimodal para fazer a ponte entre a interface da aplicação cliente (visão) e a JInk API (modelo). Assim, cada evento do 
mouse disparado na aplicação e recebido pela classe MultimodalComponent é automaticamente redirecionado para a InkController, que manipula internamente os componentes de reconhecimento da JInk fazendo chamadas aos métodos dessa API.

As classes adaptadoras são utilizadas para implementar a manipulação dos eventos resultantes do reconhecimento. As classes InkCharacterAdapter e InkWordAdapter são instanciadas na InkController e implementam interfaces providas pela JInk, de modo que sempre que um caractere ou palavra forem reconhecidos, essas classes são notificadas. Elas então efetuam a interpretação da entrada reconhecida, convertendo-a num formato padrão utilizado pelo Integrador Multimodal. Esse formato é representado pela classe Interaction.

A classe Interaction é uma estrutura usada para representar metadados sobre a interação. Ao invés de enviar apenas o resultado do reconhecimento para o Integrador Multimodal, as classes adaptadoras geram um evento do tipo Interaction. Esse evento é compartilhado pelos módulos de escrita e voz, e disponibiliza informações como: modalidade de entrada, tipo de interação (por exemplo, gestos, caracteres ou palavras), intervalo de tempo (início e fim), probabilidade de acerto e as tags que identificam o resultado. Além disso, ela possui um atributo genérico usado para inserção de dados específicos da modalidade. No caso de escrita, esse atributo é preenchido por um objeto do tipo InkContent, que armazena informações sobre o traço, como limites (coordenadas) no plano, centróide, etc.

Uma vez criada a representação da interação, esse evento é disparado para os ouvintes da interface InteractionListener, dentre os quais a classe MultimodalIntegrator é uma delas. Essa classe é responsável pela unificação das entradas, sendo detalhada mais a frente. Na Figura 5.3 é apresentada a modelagem UML das classes e interfaces do módulo de escrita e os relacionamento entre elas.

\subsubsection{Módulo de Voz}

O módulo de voz tem uma arquitetura similar a do módulo de escrita. A principal classe desse módulo é a SpeechController, que também implementa o padrão Controller e é instanciada pelo MultimodalComponent. A speechController é usada para gerenciar os componentes da JSAPI como o reconhecedor e o sintetizador de voz, configurar propriedades da engine e características do áudio, além de habilitar ou desabilitar componentes. Essa classe também realiza tratamento de erros durante a inicialização: caso uma engine de voz não esteja disponível, a aplicação continua funcionando sem essa modalidade. 


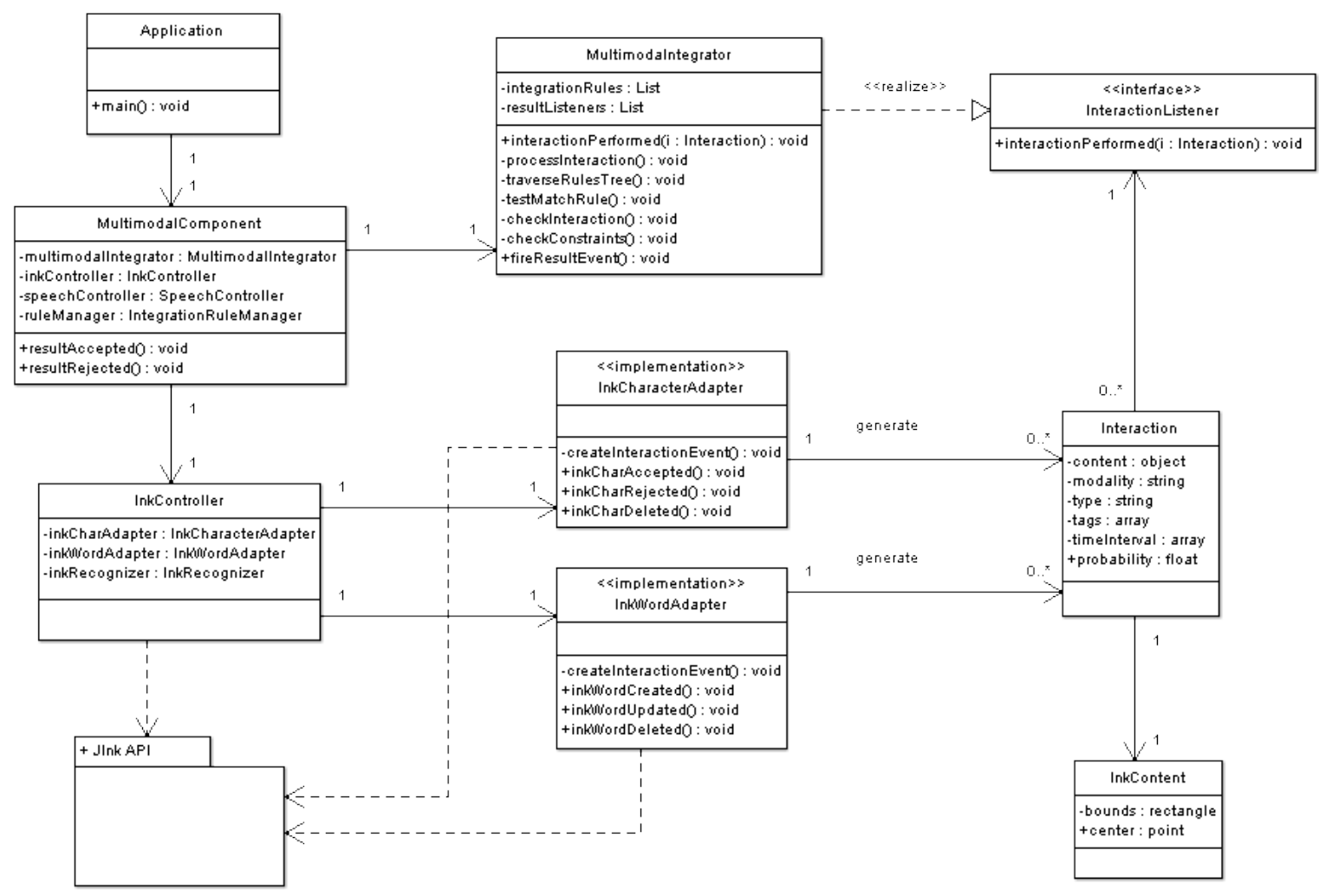

Figura 5.3: Diagrama de classes UML para o módulo de escrita.

O módulo de voz disponibiliza ainda uma classe para gerenciamento de gramáticas, a SpeechGrammarManager. Ela facilita a criação de gramáticas de regras e de ditado, além de permitir que listeners sejam associados a uma gramática específica. Ela também possibilita que as gramáticas sejam habilitadas quando requerido, realizando as modificações necessárias no reconhecedor da JSAPI.

Assim como no módulo de escrita, as classes adaptadoras são responsáveis pela obtenção do resultado parcial do reconhecedor e sua conversão em um elemento Interaction. No módulo de voz isso é feito pelas classes SpeechRuleAdapter e SpeechDictateAdapter, sendo a primeira utilizada para os eventos gerados pelas gramáticas de regras, e a segunda pelas gramáticas de ditado. Os atributos da classe Interaction são os mesmos, exceto pelo atributo content, que agora referencia um objeto do tipo speechContent. Essa classe armazena apenas as palavras resultantes do reconhecimento de voz realizado pela JSAPI, mas pode ser estendida para incluir novos dados. Assim, quando um evento Interaction é disparado, a classe Multimodalintegrator é notificada e inicia a tentativa de unificação. A Figura 5.4 apresenta a modelagem UML para o módulo de voz. 


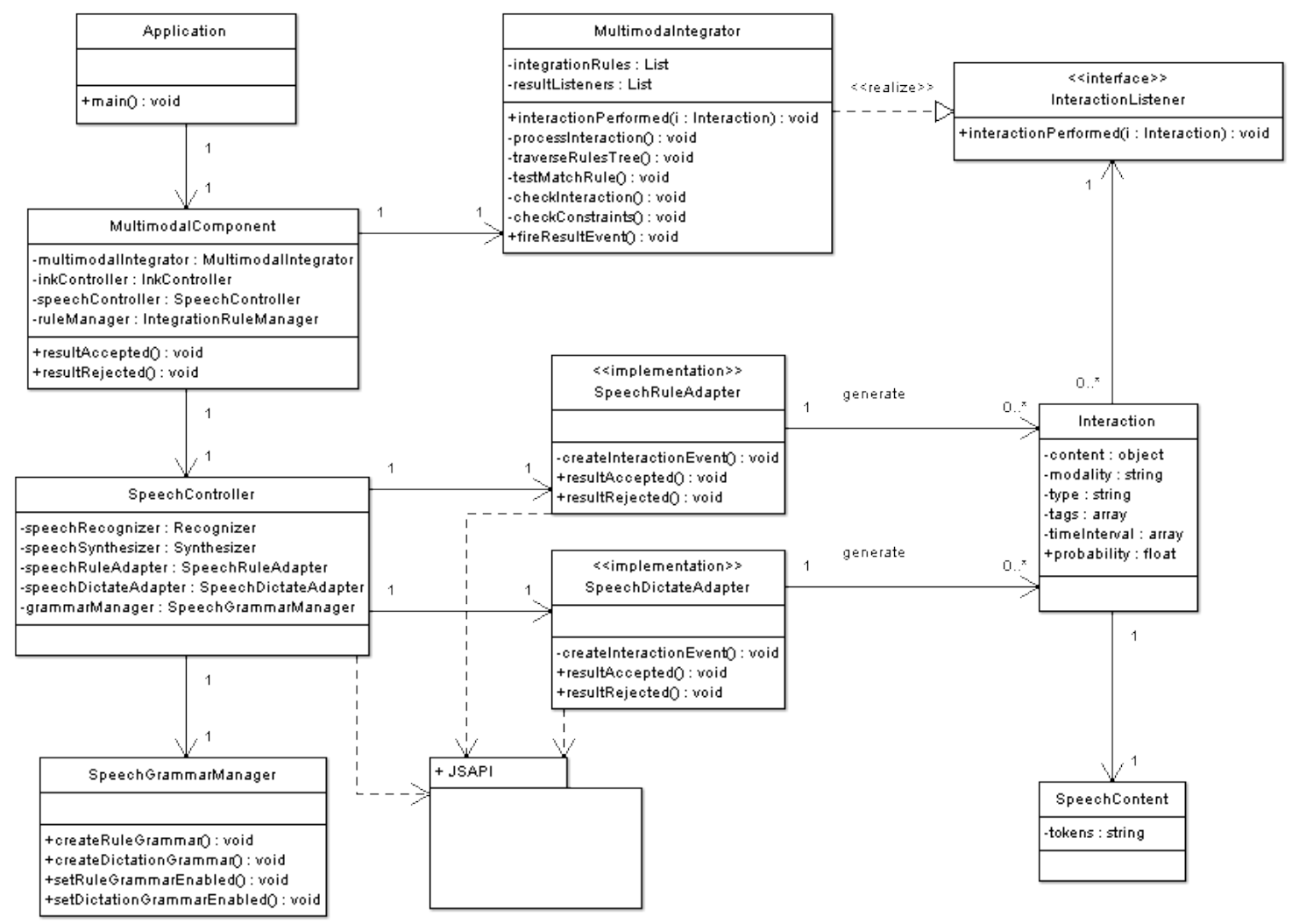

Figura 5.4: Diagrama de classes UML para o módulo de voz.

\subsubsection{Integrador Multimodal}

O Integrador Multimodal é o núcleo do JMIS Framework. É ele que efetivamente realiza a unificação dos eventos de entrada, por meio de uma implementação do método definido por Johnston [1998| e descrito na Seção 5.3.2. O módulo de integração multimodal mapeia os elementos descritos no método, tais como regras e restrições, além de se comunicar com os demais componentes do framework.

As regras de integração multimodal determinam o que pode ou não ser unificado. Elas são implementadas pela classe IntegrationRule, que possui campos como nome, categoria e restrições. As restrições definem as condições que uma regra deve satisfazer para que uma unificação seja bem-sucedida, e são implementadas pela classe IntegrationConstraints. O algoritmo suporta atualmente a verificação de restrições como: duração máxima das interações, atraso máximo permitido entre elas, probabilidade combinada mínima e se as interações devem ou não se sobrepor. Essa classe também pode ser estendida para incluir novas condições.

Juntamente com as restrições, a classe IntegrationRule possui duas referências para sub-regras, através dos atributos leftSubRule e right.SubRule. Esses atributos permitem que uma regra armazene recursivamente outras sub-regras, pos- 
sibilitando a composição de regras e a definição de interações baseadas em mais de dois eventos de entrada. A IntegrationRule também possui um campo Interaction, que indica o objeto resultante caso a regra seja satisfeita.

Partindo da geração de um evento Interaction, proveniente do resultado de reconhecimento de alguma das modalidades, o Multimodal Integrator recebe o objeto e inicia o processamento. Essa classe implementa o padrão Singleton, de forma que em um dado momento, apenas uma instância existe em memória.

Internamente, a Multimodalintegrator implementa um conjunto de árvores de regras, definidas pelo programador ou usuário. Conforme os eventos vão sendo recebidos, as árvores de regras são percorridas e testadas, utilizando como critério os atributos e a categoria. Quando uma regra é satisfeita, o objeto Interaction nela contido é disparado para os níveis superiores. Utilizando o mecanismo de backtracking, essa interação é testada até o nível mais alto: se a regra raiz é satisfeita, significa que todas as sub-composições necessárias de sub-regras também foram e a unificação foi bem-sucedida. Caso contrário, o objeto Interaction é armazenado na regra e permanece aguardando por outra interação, que pode unificar-se a ele ou descartá-lo.

Portanto, assim que um resultado de unificação é gerado, o mesmo é encapsulado num objeto MultimodalResult e enviado para todos os listeners da interface MultimodalResultListener. Entre eles o Multimodalcomponent, que irá então fazer o binding com o código da aplicação cliente. Esse componente possui ainda uma classe para gerenciamento de regras multimodais, a IntegrationRuleManager, que permite a adicionar ou remover regras do integrador em tempo de execução, além de carregar ou salvar as regras definidas em um arquivo no formato XML. A Figura 5.5 apresenta o diagrama UML para o Integrador Multimodal (algumas classes já apresentadas anteriormente são relacionadas novamente, para a facilitar a compreensão).

\subsection{Estrutura de Pacotes}

A estrutura do JMIS Framework foi dividida em pacotes. Além de ser uma prática comum em aplicações desenvolvidas sob a plataforma Java, essa organização possibilita correlacionar classes e interfaces, facilitando a compreensão do framework. Uma breve explicação sobre os pacotes e suas funções é apresentada na Tabela 5.1 ; 


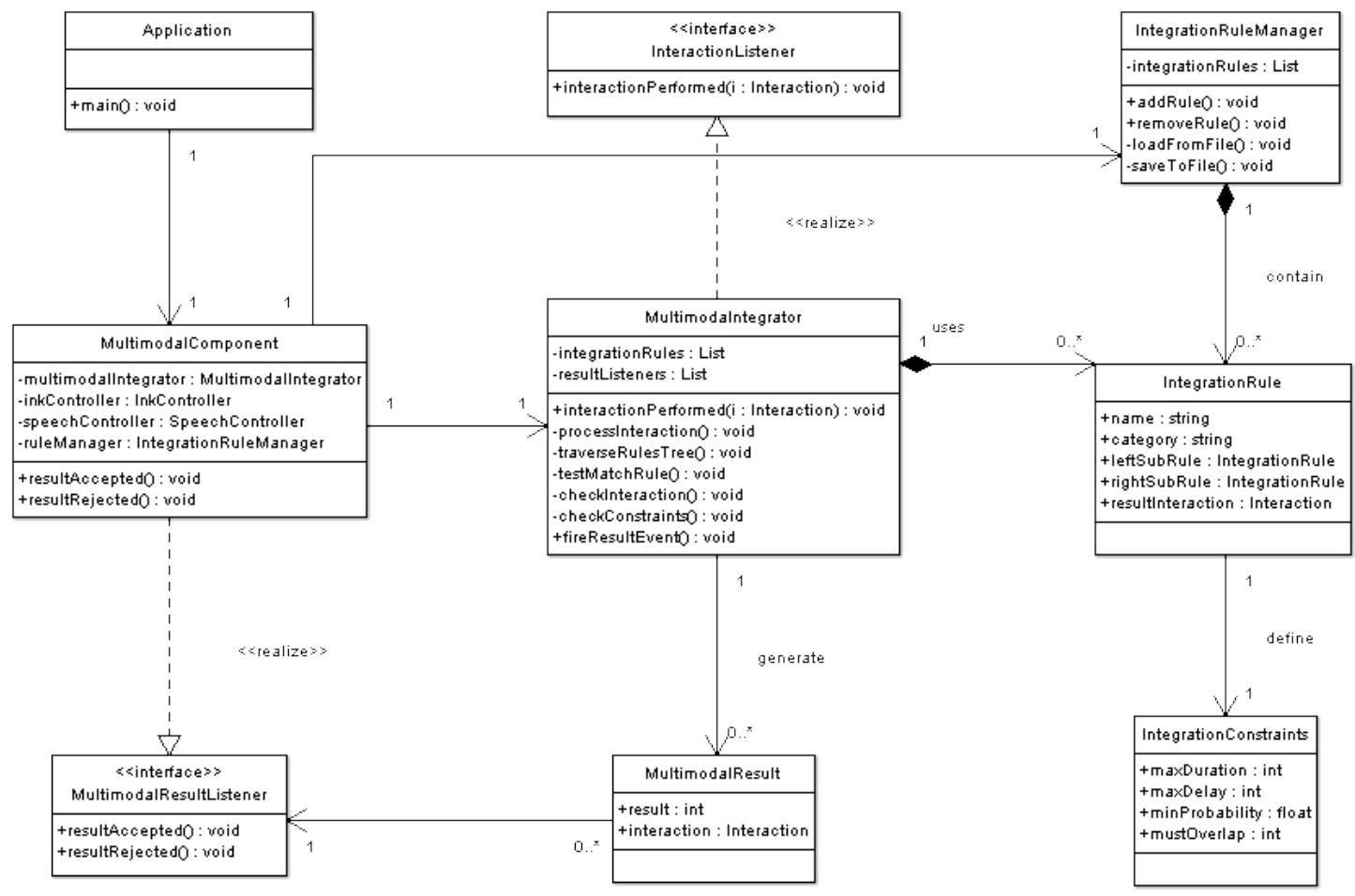

Figura 5.5: Diagrama de classes para o módulo relacionado ao Integrador Multimodal, considerado o núcleo do sistema.

\subsection{Configuração}

Para facilitar a configuração do JMIS Framework foi implementada uma interface gráfica, como ilustrado pela Figura 5.6. Essa ferramenta possibilita a adição/remoção de regras que serão utilizadas pelo integrador multimodal. As regras são definidas em hierarquias, tal como no algoritmo implementado, podendo ser compostas e reorganizadas. A interface também permite a definição de restrições, disponibilizando todas as opções para o usuário de uma maneira bastante intuitiva. Além disso, o conjunto de regras pode ser importado e exportado em arquivos XML, de modo que múltiplas aplicações/usuários possam personalizar a aplicação.

\subsection{Avaliação: Aplicações Construídas}

Nesta seção são apresentadas algumas das aplicações construídas utilizando a infraestrutura multimodal desenvolvida. 


\begin{tabular}{|l|l|}
\hline Pacote & Função \\
\hline \hline br.usp.icmc.jmis.core & $\begin{array}{l}\text { Define as principais classes do framework, } \\
\text { correspondentes ao núcleo de processa- } \\
\text { mento multimodal. }\end{array}$ \\
\hline br.usp.icmc.jmis.core.event & $\begin{array}{l}\text { Contém as classes e interfaces responsáveis } \\
\text { pelo suporte ao tratamento de eventos do } \\
\text { JMIS Framework. }\end{array}$ \\
\hline br.usp.icmc.jmis.core.util & $\begin{array}{l}\text { Disponibiliza classes utilitárias para mani- } \\
\text { pulação de arquivos e propriedades, de uso } \\
\text { interno do framework. }\end{array}$ \\
\hline br.usp.icmc.jmis.ink & $\begin{array}{l}\text { Engloba as classes de integração com a JInk } \\
\text { API, usadas no controle do reconhecedor e } \\
\text { na representação de conteúdo de escrita. }\end{array}$ \\
\hline br.usp.icmc.jmis.ink.event & $\begin{array}{l}\text { Contém as classes utilizadas para manipula- } \\
\text { ção de eventos de escrita e sua conversão em } \\
\text { interpretação multimodal. }\end{array}$ \\
\hline br.usp.icmc.jmis.speech & $\begin{array}{l}\text { Engloba as classes de integração com a JS- } \\
\text { API, usadas no controle do reconhecedor, } \\
\text { sintetizador e gerenciador de gramáticas. }\end{array}$ \\
\hline br.usp.icmc.jmis.speech.event & $\begin{array}{l}\text { Contém as classes utilizadas para manipu- } \\
\text { lação de eventos de voz e sua conversão em } \\
\text { interpretação multimodal. }\end{array}$ \\
\hline br.usp.icmc.jmis.gui & $\begin{array}{l}\text { Disponibiliza um conjunto de ferramentas } \\
\text { gráficas usadas para facilitar a configuração } \\
\text { e integração do JMIS a outras aplicações. }\end{array}$ \\
\hline br.usp.icmc.jmis.gui.conf & $\begin{array}{l}\text { Contém classes utilitárias usadas para inter- } \\
\text { nacionalização da interface de configuração e } \\
\text { localização de recursos. }\end{array}$ \\
\hline
\end{tabular}

Tabela 5.1: Resumo dos pacotes e suas respectivas funções no JMIS Framework.

\subsubsection{SpeechBoard}

A SpeechBoard é uma aplicação protótipo que estende um componente de software desenvolvido para captura de apresentações e anotações colaborativas em ambientes de computação ubíqua, utilizado na arquitetura do iClass Cattelan et al., 2003|. O objetivo dessa implementação foi integrar elementos de interação baseados em interfaces multimodais, tornando a operação do dispositivo de captura mais "user-friendly".

A SpeechBoard 5.7 incorpora uma interface baseada em escrita manual juntamente com uma interface de voz. Os resultados obtidos com a implementação da SpeechBoard possibilitam aos usuários do sistema controlar e interagir com a aplicação por meio de comandos de voz e gestos, além de poder realizar anotações baseadas em discurso oral ou por meio do reconhecimento de escrita. 


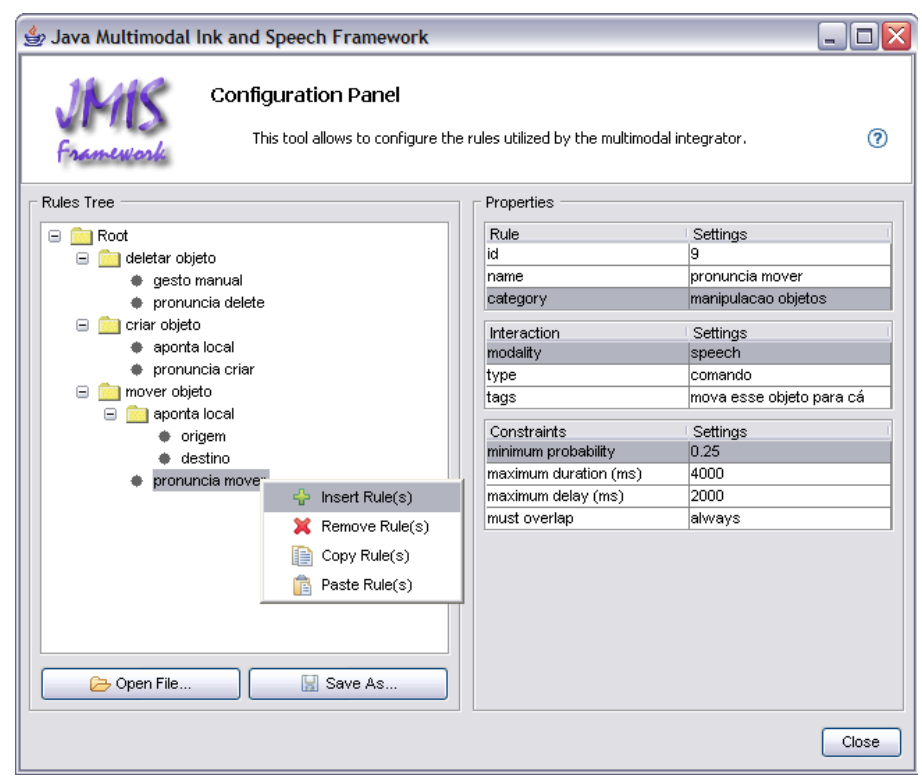

Figura 5.6: Interface de configuração do JMIS Framework: geração do conjunto de regras e definição de propriedades.

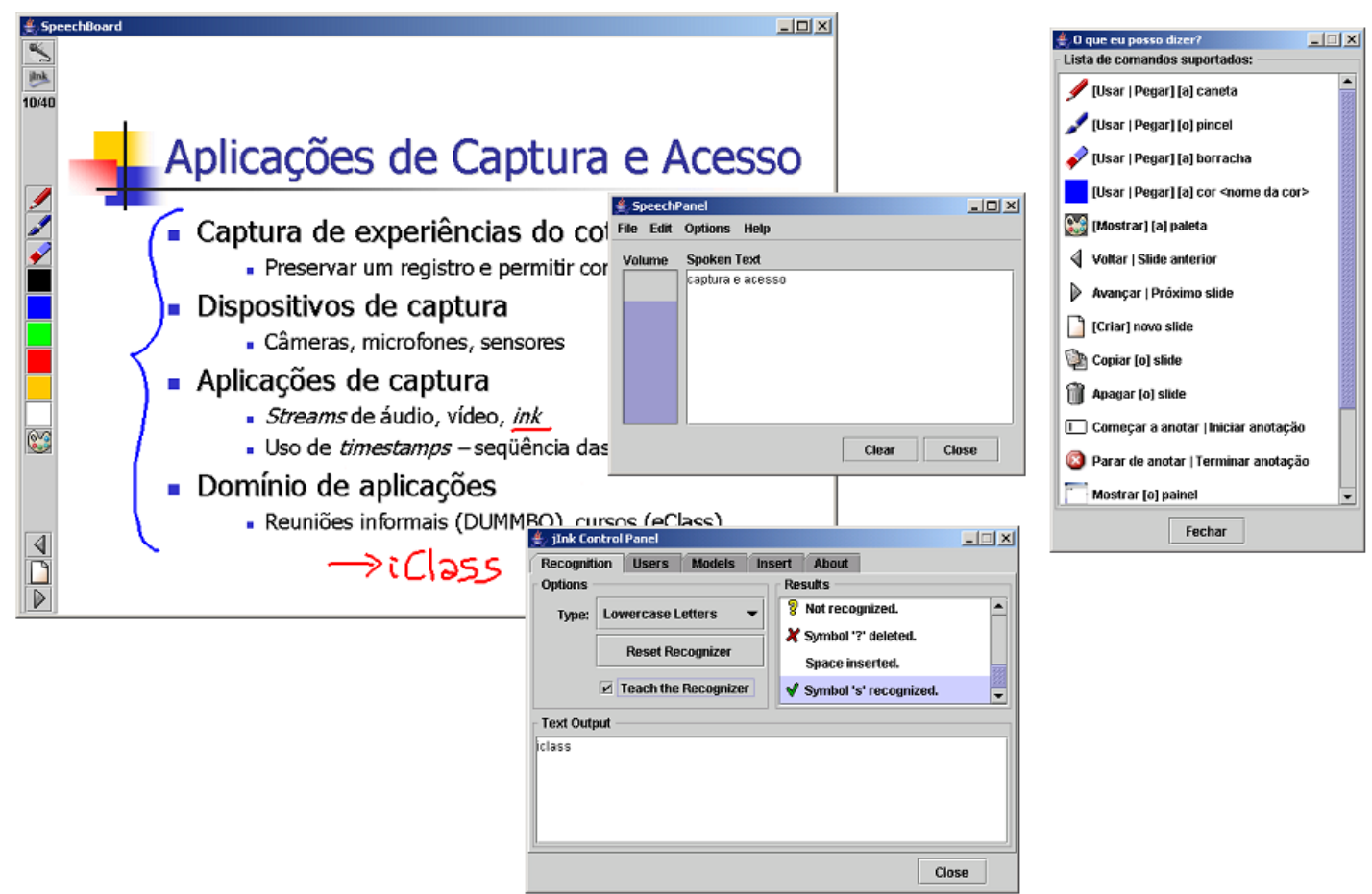

Figura 5.7: Interfaces da SpeechBoard e dos módulos de reconhecimento de voz e escrita.

O uso de interfaces multimodais em aplicações de captura que envolvem apresentações, aulas e reuniões pode se tornar uma importante ferramenta, já que várias características dessas aplicações podem ser exploradas por interfaces multimodais. 
Por exemplo, temos nesses ambientes grandes displays compartilhados onde, além do uso indispensável da voz, o apresentador pode gesticular e apontar para pontos na tela, além de fazer anotações e desenhos sobre o conteúdo.

\subsubsection{M4Note}

A SpeechBoard foi usada na construção de uma aplicação |Macedo et al., 2004| que realiza o relacionamento semântico entre a informação que está sendo apresentada e o conteúdo capturado de outras sessões, permitindo assim a criação de ligações entre os documentos.

A ferramenta M4Note (MultiMedia MultiModal Annotation Tool) Goularte et al., 2004 é uma aplicação multimodal que executa em Tablet PCs e permite a captura de vídeo, a criação de anotações e a geração de documentos XML a partir do conteúdo multimídia capturado. Pode-se interagir com o fluxo de vídeo durante a atividade de captura, selecionando-se quadros específicos para serem anotados. As anotações podem ser realizadas com tinta eletrônica em uma área de edição pré-determinada ou por meio de reconhecimento de voz, sendo, em ambos os casos, convertidas para texto.

Os quadros de vídeo anotados são transformados em imagens JPEG e, a exemplo do vídeo capturado, armazenados em disco. Ao final do processo de uso da ferramenta, são gerados documentos XML agregando todos os fluxos de mídia capturados (vídeo, áudio, imagens, slides, strokes e texto). A interface gráfica da ferramenta é apresentada na Figura 5.8.

\subsection{Considerações Finais}

Esta seção teve por objetivo apresentar os detalhes da infraestrutura multimodal construída, descrevendo as técnicas utilizadas, a especificação dos requisitos, modelagem e implementação. Ao final do capítulo foram apresentados alguns exemplos de aplicações desenvolvidas utilizando o JMIS Framework. 


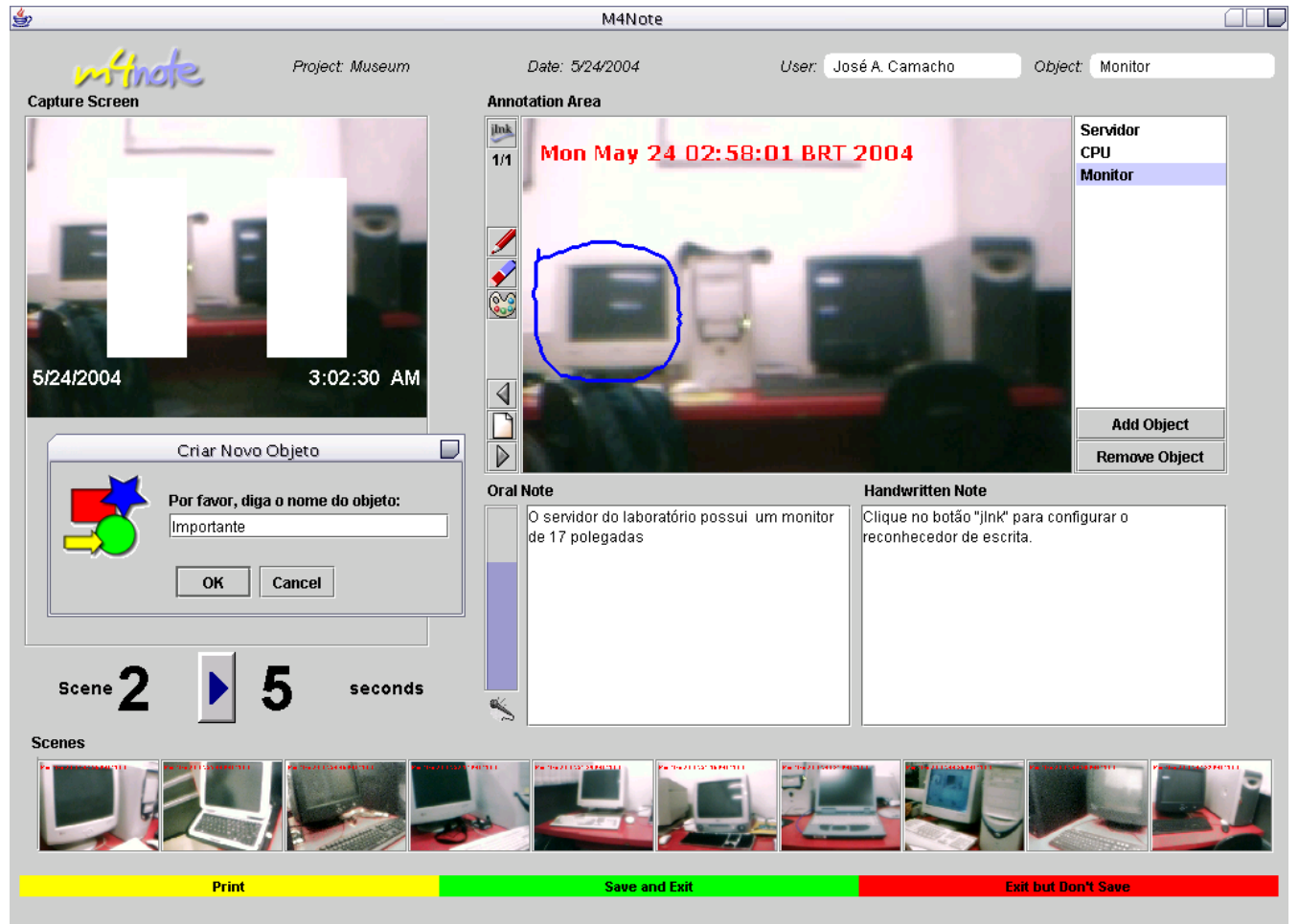

Figura 5.8: Interface da ferramenta M4Note: no canto superior esquerdo, o painel para visualização do vídeo; no canto superior direito, a área de edição dos quadros selecionados com tinta eletrônica; na parte inferior, linha do tempo com thumbnails das anotações. 


\section{- \\ Trabalhos Relacionados}

\subsection{Considerações Iniciais}

No passado, interagir com um computador significava sentar em frente a um desktop e utilizar teclado e mouse para fazê-lo executar tarefas. Hoje, com a disponibilidade de equipamentos móveis de alta capacidade e conectividade sem fio, essas tarefas estão migrando para outros dispositivos e exigindo novos requisitos de interação. É possível ler e-mails, acessar a Internet ou fazer compras on-line dentro de um carro em movimento, utilizando um smartphone ou mesmo um celular.

Novas modalidades de interação estão se tornando essenciais para suportar os estilos atuais de interação e proporcionar experiências mais ricas para o usuário. É nesse ponto que as interfaces multimodais tem se sobressaído. Elas possibilitam um aumento na eficiência com que a informação pode ser obtida/gerada, além de permitir entradas paralelas da maneira que o usuário considerar mais conveniente. A usabilidade e a acessibilidade aprimorada dos sistemas multimodais torna-os passíveis de acomodar um grande número de tarefas nos mais diversos ambientes.

Este capítulo tem por objetivo apresentar uma visão geral sobre alguns dos trabalhos mais relevantes e o estado da arte na área de Interfaces Multimodais, ilustrando a variabilidade de sistemas onde essas interfaces são bem acolhidas. São ainda detalhadas algumas das principais tecnologias e linguagens que estão atualmente em discussão pela indústria, visando o estabelecimento de padrões para a construção de aplicações multimodais. 


\subsection{Aplicações Multimodais}

A quantidade de aplicações que fazem uso de interfaces multimodais tem crescido rapidamente, abrangendo desde sistemas baseados em realidade virtual utilizados para simulação e treinamento [Duncan et al., 1999] até aplicações médicas |Holzman, 1999] e sistemas de identificação [Jain and Ross, 2004]. No sentido de demonstrar essa diversidade são apresentados nesta seção alguns exemplos de aplicações nos quais a interação multimodal é utilizada.

\subsubsection{Put-That-There}

Uma das primeiras demonstrações do conceito de interfaces multimodais foi construída no início da década de 80 , com o então chamado Put-That-There Bolt, 1980|. Esse sistema possuía uma interface que utilizava processamento de voz em paralelo a um mecanismo de apontamento, que permitia aos usuários referenciar e mover objetos $2 \mathrm{D}$ em uma tela de projeção. Por exemplo, o usuário podia dar um comando para "criar um quadrado azul lá", com a localização "lá" indicada por um cursor 2D na tela, controlado por meio de um touchpad. O processamento semântico era baseado na fala do usuário, e o significado da referência "lá" era resolvido através das coordenadas indicadas pelo cursor no momento da fala. A Figura 6.1 ilustra como o sistema era utilizado.

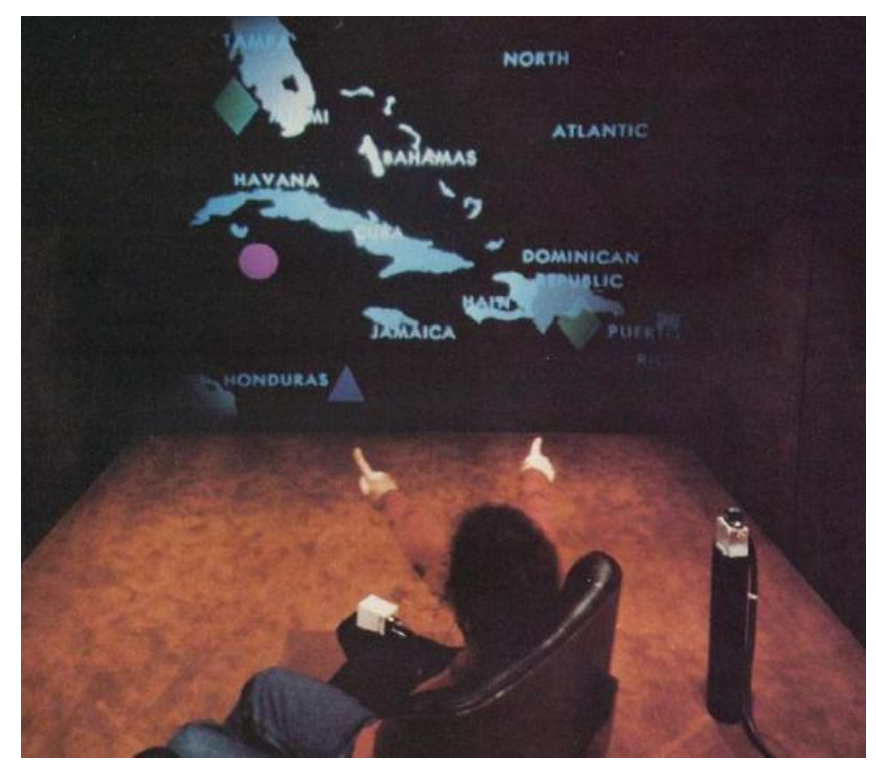

Figura 6.1: Put-That-There [Bolt, 1980], um dos primeiros sistemas multimodais. 


\subsubsection{QuickSet}

As interfaces multimodais mais recentes deixaram de utilizar apenas a entrada do mouse e são capazes de processar vários fluxos paralelos de informação semântica. O GuickSet [Cohen et al., 1997], por exemplo, é um sistema multimodal que funciona em tablets. Ele possui um conjunto de agentes de software em sua infraestrutura que processam linguagem natural e reconhecem gestos baseados em caneta, localmente ou de modo distribuído.

Com o QuickSet, o usuário pode interagir com um mapa apresentado no computador e controlar sistemas que executam externamente, incluindo sistemas de visualização 3D. Utilizando dispositivos como joysticks, o usuário pode interagir com esses ambientes virtuais, selecionando, alterando modos de visão e desenhando com tinta digital. Na Figura 6.2 são apresentados exemplos de interação com o QuickSet.
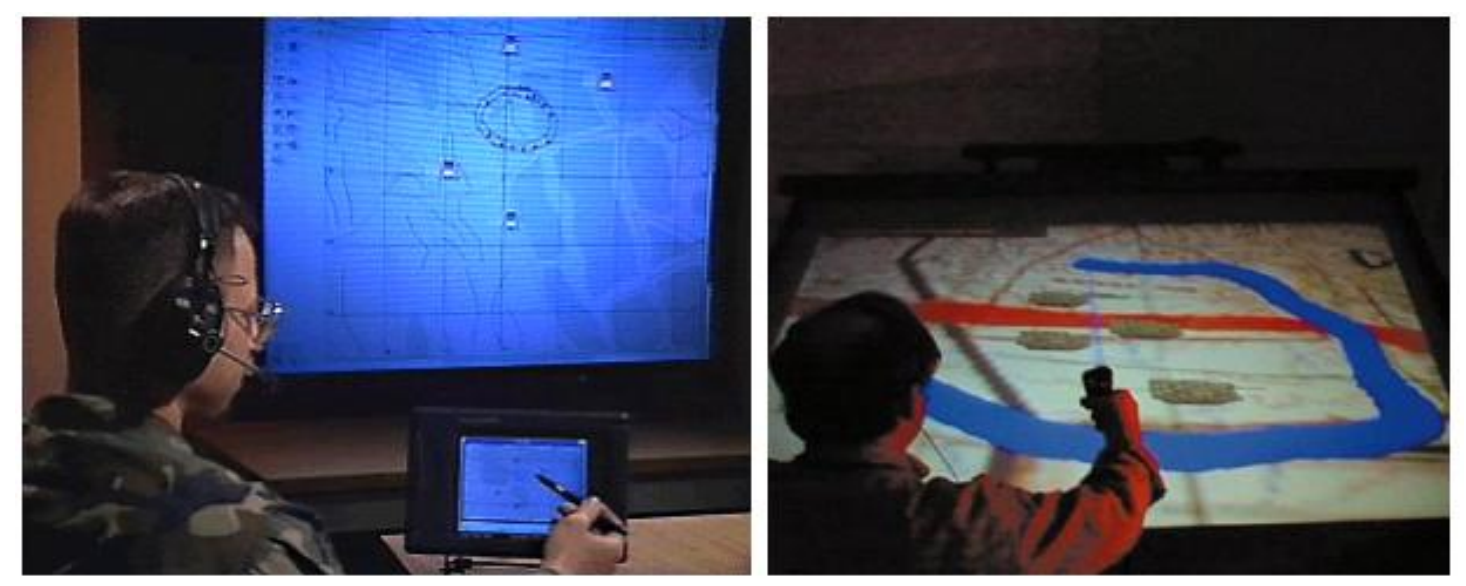

Figura 6.2: QuickSet |Cohen et al., 1997|: Interação multimodal em diversos ambientes.

\subsubsection{Field Medic Information System}

Outro sistema baseado em interação com caneta e reconhecimento de voz é o Field Medic Information System, desenvolvido pela NCR em colaboração com o Trauma Care Information Management System Consortium |Holzman, 1999|. O sistema permite que a equipe médica (por exemplo, de uma ambulância) registre os cuidados a serem tomados com um paciente, como informações sobre ferimentos, avaliação do quadro clínico, tratamentos, perfil do paciente e prioridade de socorro. Esta informação é repassada automaticamente para o hospital, de modo que este possa se preparar para receber o paciente. O sistema é composto por dois componentes principais de hardware, o Field Medic Associate (FMA) e o Field Medic Coordinator (FMC). 
O FMA é um computador flexível, em forma de colete, que usa um conjunto de fones de ouvido e microfone para entrada de voz (Figura 6.3). Conforme o médico fala ao microfone, o FMA reconhece os dados de entrada associados com os campos específicos e preenche o registro do paciente. O médico pode também consultar esse registro perguntando, por exemplo, qual o estado clínico do paciente.

Já o FMC é um sistema para ser utilizado em tablets. Ele permite ao médico alterar o registro através da voz ou de uma interface baseada em caneta. O médico pode também criar anotações desenhadas à mão livre ou por meio de áudio, ou usar os dois simultaneamente. Neste caso, ele simplesmente assinala com a caneta campos ou partes do corpo humano (Figura 6.3), enquanto descreve os problemas com o paciente. As informações armazenadas podem ser obtidas quando o médico toca com a caneta os pontos marcados.
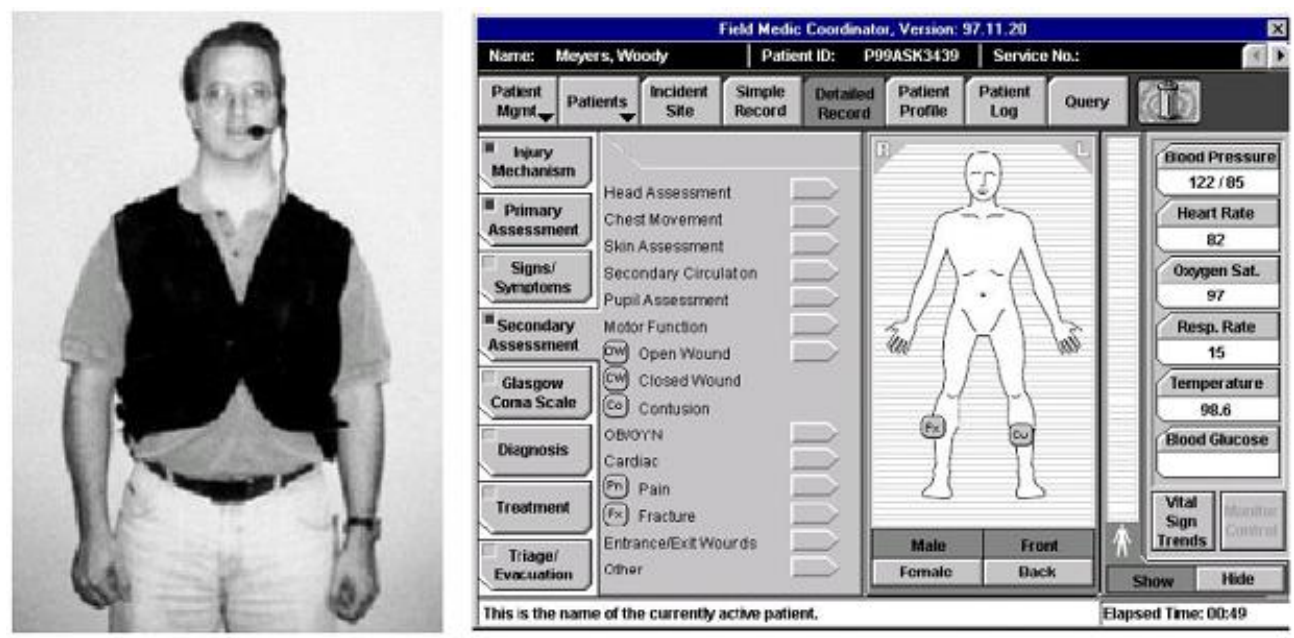

Figura 6.3: Interfaces multimodais do FMA e do FMC |Holzman, 1999|.

\subsubsection{Ford Model U Concept Car}

Desenvolvido pela Ford e SpeechWorks, o carro-conceito Ford Model U integra ao sistema de controle do interior do veículo uma interface multimodal baseada em fala e tela sensivel a toque [Pieraccini et al., 2004|. Por meio dessa interface os ocupantes do carro podem controlar funções como temperatura do ar-condicionado, telefone, navegação, tocador de MP3 e personalização.

Uma diferença da interface por voz do Ford Model U é que, diferentemente das interfaces baseadas em comandos com uma única pronúncia, onde o usuário é obrigado a decorá-los a partir de um manual de referência, esse sistema utiliza um modo mais flexível de interação baseado em um gerenciador de diálogo. Desse modo, o 
usuário apenas inicia a conversa e o sistema se encarrega de requisitar as informações necessárias para completar a tarefa. Isso faz com que o usuário memorize os comandos mais naturalmente.

A interface gráfica do sistema, visualizada através de uma tela sensível ao toque, fornece um modo alternativo e ao mesmo tempo complementar de interação, permitindo, por exemplo, que os usuários a utilizem quando o carro está parado ou fornecendo dicas de comandos de voz correspondentes. Além disso, a arquitetura do gerenciador de diálogo faz uma separação entre a lógica de interação e as fontes dos sinais de entrada, permitindo que o usuário inicie um diálogo por voz e o finalize através da interface gráfica. A Figura 6.4 apresenta uma imagem do interior do veículo e uma das configurações de tela.

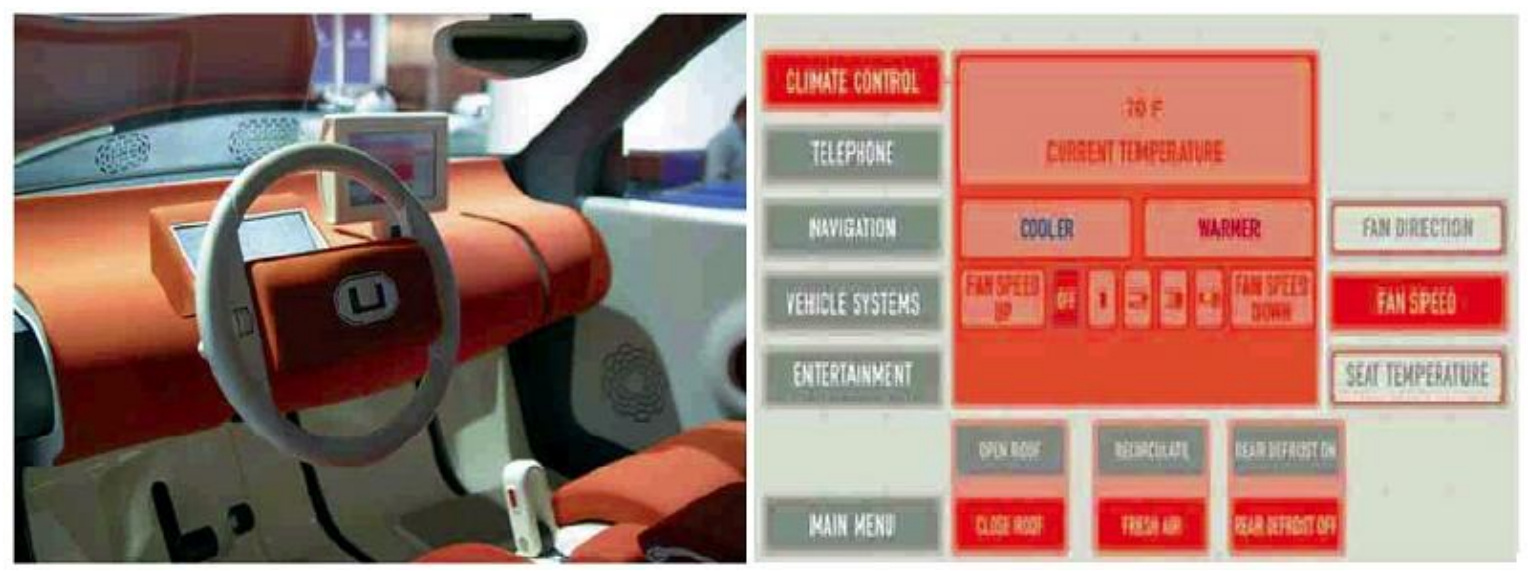

Figura 6.4: Carro-conceito Ford Model U: interior do veículo e interface gráfica com tela sensivel ao toque [Pieraccini et al., 2004].

\subsubsection{Multi-Touch Interaction Wall}

O Multi-Touch Interaction Wall |Han, 2005| consiste de uma tela de projeção com uma superfície capaz de detectar múltiplos pontos de contato simultaneamente. Ele permite que vários usuários interajam utilizando as mãos, realizando gestos e movendo objetos com simples toques dos dedos, o que proporciona um grande aumento na usabilidade e intuitividade do sistema.

A implementação da tela sensivel ao toque do Multi-Touch utiliza uma técnica denominada Frustrated Total Internal Reflection (FTIR), a qual se baseia na reflexão de luz infra-vermelha dentro de uma superfície plana. Quando um material toca a superfície, este causa um desvio na direção do feixe de luz, indicando a posição do contato. O sistema então processa as coordenadas e as envia a aplicação, que as manipula de maneira independente. 
Foram desenvolvidas uma série de aplicações para demonstrar as possibilidades de uso do Multi-Touch, como ilustrado na Figura 6.5. Em uma dessas aplicações, o usuário pode mover e organizar fotos utilizando as duas mãos, aplicar efeitos de zoom e rotacionar imagens com movimentos naturais e intuitivos. Em outra demonstração, um ambiente desktop é simulado, com um teclado sendo plotado na tela e o usuário movimentando objetos e janelas. Uma terceira aplicação permite a exploração geoespacial de ambientes: o usuário navega por um ambiente $3 \mathrm{D}$, podendo exibir mapas e correlacionar diferentes visualizações de um mesmo local. Em uma demonstração de mecânica de fluidos, usuários podem interagir com fumaça e lava, manipulando-os diretamente e gerando um efeito visual bastante impressionante. Por fim, uma aplicação de jogo é apresentada, demonstrando a capacidade do sistema em acomodar múltiplos usuários de maneira competitiva ou colaborativa.
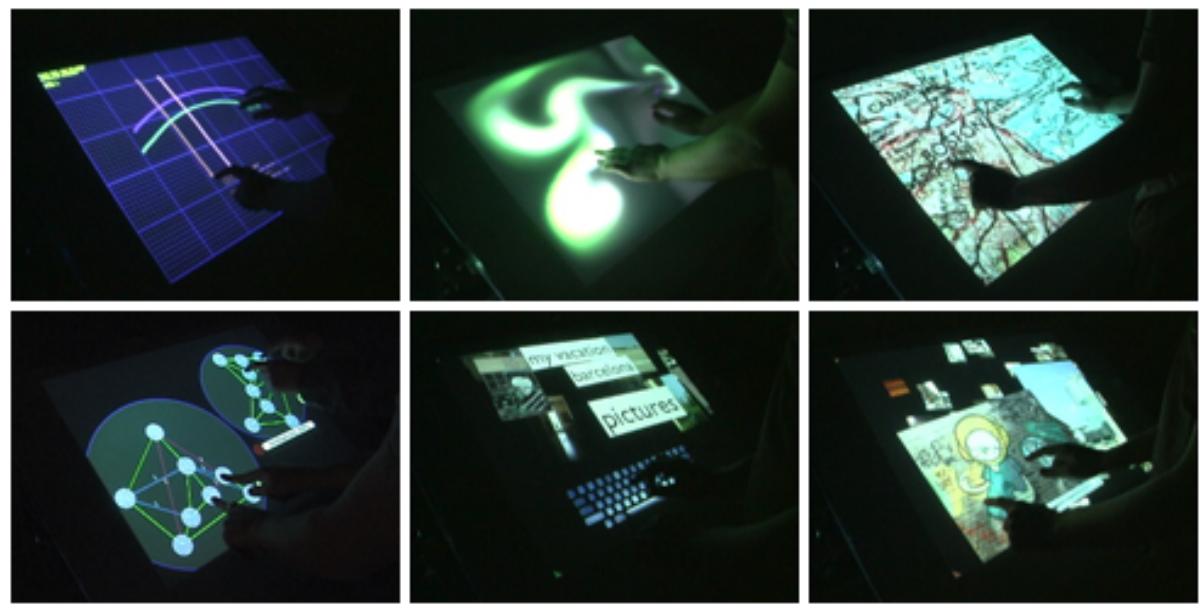

Figura 6.5: Exemplos de aplicações construídas utilizando a tecnologia do Multi-Touch [Han, 2005].

\subsection{Linguagens e Padrões Multimodais}

A até pouco tempo, a maioria dos sistemas multimodais era implementada utilizando linguagens de programação tradicionais, estruturadas ou orientadas a objetos, como C, C++ e Java. Programadores usavam essas linguagens para controlar o fluxo das aplicações e invocar componentes de baixo-nível, como reconhecedores, sintetizadores de voz e tocadores de áudio. Embora poderosas, a utilização dessas linguagens em ambientes distribuídos como a Web era uma tarefa complicada, devido a variabilidade de tecnologias e padrões suportados em cada cliente. Essa dificuldade de integração limitava a portabilidade dos sistemas multimodais, restringindo-os ao ambiente desktop e ao modelo de aplicações stand-alone. 
No sentido de superar essas limitações, o W3C e outros consórcios da indústria têm trabalhado no desenvolvimento de linguagens e especificações para as diferentes funções de sistemas multimodais, de modo a oferecer uma infra-estrutura básica de alto-nível para a construção desses sistemas. Essas linguagens incluem mecanismos de controle do fluxo de interação, gerenciamento de entrada/saída, interfaces com infra-estruturas de baixo-nivel e padrões que permitem a interoperabilidade dos componentes multimodais. Algumas dessas linguagens são discutidas nesta seção.

\subsubsection{W3C MMIF - Multimodal Interaction Framework}

O W3C Multimodal Interaction Framework (MMIF) |W3C, 2002a $\mid$ é uma especificação que descreve como o suporte a interação multimodal pode ser implementado no ambiente Web a partir de padrões definidos pelo W3C. Ele pode ser visto como uma base para o desenvolvimento de aplicações multimodais em termos de linguagens de marcação, scripts, guidelines e outros recursos. O framework é implementado utilizando o padrão DOM (Document Object Model), o qual é responsável por especificar interfaces que permitem aos programas acessar e atualizar dinamicamente o conteúdo, a estrutura e o estilo de documentos.

A proposta do MMIF é identificar e relacionar os principais componentes de um sistema multimodal, determinando quais linguagens podem ser utilizadas para descrever e manipular a informação proveniente de cada componente. O objetivo é propor uma abstração de uma arquitetura que suporte as várias modalidades de entrada/saída disponíveis atualmente e que possa ser estendida para incluir modalidades que venham a surgir no futuro.

O MMIF pode ser dividido em três módulos principais: componentes de entrada, gerenciador de interação e componentes de saída. A Figura 6.6 ilustra de maneira simplificada os componentes do framework e o fluxo de informação entre eles.

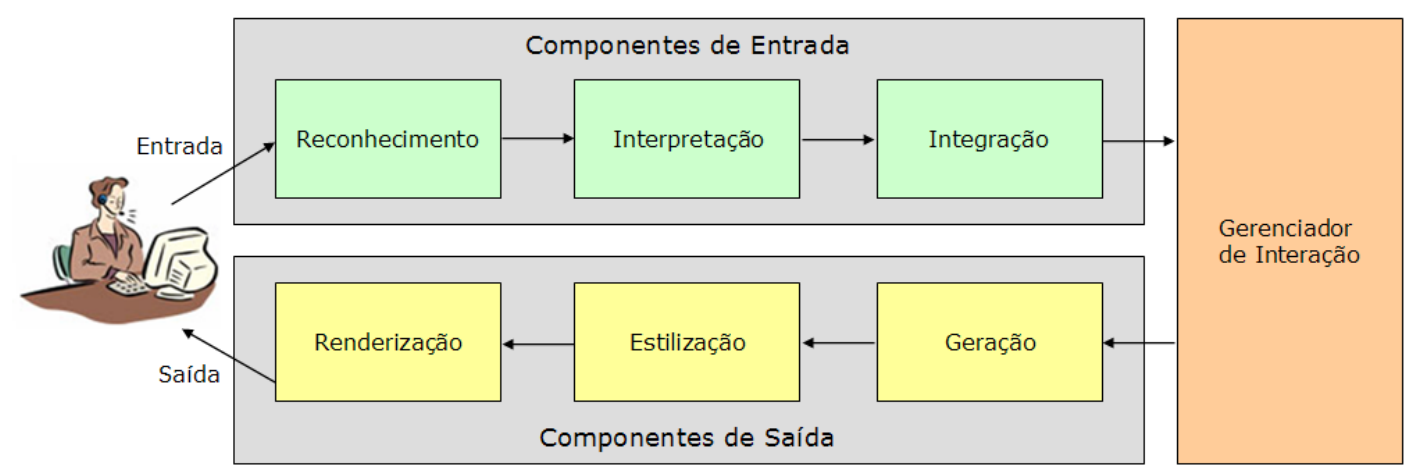

Figura 6.6: Fluxo de informação entre os componentes do W3C Multimodal Interaction Framework |W3C, 2002a $\mid$. 


\section{Componentes de Entrada}

Os componentes de entrada correspondem ao módulo do sistema responsável por capturar, processar e interpretar os diversos modos de interação do usuário. Esses componentes são divididos em três categorias [W3C, 2002a]:

Componentes de Reconhecimento: Capturam os diversos modos de interação do usuário e traduzem as entradas em um formato padrão para serem processadas posteriormente. O reconhecimento pode utilizar gramáticas descritas por linguagens de marcação, de modo a restringir o escopo de entradas permitidas e aumentar a precisão do sistema. Alguns exemplos de componentes de reconhecimento incluem voz, escrita, gestos, visão, etc.

Componentes de Interpretação: Processam os resultados dos componentes de reconhecimento, atribuindo-lhes semântica. Cada componente de interpretação identifica o significado da entrada do usuário, como por exemplo, diferentes formas de se pronunciar um mesmo comando ou várias representações de um único gesto, podem ser resolvidas por esse componente. A saída resultante de cada componente de interpretação pode ser expressa utilizando a linguagem EMMA (detalhada na Seção 6.3.6.

Componente de Integração: Combina as saídas de múltiplos componentes de integração. Um exemplo seria a integração de entradas de voz e gestos, em que o usuário aponta para um objeto e o movimenta através de comandos de voz. O componente detecta a intenção do usuário a partir da fusão das duas modalidades e gera um resultado final de acordo com regras de integração previamente definidas.

\section{Gerenciador de Interação}

O gerenciador de interação é o componente lógico que controla o fluxo de dados e coordena a execução dos múltiplos componentes de entrada e saída. O gerenciador é responsável por manter o estado e o contexto da aplicação, de modo a responder aos eventos de entrada e gerar as saídas apropriadas |W3C, 2002a|.

Um componente de sessão é utilizado pelo gerenciador para armazenar informações sobre estado, o que pode ser útil em aplicações baseadas em sessões (tais como jogos multiplayer, reuniões e ferramentas colaborativas) ou quando uma aplicação provê múltiplos modos de interação que podem ser escolhidos em tempo de execução pelo usuário. Já o contexto é controlado por um componente de sistema e 
ambiente, o qual fornece informações sobre capacidades dos dispositivos, preferências do usuário e condições do ambiente.

Em algumas arquiteturas o gerenciador de interação pode ser implementado como um único componente. Em outras, ele pode ser tratado como uma composição de componentes menores, ou ainda estar distribuído entre os componentes de entrada e saída.

\section{Componentes de Saída}

Os componentes de saída são utilizados para gerar um ou mais modos de saída para o usuário, tais como voz sintetizada, áudio, texto, gráficos e animações. Esses componentes são divididos em três categorias [W3C, 2002a]:

Componente de Geração: Determina quais modalidades de saída serão utilizadas para retornar informação para o usuário, podendo selecionar uma única modalidade de saída ou modalidades complementares. A linguagem de representação interna usada para descrever a saída do componente de geração ainda está em fase de especificação.

Componentes de Estilização: Adiciona informação sobre como a saída será apresentada ao usuário. Por exemplo, um componente de estilização para displays gráficos pode especificar como os objetos serão posicionados na tela, enquanto que um componente para voz pode inserir pausas e variações no texto que será renderizado por um sintetizador. A saída dos componentes de estilização pode ser representada em linguagens específicas para cada componente de renderização, como por exemplo, SSML para componentes de síntese de voz, tags XHTML e SVG para componentes gráficos e SMIL para saídas multimídia.

Componentes de Renderização: Converte a informação proveniente do componente de estilização em um formato facilmente entendido pelo usuário. Por exemplo, um componente renderização visual pode mostrar um vetor de pontos como um gráfico, ou um sintetizador de voz converter texto em voz.

\subsubsection{InkML - Ink Markup Language}

A Ink Markup Language (InkML) |W3C, 2003b| é uma linguagem de representação de dados baseada na Extensible Markup Language (XML) [W3C, 1996] que permite descrever entradas de tinta digital provenientes de interação com caneta eletrônica. A InkML é parte da especificação definida pelo W3C para a construção de aplicações 
multimodais, a W3C Multimodal Interaction Framework W3C, 2002a (delhada na Seção 6.3.1, e o objetivo dessa linguagem é prover um formato comum para:

- Facilitar a entrada e o processamento de escrita manual, gestos, rascunhos e outras formas de anotação;

- Armazenar traços de escrita manual para reconhecimento de escrita (incluindo símbolos matemáticos e de outras áreas), assinaturas e gestos;

- Possibilitar a transferência de dados de tinta digital entre dispositivos e softwares.

\section{Visão Geral}

A popularização dos dispositivos eletrônicos com entrada baseada em caneta vem tornando cada vez mais necessário o desenvolvimento e a adaptação de aplicações que explorem esse modo de interação. Uma interface baseada em caneta é composta principalmente por uma tela ou outro tipo de superfície sensível que captura as coordenadas e os movimentos da caneta e os converte em tinta digital. Essa tinta pode ser repassada para um software de reconhecimento que permite ao computador interpretá-la e executar as ações apropriadas, ou simplesmente ser manipulada como um objeto componente de um documento, incluindo texto em diferentes linguagens, desenhos e equações, tal como ela foi inserida pelo usuário.

Atualmente, a indústria de hardware e software trata dados de tinta digital utilizando formatos proprietários, que são normalmente restritos. Há uma necessidade de um formato comum público, que permita a captura, transmissão, processamento e a apresentação desse tipo de dado, tornando-o portável para diferentes dispositivos, aplicações e vendedores. Na tentativa de superar essas limitações foi proposta a InkML, que suporta de modo independente de plataforma uma representação completa de dados de tinta digital. Um exemplo é que, ao invés de permitir apenas a captura da posição da caneta no tempo, ela detalha outras características da interação com o dispositivo, tais como a inclinação da caneta, ou a pressão exercida pelo usuário. Tais informações são fundamentais para um reconhecimento de escrita mais preciso.

\section{Usos da InkML}

O W3C presume que com o estabelecimento de um padrão não-proprietário para a representação de dados de tinta digital um grande número de aplicações irá surgir, explorando as capacidades e conveniências da interação baseada em caneta. Dentre essas, pode-se citar [W3C, 2003b]: 
Mensagens em tinta digital: Transmissão bi-direcional de tinta digital, principalmente através de redes sem fio, possibilitando que usuários móveis escrevam e/ou desenhem nas telas de seus dispositivos e enviem essas informações. O receptor pode ser outro usuário em seu computador desktop, tablet, palmtop, telefone celular ou mesmo uma máquina de fax.

Integração com outras mídias: Uma foto tirada com uma câmera digital ou um desenho criado em um tablet PC, por exemplo, podem ser anotados de tal forma que a tinta digital possa ser sincronizada com um comentário falado. A anotação de tinta poderia ser usada para indexar a imagem, por exemplo associando uma marca específica para distinguir diferentes categorias.

Gravação e recuperação de anotações: Uma aplicação pode, por exemplo, permitir que usuários gravem anotações escritas manualmente com tinta digital e depois as recuperem utilizando palavras-chave associadas à anotação. Essas palavraschave seriam, basicamente, partes do texto transcrito por um reconhecedor de escrita.

Preenchimento eletrônico de formulários: Essa atividade pode ser amplamente facilitada, provendo uma maneira natural e robusta para a entrada de dados em dispositivos sem teclado. Sistemas de reconhecimento de escrita manual poderão inclusive serem disponibilizados na rede na forma de Web Services. Um exemplo de aplicação seria no processamento de transações financeiras, onde um usuário paga a compra de um livro pela Web por meio de sua assinatura, que é reconhecida por um software verificador de assinaturas.

Entrada por caneta em sistemas multimodais: Interfaces multimodais podem integrar de maneira robusta e flexível entradas provenientes de interação com caneta e outras modalidades, como a fala. A robustez provém da redundância entre as modalidades, que possibilita que erros ou imprecisões de reconhecedores individuais sejam compensados. Já a flexibilidade vêm do fato que os usuários podem escolher qual modalidade é mais apropriada para executar uma determinada tarefa, em um dado momento. Por exemplo, em ambientes onde há muito ruído ou há a necessidade de privacidade, a modalidade baseada em caneta é preferível.

\section{Elementos principais e Sintaxe da InkML}

A InkML ainda está em fase de definição, sendo que atualmente a linguagem especifica apenas um conjunto básico de elementos, suficiente para o desenvolvimento de aplicações simples que utilizam tinta digital |W3C, 2003b|. O elemento raiz de um 
documento InkML é dado pela marcação <ink>. Para descrever traços contíguos de tinta, o elemento é o <trace>, que armazena uma seqüência de pontos correspondentes às coordenadas $\mathrm{X}$ e $\mathrm{Y}$ da posição da caneta. Atributos tais como cor e espessura do traço são descritos pelo elemento $<$ brush $>$, e traços que possuem as mesmas características (por exemplo, escritos com a mesma cor) podem ser agrupados em um elemento <traceGroup $>$.

O elemento <captureDevice> é usado para armazenar informações sobre o dispositivo de captura, como por exemplo, a taxa de amostragem e a resolução. Para aplicações colaborativas, em que múltiplos usuários compartilham uma área de edição e a tinta digital pode vir de diferentes dispositivos, o elemento <context> permite representar informações pertinentes ao contexto de cada usuário. Já o elemento <traceRef> provê uma rotulagem semântica dos traços. Ele inclui um atributo genérico que pode ser usado por aplicações para descrever o tipo de traço representado (por exemplo, "escrita manual”, "desenho", etc.). Em todos os casos a especificação da InkML utiliza valores pré-definidos para elementos não especificados no documento.

Por ser uma linguagem derivada da XML, a InkML pode ser estendida, de modo que podem ser criados elementos específicos de aplicações para complementar a descrição fornecida pelos seus elementos básicos. Por exemplo, uma marcação do tipo <page> pode ser útil em uma aplicação que manipula documentos com múltiplas páginas. Ou então, em aplicações que processam formulários, um elemento $\langle$ field $\rangle$ pode ser útil para indicar um grupo de traços pertencentes a um campo particular. A combinação de elementos InkML com outros elementos XML deve evitar ambigüidades, de modo que é preciso utilizar qualificadores como namespaces.

As aplicações que utilizam interfaces com tinta digital podem ser categorizadas em dois tipos básicos: aquelas que capturam todo o conteúdo e o armazenam para posterior processamento, tal como aplicações de baseadas em formulários, nas quais os campos são preenchidos em tablets ou palmtops e depois processadas remotamente; e aquelas em que a captura e a transmissão de tinta digital ocorre em tempo real. A InkML oferece suporte para a manipulação de ambos tipos de aplicações, utilizando para isso um conjunto específico de marcações |W3C, 2003b|, que não serão tratadas neste documento.

\subsubsection{VoiceXML - Voice Extensible Markup Language}

O VoiceXML (Voice Extensible Markup Language) |W3C, 2000b| é um padrão ainda em definição pelo W3C que permite a criação e o controle de diálogos em aplicações distribuídas baseadas em interação por voz. Ele provê suporte a funcionali- 
dades como reconhecimento e síntese de voz, gravação e reprodução de áudio digital e identificação de tons telefônicos DTMF (Dual Tone Multy-Frequential).

O objetivo do VoiceXML é tornar o desenvolvimento de aplicações interativas baseadas em voz similar ao desenvolvimento para Web, facilitando a sua construção e a transmissão de conteúdo para diferentes dispositivos. Dentre as vantagens do VoiceXML, pode-se citar |W3C, 2000b|:

- Libera os desenvolvedores de detalhes de baixo-nível específicos de cada plataforma;

- Separa o código de interação com o usuário (arquivo VXML) da lógica da aplicação;

- Minimiza a interação cliente/servidor por meio da especificação de múltiplas interações por documento;

- Por se tratar de um padrão, garante portabilidade de serviço entre provedores de plataformas, ferramentas e conteúdo.

Atualmente, o VoiceXML tem sido bastante explorado na área de telefonia para a implementação de sistemas baseados em IVR (Interactive Voice Response). Esses sistemas são utilizados por call centers, serviços de help desk, bancos on-line e agências aéreas para a automatização de tarefas como: solicitar dados dos clientes, responder à perguntas simples, executar mensagens pré-gravadas ou provenientes de TTS, etc. Geralmente o sistema interage com o usuário através de DTMF, onde uma mensagem é tocada e a pessoa tecla o número correspondente à opção desejada.

\section{Arquitetura do VoiceXML}

O VoiceXML possibilita que serviços associados ao processamento e à recuperação de dados sejam disponibilizados a serviços de voz, utilizando para isso a tradicional arquitetura cliente-servidor. Nessa arquitetura, os clientes, que vão desde desktops com grande poder de processamento e memória (cliente pesado) à telefones celulares (cliente leve) com grandes limitações de recursos, têm acesso aos dados do sistema por meio de diferentes servidores, como ilustrado na Figura 6.7.

$\mathrm{Na}$ arquitetura apresentada na Figura 6.7, o servidor HTTP armazena os documentos, executa a lógica da aplicação e realiza o acesso ao banco de dados. No caso do cliente pesado, esse servidor processa diretamente a requisição e envia um documento VXML (junto a um XHTML para a apresentação visual, por exemplo) como 


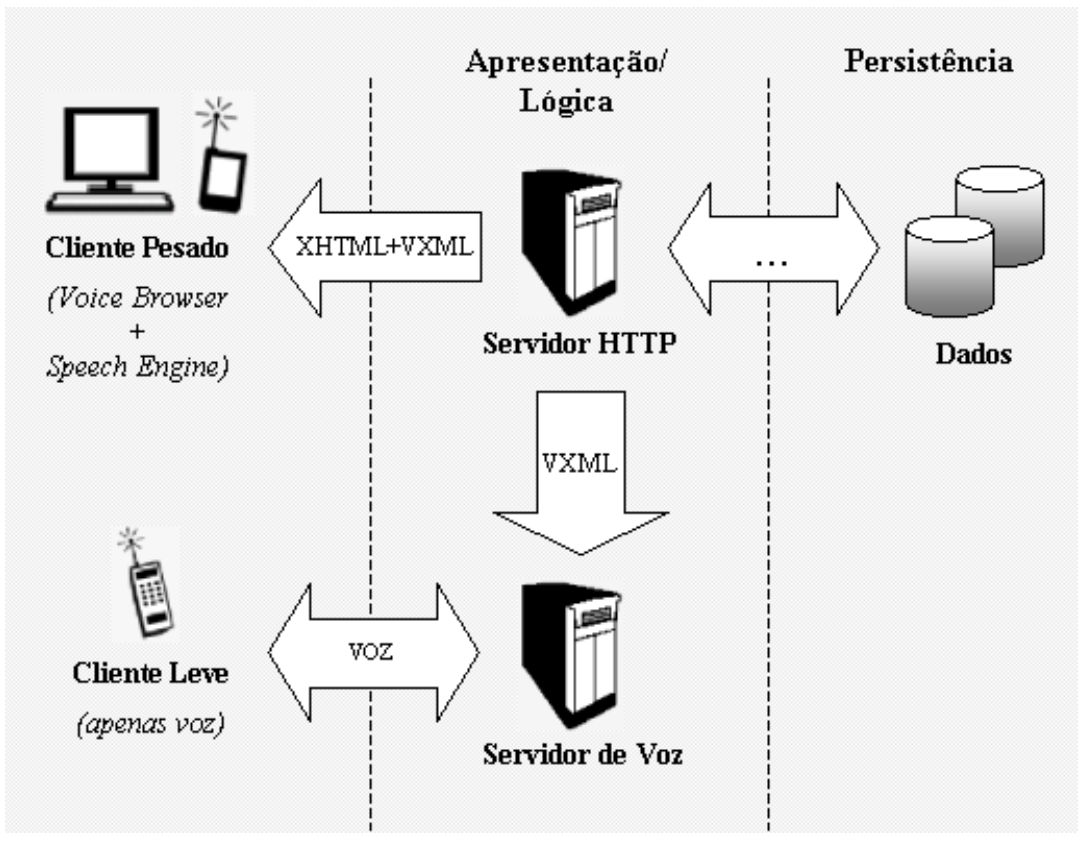

Figura 6.7: Exemplo de uma arquitetura cliente-servidor utilizando VoiceXML.

resposta. Esse documento é interpretado por um voice browser no cliente, que utiliza localmente uma engine para o reconhecimento (entrada) e síntese (saída) de voz. Desse modo, todo o processamento da voz é realizado no cliente.

No caso de um cliente leve, a voz é processada remotamente por um servidor de voz. Esse último atua como um intermediário, obtendo o documento VXML do servidor HTTP e sintetizando a voz para o cliente. Ele também é responsável por reconhecer a entrada de voz vinda do cliente e, de acordo com a lógica de interação descrita no VXML, sintetizar a resposta ou convertê-la numa requisição para o servidor HTTP.

\section{Estrutura de um Documento VoiceXML}

Um documento VXML pode ser visto como uma máquina de estados finitos, no qual o usuário sempre está em um estado do diálogo em um dado momento /W3C, 2000b. De acordo com a interação do usuário e a seqüência lógica definida no documento, é determinada a resposta do sistema.

Os componentes principais de um documento VXML são os diálogos, que podem ser de dois tipos: formulários e menus. Os formulários são responsáveis por apresentar e coletar dados para variáveis, sendo que cada campo do formulário pode ter uma gramática especificando as suas possiveis entradas. Já os menus oferecem opções que de acordo com a escolha do usuário determinam a transição para o próximo diálogo. 
Um diálogo também pode ser composto de vários sub-diálogos, que são semelhantes à chamadas de função em programação estruturada. Eles permitem que a interação seja passada para um novo diálogo e depois retornada para o diálogo principal, armazenando o estado da interação antes da chamada. Os sub-diálogos podem representar tarefas ou seqüências de diálogos comuns que podem ser reutilizados por outros documentos.

A listagem abaixo apresenta um exemplo de diálogo, no qual a aplicação pede ao usuário que escolha uma bebida e então submete a resposta ao servidor:

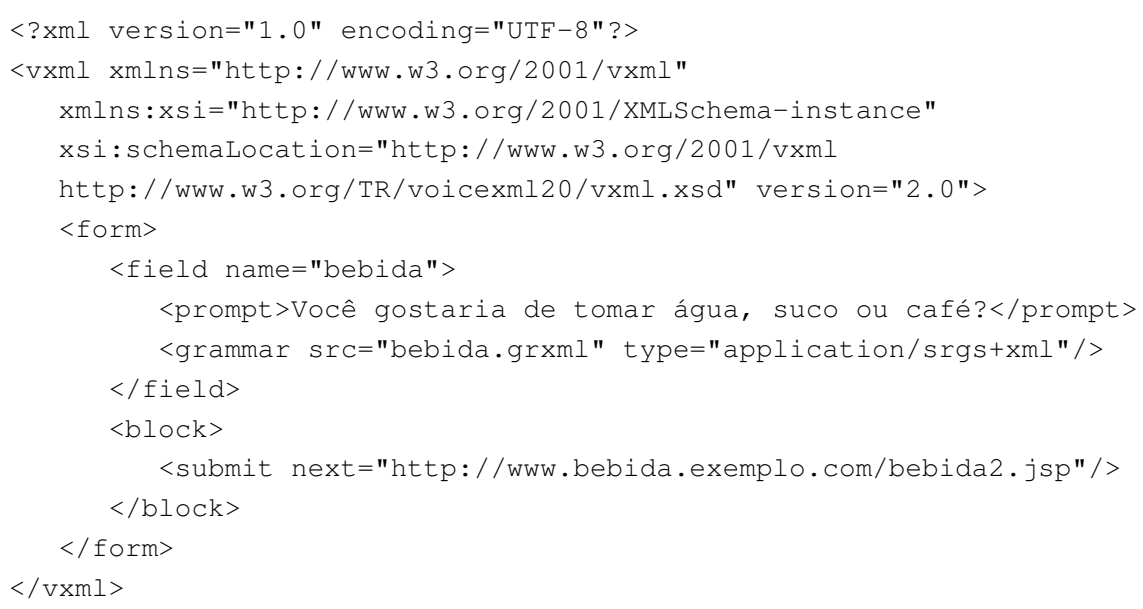

O elemento raiz de um documento VoiceXML é o <vxml>. Este é composto por atributos como o namespace, a localização e o número da versão atual da especificação. O elemento $<$ form $>$ representa um diálogo do tipo formulário, que no exemplo tem como itens um elemento $\langle$ field $\rangle$ e um $\langle$ block $\rangle$. O elemento $\langle$ field $\rangle$ especifica um campo de entrada de dados, onde é requisitado ao usuário algum tipo de informação. A tag <prompt> define a pergunta a ser feita para o usuário e a tag $<$ grammar $>$ indica a gramática associada ao campo. Por fim, o elemento $<\mathrm{block}>$ define uma seqüência de comandos a serem executados. Na listagem acima o comando é o <submit $>$, que envia o resultado do formulário para a próxima página.

Um exemplo de interação construído com o diálogo apresentado poderia ser o seguinte:

Sistema: - Você gostaria de tomar água, suco ou café?

Usuário: - Refrigerante.

Sistema: - Não entendi o que você disse. (mensagem padrão específica da aplicação)

Sistema: - Você gostaria de tomar água, suco ou café?

Usuário: - Suco.

Sistema: (continua o processamento no documento bebida2.jsp) 


\subsubsection{SALT - Speech Application Language Tags}

A Speech Application Language Tags (SALT) [SALT Forum, 2002], assim como o VoiceXML, é uma linguagem de marcação para interfaces baseadas em voz. Ela consiste de um pequeno conjunto de elementos XML, com seus atributos, eventos e métodos associados, que permitem incorporar interfaces de voz a aplicações e serviços Web. A linguagem SALT pode ser utilizada junto com HTML, XHTML, WML, SVG e outros padrões para a construção de interfaces de voz apenas (utilizadas em telefonia, por exemplo) ou de interfaces multimodais.

A SALT possibilita que usuários interajam com uma aplicação multimodal de várias formas, seja por meio da fala, caneta, teclado ou mouse, e produzam saídas de voz sintetizada, áudio, vídeo, gráficos ou texto. Cada um desses modos pode ser utilizado independentemente ou paralelamente. Uma aplicação SALT é feita para ser executada tanto em browsers multimodais, como também em browsers visuais e voice browsers: uma vez que o SALT apenas estende as linguagens de marcação padrão ao invés de alterá-las, documentos SALT podem ser utilizados simplesmente omitindo-se ou ignorando-se suas tags.

A especificação completa do padrão SALT está sendo desenvolvida pelo SALT Forum, uma iniciativa da indústria envolvendo grandes corporações como Microsoft, Intel, Cisco, Philips e Scansoft. O objetivo desse comitê é desenvolver uma linguagem aberta, com uma API independente de plataforma e implementação, que torne possível o acesso multimodal a informação através de telefones, tablet PCs, PDAs e outros dispositivos móveis |Microsoft Corp., 2006].

\section{Princípios de Projeto}

A SALT baseia-se em padrões existentes da indústria para a síntese de voz, formatação de gramáticas e geração de resultados semânticos, o que faz com que ela seja uma linguagem de marcação em nível de aplicação usada para "esconder" detalhes de baixo-nível do sistema. De acordo com o SALT Forum|2006], a linguagem foi projetada com os seguintes princípios:

Fácil Integração à Aplicações Web: A execução de uma aplicação SALT baseia-se no modelo de execução DOM das páginas Web, o que permite integrá-lo facilmente à outras linguagens visuais de marcação. Isso também possibilita que desenvolvedores Web aproveitem seus conhecimentos para a construção de interfaces de voz, uma vez que o modelo de programação do SALT é praticamente o mesmo.

Separação da Interface de Voz da Lógica da Aplicação: Uma página SALT é composta de três porções de código |Wang, 2002|: (1) uma seção de dados, corres- 
pondente à informação que o sistema necessita obter do usuário; (2) uma seção de apresentação que, juntamente com objetos gráficos, contém os templates para a geração de diálogos com o usuário; (3) uma seção de script que inclui a lógica de inferência para controlar o fluxo do diálogo e atingir o objetivo da página. Essa separação contribui para que uma interface de voz SALT seja fracamente acoplada à estrutura da página (por exemplo, um formulário HTML), permitindo que os componentes de voz e diálogos sejam reutilizados.

Amplo Escopo de Dispositivos: O padrão SALT não foi projetado para nenhum tipo de dispositivo em particular, mas sim para um amplo escopo de arquiteturas. $\mathrm{O}$ modelo genérico com que o SALT implementa a integração de voz possibilita que ele seja utilizado desde PCs a telefones, requerendo um custo mínimo para sua adaptação a diferentes dispositivos.

Utilização em Múltiplos Cenários: O SALT permite que uma mesma aplicação também seja utilizada em diferentes cenários: (1) multimodal, onde uma página visual pode ser aprimorada com uma interface de voz no mesmo dispositivo; (2) cross-modal, em que uma única página de aplicação pode ser reutilizada de diferentes modos em diferentes dispositivos (por exemplo, somente visual ou somente voz).

\section{Elementos da SALT}

A SALT não possui elementos de controle, de modo que os desenvolvedores devem embuti-la em outras linguagens hospedeiras para especificar o fluxo de execução e interação. O núcleo da linguagem SALT é uma coleção de objetos que possibilitam que uma aplicação manipule entradas/saídas de voz e comunique-se com outros componentes de baixo-nível como gerenciadores de discurso, interfaces de telefonia, etc. Os elementos SALT são independentes de linguagem de programação e incluem:

- <prompt>: Utilizada para especificar a saída do sistema, essa tag apresenta gravações de áudio e voz sintetizada para o usuário. O elemento <prompt > também possui comandos para gerenciar a execução das mídias, como play, pause, stop e controles de velocidade e volume.

- <listen>: Utilizada para especificar a entrada do sistema, essa tag reconhece palavras e frases ditas pelo usuário. Ela pode ser usada de três modos: (1) automatic, empregada em cenários de telefonia ou sem interação manual, nos quais a própria aplicação controla quando iniciar ou parar o reconhecimento; (2) single, para aplicações do tipo "push-to-talk", em que o reconhecimento é explicitamente controlado pelo usuário; (3) multiple, usada em aplicações de 
ditado ou do tipo microfone aberto, onde os resultados do reconhecimento são retornados em intervalos conforme o usuário pronuncia as palavras.

- <grammar>: Especifica as frases, palavras e construções gramaticais que um usuário pode falar. Para permitir a interoperabilidade das aplicações SALT, o objetivo é que os browsers SALT suportem pelo menos a forma XML da SRGS (Speech Recognition Grammar Specification) |W3C, 2000a].

- $<\mathrm{dtmf}>$ : Usado em aplicações de telefonia para especificar gramáticas DTMF e lidar com entradas de teclado e outros eventos. O elemento <dtmf $>$ permite a configuração de atributos como timeouts, seqüências válidas de DTMF e detecção de entradas que não constam na gramática.

- <record >: Captura e grava a voz do usuário. É usado para especificar parâmetros relacionados à gravação e os resultados podem ser processados por meio de tags como <bind $>$ ou código script.

- <bind>: Integra as palavras e frases reconhecidas à lógica da aplicação. Pode ser usado para inspecionar os resultados do reconhecimento e copiar partes consideradas relevantes para inserí-las na página que hospeda o código SALT.

\subsubsection{X+V - XHTML + Voice}

A XHTML + Voice $(\mathrm{X}+\mathrm{V}) \mid \mathrm{W} 3 \mathrm{C}, 2$ 2002b $\mid$ é uma linguagem de marcação desenvolvida para a construção de interfaces multimodais. Assim como a SALT, os programadores utilizam a $\mathrm{X}+\mathrm{V}$ para inserir elementos de voz em aplicações Web. Entretanto, ao invés de inventar novas tags, a X+V reutiliza as tags existentes no XHTML 1.1 e no VoiceXML 2.0.

O XHTML consiste basicamente de HTML compativel com as regras de formatação do XML e é o padrão atual para construção de páginas Web. Já o VoiceXML foi desenvolvido para a criação de diálogos de aúdio e voz sintetizada, reconhecimento de voz e DTMF, como mencionado na Seção 6.3.3. Juntos, o XHTML e o VoiceXML provêem um suporte rico e padronizado para a integração de interfaces de voz ao tradicional ambiente gráfico da Web.

O padrão $\mathrm{X}+\mathrm{V}$ ainda está em desenvolvimento, sendo que apenas em 2002, IBM, Motorola e Opera Software submeteram a especificação do X+V ao W3C. O objetivo era definir um padrão que satisfizesse um conjunto de características como flexibilidade, facilidade de uso e adaptação a diferentes tipos de dispositivos. Assim como o VoiceXML, o $\mathrm{X}+\mathrm{V}$ surgiu em resposta à demanda crescente por interação baseada em voz para pequenos dispositivos móveis, permitindo que os mesmos suportem interação visual (por caneta ou teclado), interação por voz, ou ambos [IBM Corp., 2004]. 


\section{Arquitetura da $\mathrm{X}+\mathrm{V}$}

Uma aplicação Web multimodal escrita em $\mathrm{X}+\mathrm{V}$ é composta por três elementos principais [IBM Corp. 2004]: um documento XHTML, que pode ser visto como um contêiner para as marcações visuais (formulários, campos de texto, caixas de seleção, imagens, etc.); fragmentos de marcações VoiceXML (campos de voz, formulários, etc.); e um contêiner para a marcação de eventos XML, que correlacionam os elementos visuais aos de voz e definem seu comportamento.

A $\mathrm{X}+\mathrm{V}$ utiliza a noção de documentos e formulários. Um único documento VoiceXML pode conter múltiplos formulários de voz, que por sua vez podem ser embutidos em documentos XHTML para criar aplicações multimodais. Essas aplicações são compativeis com diferentes plataformas e dispositivos, podendo ser executadas em browsers multimodais, browsers visuais apenas ou em sistemas baseados somente em voz, como IVRs. A Figura 6.8 ilustra essa característica.

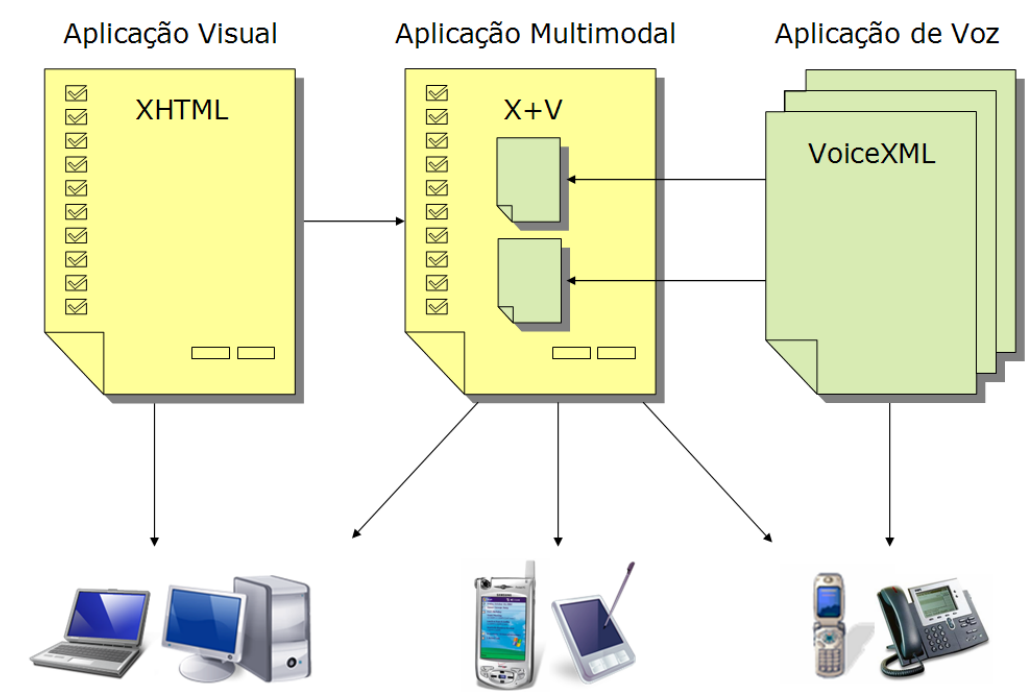

Figura 6.8: Múltiplos formulários VoiceXML embutidos em um documento XHTML. O resultado é uma aplicação multimodal $\mathrm{X}+\mathrm{V}$ que executa em diferentes dispositivos.

Como todas as partes do $\mathrm{X}+\mathrm{V}$ são conformantes com o XML, as marcações de voz podem ser inseridas de duas maneiras: no mesmo arquivo que o XHTML ou em arquivos separados. Isso proporciona uma certa flexibilidade na construção de aplicações, já que as marcações visuais e de voz podem ser desenvolvidas separadamente e combinadas depois IBM Corp., 2003. Outra vantagem é a possibilidade de reutilizar os fragmentos de voz em múltiplas páginas XHTML. Um exemplo seria uma aplicação para reserva de passagens aéreas, em que o usuário deve informar a cidade de partida e o destino. Se o fragmento de voz está separado, a marcação correspondente a relação de cidades pode ser reaproveitada. 
A $\mathrm{X}+\mathrm{V}$ particiona a linguagem VoiceXML em múltiplos módulos, incluindo módulos para síntese de voz, gerenciamento de gramáticas e diálogos. Uma vez que o ambiente de uma aplicação Web é orientado a eventos, a $\mathrm{X}+\mathrm{V}$ incorpora o framework DOM usado no padrão de eventos XML. Com isso, eventos HTML do tipo "on mouseover" ou "on input focus" são utilizados para criar a correlação entre as marcações de voz e visuais.

\section{$\mathrm{X}+\mathrm{V}$ versus SALT}

$\mathrm{X}+\mathrm{V}$ e SALT são linguagens de marcação para a criação de aplicações Web que suportam interação por voz. Embora ambas linguagens tenham conceitos bastantes similares, existem algumas diferenças fundamentais entre elas [IBM Corp., 2004]:

1. A SALT não é "amarrada" a nenhuma linguagem de marcação visual ou modelo de eventos. Pelo contrário, ela é um conjunto genérico de tags que pode ser inserido em várias outras linguagens. Isso faz com que ela requeira um contêiner para prover o fluxo de execução da aplicação, embora ela não defina um. Já a $\mathrm{X}+\mathrm{V}$ pode usar tanto um formulário VoiceXML (que possui seu próprio fluxo de interação na forma de um algoritmo de interpretação de formulários), como também o fluxo da linguagem hospedeira XHTML.

2. Uma aplicação desenvolvida em SALT utilizando uma linguagem hospedeira específica deve ser adaptada para cada ambiente de execução distinto (por exemplo, celulares ou PDAs de diferentes fabricantes). Em contraste, a X+V define todos os aspectos do ambiente de execução através dos padrões XHTML e VoiceXML, garantindo a portabilidade das aplicações entre dispositivos compativeis com esses padrões.

3. A quantidade de marcações é outro diferencial entre as duas linguagens. Enquanto SALT define poucas tags de alto-nível, a $\mathrm{X}+\mathrm{V}$ possui um conjunto bem maior e abrangente de marcações. A modularidade da arquitetura da $\mathrm{X}+\mathrm{V}$ também torna mais simples a separação das diferentes interfaces de uma aplicação, uma vez que a dependência da linguagem SALT em relação à linguagem contêiner torna difícil a separação das funções do código.

\subsubsection{EMMA - Extensible MultiModal Annotation markup language}

A Extensible MultiModal Annotation markup language (EMMA) |W3C, 2003a| é uma linguagem de marcação desenvolvida para uso em sistemas que realizam a interpretação semântica de entradas como voz, escrita manual, etc. A EMMA possibilita 
a representação textual da interação do usuário, bem como a definição de elementos e atributos que focam na anotação das interpretações das entradas. O objetivo é que a linguagem seja utilizada como um padrão para troca de informações entre os componentes em um sistema multimodal, permitindo descrever e combinar dados de múltiplas fontes.

A proposta da EMMA é representar informações que são geradas automaticamente por um componente de interpretação a partir da entrada do usuário. Esses componentes podem ser reconhecedores de voz, reconhecedores de escrita, engines de processamento de linguagem natural, interpretadores de gestos, sinais DTMF, etc. A informação específica de cada modalidade provida por esses componentes é convertida em uma representação EMMA, para ser então processada por um integrador.

A especificação descreve marcações para representar interpretações das entradas do usuário, juntamente de anotações como taxas de confiança, timestamps, modalidades de entrada, etc. Por exemplo, se em uma aplicação de mapas com interação por caneta, um usuário executa um gesto correspondente ao comando zoom, uma possivel representação EMMA dessa interpretação pode ser:

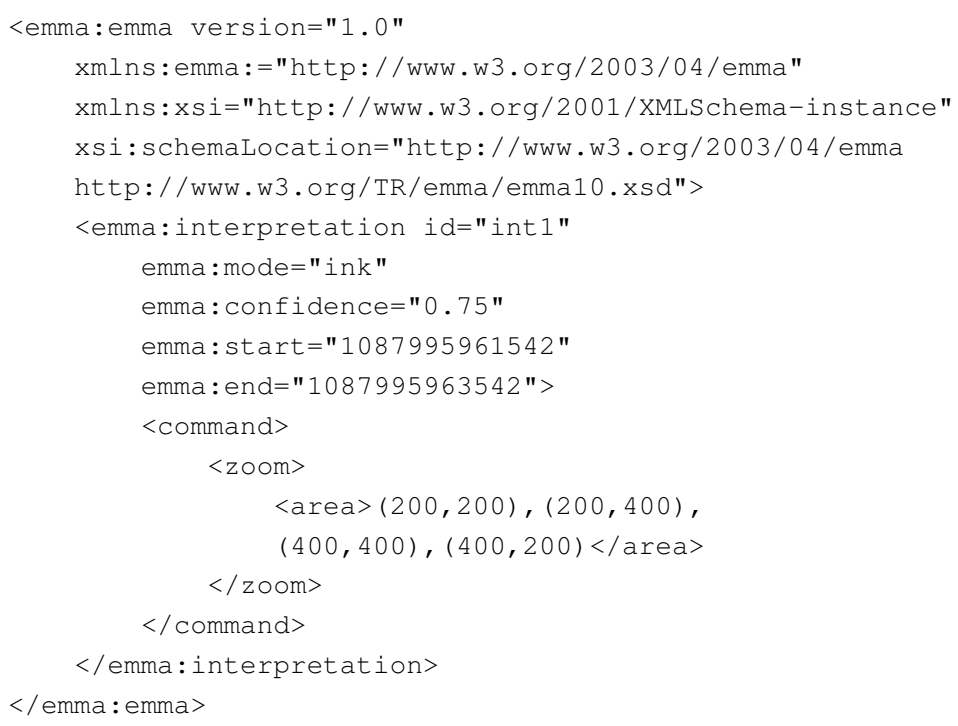

Nesse exemplo, o elemento <emma: interpretation> corresponde à interpretação gerada pelo reconhecedor. O atributo <emma : mode $>$ especifica a modalidade de entrada, enquanto que o atributo <emma : confidence $>$ informa a probabilidade de acerto do reconhecimento (taxa de precisão); os atributos <emma: start> e <emma : end> informam o timestamp inicial e final da entrada, respectivamente. Os elementos $<$ command $>$, <zoom> e <area > são específicos da aplicação e descrevem o resultado da interpretação da entrada. 


\section{Tipos de Dados}

Tipicamente, um documento EMMA pode conter três tipos de dados que são utilizadas para descrever a informação entrada pelo usuário:

Dados de Instância: Correspondem à representação em XML de uma interpretação da entrada do usuário. São marcações específicas da aplicação cuja informação é relevante para um consumidor de documentos EMMA.

Modelo de Dados: Consiste das restrições na estrutura e no conteúdo de uma instância. O modelo de dados é geralmente um esquema pré-estabelecido pela aplicação, podendo também não ser especificado.

Metadados: Correspondem às anotações associadas aos dados obtidos na instância. Os valores das anotações são adicionados pelos processadores de entrada em tempo de execução.

A principal vantagem da adoção de um padrão comum de representação de dados como o EMMA, é com relação a interoperabilidade |Larson, 2003|. Componentes de diferentes fabricantes poderão ser acoplados em uma aplicação multimodal e trabalhar em conjunto. Por exemplo, um reconhecedor de voz de um fabricante $A$, um reconhecedor de escrita de um fabricante $B$, um componente de integração de um fabricante $C$, e um gerenciador de interação de um fabricante $D$, conseguirão trocar informações EMMA entre si. EMMA poderá ser utilizada então como uma linguagem de intercâmbio entre componentes de sistemas multimodais.

\subsection{Considerações Finais}

Este capítulo teve por objetivo descrever alguns exemplos de aplicações comumente referenciadas pela literatura, além de fornecer uma visão geral das tecnologias e padrões que estão atualmente em fase de especificação na área de interfaces multimodais. O uso desses padrões deverá proporcionar uma maior agilidade no desenvolvimento de sistemas multimodais, além de assegurar a compatibilidade das aplicações entre diferentes tipos de dispositivos e softwares, facilitando a extensão e o reuso de componentes. 


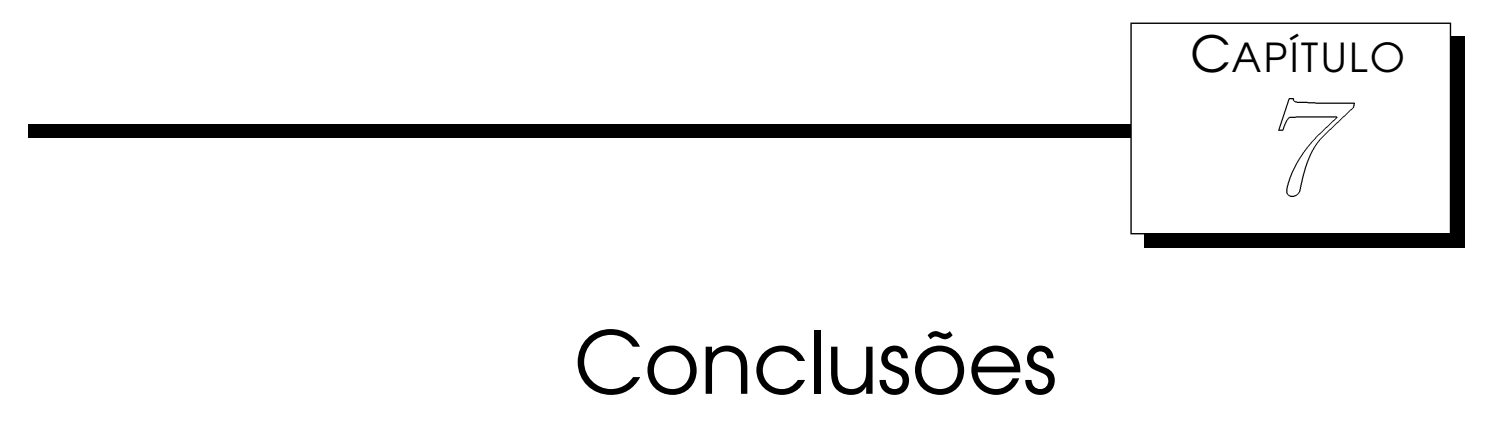

\subsection{Considerações Iniciais}

Interfaces multimodais que suportam simultaneamente diferentes tipos de entrada do usuário estão se tornando cada vez mais comuns. Áreas de pesquisa como Interação Humano-Computador e Computação Ubíqua tem concentrado esforços para melhor explorar as capacidades desse tipo de interface, seja por meio da construção de infraestruturas de hardware ou do desenvolvimento de novas aplicações. A literatura reporta diversas técnicas e aplicações que utilizam esse conceito para proporcionar experiências mais ricas de interação aos usuários. Os ganhos em termos de usabilidade e acessibilidade com a implementação de interfaces multimodais justificam o seu alto custo de desenvolvimento.

Atualmente, vários consórcios da indústria também tem se mobilizado com o objetivo de definir padrões e linguagens para o desenvolvimento de interfaces multimodais. O uso de multimodalidade no ambiente Web pode ser um fator fundamental para a popularização desse tipo de interface. Além disso, a padronização permite que uma mesma aplicação execute em diferentes plataformas e dispositivos, garantindo a portabilidade e diminuindo custos através do reuso de software.

Enquanto estes padrões ainda não estão totalmente definidos, iniciativas individuais como a do trabalho aqui reportado tentam suprir a falta de ferramentas de suporte ao desenvolvimento de aplicações multimodais. Este trabalho teve como objetivo investigar a construção de uma infraestrutura para facilitar o desenvolvimento de 
interfaces multimodais e sua integração a aplicações de computação ubíqua. Como resultado, uma API de reconhecimento de escrita (JInk) e um framework de integração multimodal (JMIS) foram implementados e detalhados nesta dissertação.

\subsection{Resultados e Contribuições}

Dentre os principais resultados obtidos e contribuições, pode-se citar:

- A extensão da arquitetura da Java Ink API para acomodar o reconhecimento de diferentes tipos de caracteres. Isso proporcionou um alcance ainda maior a API, que agora pode ser utilizada em aplicações de diferentes domínios. Um exemplo é o Geometrics Editor, uma ferramenta desenvolvida em conjunto com pesquisadores da UNESP-Rio Claro, que visa auxiliar o ensino de geometria por meio do reconhecimento de formas geométricas [Inácio Jr., 2005].

- Integração da JInk API com diversas aplicações protótipo, dentre as quais um reconhecedor de caracteres japoneses, um rastreador de gestos baseado em interação com câmera e uma aplicação de reconhecimento de escrita com uso de dicionários Inácio Jr., 2005]. Esses programas não foram detalhados neste documento pelo fato de a JInk ser apenas uma infraestrutura auxiliar do framework multimodal.

- A implementação de uma infraestrutura completa para integração de modalidades de escrita e voz, o JMIS Framework. Utilizando uma arquitetura modular e um conjunto de padrões de projeto, o JMIS possibilita fácil integração às aplicações e baixa dependência de infraestruturas para processamento unimodal.

- Integração do JMIS Framework no contexto do Projeto InCA-Serve. A implementação da SpeechBoard como prova-de-conceito é um exemplo das possibilidades de uso da arquitetura construída em aplicações de computação ubíqua. Como resultado, os usuários podem controlar e interagir com a aplicação através de comandos de voz e escrita.

- Integração da infraestrutura multimodal no desenvolvimento de uma ferramenta para anotação sobre vídeo. A M4Note Goularte et al., 2004 é uma aplicação multimodal que executa em Tablet PCs e que permite a captura de vídeo, a criação de anotações e a geração de documentos a partir do conteúdo multimídia. 


\subsection{Limitações e Problemas Encontrados}

A primeira restrição se refere ao número de modalidades de interação envolvidas no JMIS Framework. São exploradas apenas entradas baseadas em interação com caneta e voz, não sendo foco, ao menos inicialmente, a utilização de outras modalidades. O uso da Java Ink API e da Java Speech API para o processamento individual das modalidades também é um requisito, não sendo possivel substituí-las por outras infraestruturas.

Dada a complexidade das tecnologias envolvidas, a implementação do sistema possui limitações de escopo, de modo a tornar a proposta factível. Uma dessas limitações é o reconhecimento de escrita manual realizado pela JInk API, que oferece suporte apenas reconhecimento em escrita não-cursiva. Os modelos devem ser previamente treinados pelo usuário, não sendo fornecido nenhum conjunto de caracteres default.

Outra limitação se refere a performance da infraestrutura de reconhecimento de voz. O processo é relativamente lento e o alto processamento demandado pelo software o torna impraticável em dispositivos com menor poder computacional. Atualmente a robustez também é um problema. A estabilidade para suportar, por exemplo, troca de usuários e interferência de sons do ambiente, ainda precisa ser aprimorada. Apesar desses problemas, o reconhecimento de voz foi considerado satisfatório: grande parte dos erros apresentados eram resultantes de ambigüidades da fala, ou então de problemas com a dicção do usuário, que deve ser bastante clara.

\subsection{Trabalhos futuros}

Como continuidade da pesquisa aqui apresentada, se faz oportuna a realização de sessões de experimento do framework e de desenvolvimento de aplicações no contexto de disciplinas de Interação Usuário-Computador e de Computação Ubíqua. A avaliação da interação do usuário com interfaces multimodais tem sido reportada em vários contextos tais como o de objetos tangiveis Taib and Ruiz 2005; Petridis et al. [2006] e de usuários móveis Jost et al. 2005.

A condução de avaliações relacionadas a reusabilidade do JMIS Framework também é outro ponto a ser trabalhado. Devido ao curto tempo de implementação, ainda não foi realizada nenhuma comparação em termos de métricas, linhas de código ou esforço de implementação necessário com e sem o uso do framework.

Os vários trabalhos realizados com suporte de versões preliminares do framework proposto (listados na Seção 1.4 não realizaram experimentos formais com 
usuários. Um experimento preliminar foi realizado com a M4Note Cattelan et al., 2005], mas a demanda por novos experimentos com usuários de aplicações multimodais deve direcionar a realização de vários trabalhos futuros do grupo.

Uma dos desafios da interação multimodal é o treinamento dos vocabulários por parte dos usuários, estando a identificação de automática de novos vocabulários Kaiser [2005], a adaptação combinada usuário-sistema Pan et al. [2005] e o estudo de aspectos lingüísticos de conversação Chai et al. 2005] entre as abordagens adotadas para o problema. O trabalho suporta o mapeamento "on-the-fly" de novos símbolos no caso da interação por tinta eletrônica, mas o tratamento combinado com voz constituise um trabalho futuro.

O trabalho, até o momento, focou no apoio a usuários tratados isoladamente. Problemas interessantes podem ser explorados em trabalhos futuros levando em conta interfaces multimodais multi-usuário, como aqueles discutidos por Tse et al. [2006, no contexto de interação de múltiplos usuários em mesas interativas, e por Barthelmess et al. 2006, no contexto do trabalho em grupo. 


\section{Referências Bibliográficas}

20th Century Fox (2002). Minority Report. Movie. Directed by Steven Spielberg.

Abowd, G. D. and Mynatt, E. D. (2000). Charting past, present, and future research in ubiquitous computing. ACM Trans. on Computer-Human Interaction, 7(1):29-58.

Alexander, C., Ishikawa, S., Silverstein, M., Jacobson, M., Fiksdahl-King, I., and Angel, S. (1977). A Pattern Language. Oxford University Press, New York, NY, USA.

Apache Software Foundation (2000). Struts. Disponível na Internet em http://struts.apache.org. Acessado em 20/09/2006.

Bachmann, F., Bass, L., Buhman, C., Comella-Dorda, S., Long, F., Robert, J., Seacord, R., and Wallnau, K. (2000). Technical Concepts of Component-Based Software Engineering. Technical report, Carnegie Mellon University - Software Engineering Institute.

Barthelmess, P., Kaiser, E., Lunsford, R., McGee, D., Cohen, P., and Oviatt, S. (2006). Humancentered collaborative interaction. In HCM '06: Proceedings of the 1st ACM international workshop on Human-centered multimedia, pages 1-8, New York, NY, USA. ACM Press.

Bolt, R. A. (1980). Put-That-There: Voice and Gesture at the Graphics Interface. Computer Graphics, 14(3):262-70.

Bosch, J., Molin, P., Mattsson, M., and Bengtsson, P. (1997). ObjectOriented Frameworks Problems and Experiences.

Bouchet, J., Nigay, L., and Ganille, T. (2004). Icare - software components for rapidly developing multimodal interfaces. In ICMI '04: Proceedings of the 6th International Conference on Multimodal Interfaces, pages 251-258, New York, NY, USA. ACM Press.

Brown, A. W. and Short, K. (1997). On Components and Objects: The Foundations of Component-Based Development. In SAST '97: Proceedings of the 5th International Symposium on Assessment of Software Tools (SAST '97), pages 112-121, Washington, DC, USA. IEEE Computer Society. 
Buschmann, F., Meunier, R., Rohnert, H., Sommerlad, P., and Stal, M. (1996). PatternOriented Software Architecture: A System of Patterns. John Wiley \& Sons, Inc., New York, NY, USA.

Carnegie Mellon University (2004). CMU Sphinx. Disponivel na Internet em http://cmusphinx.org. Acessado em 30/08/2006.

Cattelan, R. G., Andrade, A. R., Rocha, C. F. P., and Pimentel, M. G. C. (2003). iClass: um sistema para captura e acesso de sessões em ambiente educacional. Revista Eletrônica de Iniciação Científica (REIC) da SBC. Disponível na Internet em http://www.sbc.org.br/reic. Acessado em 10/09/2006., page 19.

Cattelan, R. G., Jr, V. R. I., and Pimentel, M. G. C. (2005). Pervasive Imaging: a Capture and Access Perspective. In Proceedings of the 2005 Workshop of Pervasive Image Capture and Sharing.

Chai, J. Y., Prasov, Z., Blaim, J., and Jin, R. (2005). Linguistic theories in efficient multimodal reference resolution: an empirical investigation. In IUI '05: Proceedings of the 10th international conference on Intelligent user interfaces, pages 43-50, New York, NY, USA. ACM Press.

Chan, K. F. and Yeung, D. Y. (1999). Recognizing on-line handwritten alphanumeric characters through flexible structural matching. Pattern Recognition, 32(7):1099-1114.

Cloudgarden (2001). TalkingJava SDK. Disponível na Internet em http://www.cloudgarden.com/JSAPI. Acessado em 30/08/2006.

Cohen, P. R., Darlymple, M., Pereira, F. C. N., Sullivan, J. W., Gargan, R. A., Schlossberg, J. L., and Tyler, S. W. (1989). Synergic Use of Direct Manipulation and Natural Language. In In Proceedings of the Conference on Human Factors in Computing Systems - (CHI 89), pages 227-233, Austin, TX.

Cohen, P. R., Johnston, M., McGee, D., Oviatt, S., Pittman, J., Smith, I., Chen, L., and Clow, J. (1997). QuickSet: Multimodal interaction for distributed applications. In Proceedings of the Fifth ACM International Multimedia Conference, pages 31-40.

Corradini, A., Mehta, M., Bernsen, N.-O., Martin, J.-C., and Abrilian, S. (2003). Multimodal Input Fusion in Human-Computer Interaction - On the Example of the on-going NICE Project. In To appear in Proceedings of the NATO-ASI Conference on Data Fusion for Situation Monitoring, Incident Detection, Alert and Response Management, Yerevan, Armenia.

Costa, E. J. X. and Cabral Jr., E. F. (2000). EEG-based discrimination between imagination of left and right hand movements using adaptive gaussian representation. Journal of Medical Engineering and Physics, 22(5):345-348.

D. L. Hall and J. Llinas (1997). An Introduction to Multisensor Data Fusion. In Proceedings of the IEE, volume 85, pages 6-23. 
de Souza, C. R. B., Redmiles, D., Cheng, L.-T., Millen, D., and Patterson, J. (2004). Sometimes you need to see through walls: a field study of application programming interfaces. In CSCW '04: Proceedings of the 2004 ACM conference on Computer supported cooperative work, pages 63-71, New York, NY, USA. ACM Press.

Dix, A. J., Finlay, J. E., Abowd, G. D., and Beale, R. (1998). Human-Computer Interaction. Prentice Hall, Second Edition edition.

Duncan, L., Brown, W., Esposito, C., Holmback, H., and Xue, P. (1999). Enhancing virtual maintenance environments with speech understanding. Technical report, Boeing M\&CT TechNet. Intranet publication.

Fayad, M. and Schmidt, D. C. (1997). Object-oriented Application Frameworks. Communications of the ACM, 40(10):32-38.

Flippo, F., Krebs, A., and Marsic, I. (2003). A framework for rapid development of multimodal interfaces. In Proceedings of the 5th International Conference on Multimodal Interfaces, pages 109-116. ACM Press.

Forsberg, A., Dieterich, M., and Zeleznik, R. (1998). The Music Notepad. In UIST '98: Proceedings of the 11th Annual ACM Symposium on User Interface Software and Technology, pages 203-210, New York, NY, USA. ACM Press.

Fowler, M. (2002). Public versus Published Interfaces. IEEE Software, 19:18-19.

Freeman, H. (1974). Computer processing of line drawing images. ACM Computing Surveys, 6(1):57-98.

Froehlich, G., Hoover, H. J., Liu, L., and Sorenson, P. G. (1997). Hooking into Object-Oriented Application Frameworks. In International Conference on Software Engineering, pages 491501.

Froehlich, G., Hoover, J., Liu, L., and Sorenson, P. (1998). Designing Object-Oriented Frameworks.

Gamma, E., Helm, R., Johnson, R., and Vlissides, J. (1995). Design Patterns: Elements of Reusable Object-Oriented Software. Addisson-Wesley, Toronto, Ontario. Canada.

Goularte, R., Camacho-Guerrero, J. A., Inácio Jr., V. R., and Cattelan, R. G. (2004). M4Note: a multimodal tool for multimedia annotation. In Proceedings of the WebMedia \& LA-Web 2004 Joint Conference (SBC/IW3C)(to appear).

Han, J. Y. (2005). Low-Cost Multi-Touch Sensing through Frustrated Total Internal Reflection. In UIST '05: Proceedings of the 18th Annual ACM Symposium on User Interface Software and Technology, pages 115-118, New York, NY, USA. ACM Press.

Hanheide, M., Bauckhage, C., and Sagerer, G. (2005). Combining environmental cues \& head gestures to interact with wearable devices. In ICMI '05: Proceedings of the 7th international conference on Multimodal interfaces, pages 25-31, New York, NY, USA. ACM Press. 
Harrison, B. L. et al. (1998). Squeeze me, hold me, tilt me! an exploration of manipulative user interfaces. In Proc. of the ACM Conference on Human Factors in Computing Systems.

Hauptmann, A. G. and McAvinney, P. (1993). Gestures with Speech for Graphics Manipulation. International Journal of Man-Machine Studies, 38:231-249.

Holzman, T. G. (1999). Computer-human interface solutions for emergency medical care. Interactions, 6(3):13-24.

Honkala, M. and Pohja, M. (2006). Multimodal interaction with xforms. In ICWE '06: Proceedings of the 6th International Conference on Web Engineering, pages 201-208, New York, NY, USA. ACM Press.

IBM (1998a). Speech for Java. Disponivel na Internet em http://www.alphaworks.ibm.com/tech/speech. Acessado em 30/08/2006.

IBM (1998b). ViaVoice. Disponivel na Internet em http://www306.ibm.com/software/voice/viavoice. Acessado em 30/08/2006.

IBM Corp. (2003). Developing Multimodal Applications using XHTML+Voice. Disponível na Internet em http://www-306.ibm.com/software/pervasive/multimodal. Acessado em 06/01/2007.

IBM Corp. (2004). XHTML+Voice Programmer's Guide - Version 1.0. Disponível na Internet em http://www-306.ibm.com/software/pervasive/multimodal. Acessado em 06/01/2007.

Inácio Jr., V. R. (2003). Componentes para Intercâmbio de Informações em Ambientes de Computação Ubíqua. Relatório Final do Programa de Treinamento de Estudantes de Graduação em Técnicas Especializadas da PRP/USP.

Inácio Jr., V. R. (2005). Componentes para Desenvolvimento de Interfaces Multimodais em Aplicações de Computação Ubíqua. Relatório Final das Atividades Desenvolvidas em Programa de Mestrado - Reportado a FAPESP.

Irawati, S., Calderón, D., and Ko, H. (2006). Spatial ontology for semantic integration in 3d multimodal interaction framework. In VRCIA '06: Proceedings of the 2006 ACM international conference on Virtual reality continuum and its applications, pages 129-135, New York, NY, USA. ACM Press.

Ishii, H. and Ullmer, B. (1997). Tangible bits: Towards seamless interfaces between people, bits and atoms. In Proc. of the ACM Conference on Human Factors in Computing Systems, pages 234-241.

Jain, A. K. and Ross, A. (2004). Multibiometric systems. Communications of the ACM, 47(1):3440.

Johnson, R. and Foote, B. (1988). Designing Reusable classes. Journal of Object-Oriented Programming - JOOP, 1(2):22-35. 
Johnson, R. E. (1997a). Components, Frameworks, Patterns. In SSR '97: Proceedings of the 1997 symposium on Software reusability, pages 10-17, New York, NY, USA. ACM Press.

Johnson, R. E. (1997b). Frameworks = (Components + Patterns). Communications of the ACM, 40(10):39-42.

Johnston, M. (1998). Unification-based Multimodal Parsing. In Proceedings of the 36th Annual Meeting on Association for Computational Linguistics, pages 624-630, Morristown, NJ, USA.

Johnston, M., Cohen, P. R., McGee, D., Oviatt, S. L., Pittman, J. A., and Smith, I. (1997). Unification-based Multimodal Integration. In Proceedings of the 8th Conference on European Chapter of the Association for Computational Linguistics, pages 281-288, Morristown, NJ, USA.

Jokinen, K. and Raike, A. (2003). Multimodality - Technology, Visions and Demands for the Future. In Proceedings of the First Nordic Symposium on Multimodal Interaction, pages 2526.

Jost, M., Haubler, J., Merdes, M., and Malaka, R. (2005). Multimodal interaction for pedestrians: an evaluation study. In IUI '05: Proceedings of the 10th international conference on Intelligent user interfaces, pages 59-66, New York, NY, USA. ACM Press.

Kaiser, E. C. (2005). Multimodal new vocabulary recognition through speech and handwriting in a whiteboard scheduling application. In IUI '05: Proceedings of the 1Oth international conference on Intelligent user interfaces, pages 51-58, New York, NY, USA. ACM Press.

Larson, J. A. (2003). EMMA: W3CŠs Extended Multimodal Annotation Markup Language. Disponivel na Internet em http://www.larson-tech.com/Writings/EMMA.htm. Acessado em $13 / 01 / 2007$.

Latoschik, M. E. (2005). A user interface framework for multimodal vr interactions. In ICMI '05: Proceedings of the 7th international conference on Multimodal interfaces, pages 76-83, New York, NY, USA. ACM Press.

Laverty, R. and Defee, I. (1997). Multimodal interaction in multimedia applications. IEEE First Workshop on Multimedia Signal Processing, pages 25-30.

Lin, J., Newman, M. W., Hong, J. I., and Landay, J. A. (2000). Denim: finding a tighter fit between tools and practice for web site design. In CHI 'OO: Proceedings of the SIGCHI conference on Human factors in computing systems, pages 510-517, New York, NY, USA. ACM Press.

Macedo, A. A., Camacho-Guerrero, J. A., Cattelan, R. G., Inácio Jr., V. R., and Pimentel, M. G. C. (2004). Interaction Alternatives for Linking Everyday Presentations. In Proceedings of the 2004 ACM Conference on Hypertext and Hypermedia, pages 112-113.

Meijler, T. D. and Nierstrasz, O. (1997). Beyond Objects: Components. In Papazoglou, M. P. and Schlageter, G., editors, Cooperative Information Systems: Current Trends and Directions, pages 49-78. Academic Press. 
Microsoft (1999). Microsoft Agent. Disponível na Internet em http://www.microsoft.com/msagent. Acessado em 30/08/2004.

Microsoft (2006). Windows API Reference. Disponivel na Internet em http://msdn2.microsoft.com/en-us/library/aa383749.aspx. Acessado em 20/12/2006.

Microsoft Corp. (2006). Speech Application Language Tags (SALT). Disponivel na Internet em http://www.microsoft.com/speech/evaluation/speechtags. Acessado em 20/12/2006.

Morimoto, C. H., Koons, D., Amir, A., Flickner, M., and Zhai, S. (1999). Keeping an Eye for HCI. In Proceedings of the XII Brazilian Symposium in Computer Graphics and Image Processing - SIBGRAPI, pages 171-176, State University of Campinas, São Paulo, Brazil.

Nock, H. J., Iyengar, G., and Neti, C. (2004). Multimodal processing by finding common cause. Communications of the ACM, 47(1):51-56.

Oviatt, S., DeAngeli, A., and Kuhn, K. (1997). Integration and Synchronization of Input Modes During Multimodal Human-Computer Interaction. In In Proceedings of the Conference on Human Factors in Computing Systems - (CHI 97), pages 415-422, Atlanta, GA.

Oviatt, S. L. (2002). The Human-Computer Interaction Handbook: Fundamentals, Evolving Technologies and Emerging Applications, chapter 14, Multimodal Interfaces, pages 286-304. Lawrence Erlbaum Assoc.

Oviatt, S. L. and Cohen, P. R. (2000). Multimodal interfaces that process what comes naturally. Communications of the ACM, 43(3):45-53.

Oviatt, S. L., Cohen, P. R., Wu, L., Vergo, J., Duncan, L., Suhm, B., Bers, J., Holzman, T., Winograd, T., Landay, J., Larson, J., and Ferro, D. (2000). Designing the User Interface for Multimodal Speech and Gesture Applications: State-of-the-art Systems and Research Directions. Human Computer Interaction, 15(4):263-322.

Palm (1997). Graffiti. Disponivel na Internet em http://www.palm.com/us/products/input. Acessado em 30/12/2006.

Pan, S., Shen, S., Zhou, M. X., and Houck, K. (2005). Two-way adaptation for robust input interpretation in practical multimodal conversation systems. In IUI '05: Proceedings of the 10th international conference on Intelligent user interfaces, pages 35-42, New York, NY, USA. ACM Press.

Paterno;, F. and Giammarino, F. (2006). Authoring interfaces with combined use of graphics and voice for both stationary and mobile devices. In AVI '06: Proceedings of the working conference on Advanced visual interfaces, pages 329-335, New York, NY, USA. ACM Press.

Petridis, P., Mania, K., Pletinckx, D., and White, M. (2006). Usability evaluation of the epoch multimodal user interface: designing 3d tangible interactions. In VRST '06: Proceedings of the ACM symposium on Virtual reality software and technology, pages 116-122, New York, NY, USA. ACM Press. 
Pieraccini, R., Dayanidhi, K., Bloom, J., Dahan, J., Phillips, M., Goodman, B. R., and Prasad, K. V. (2004). Multimodal conversational systems for automobiles. Communications of the ACM, 47(1):47-49.

Plamondon, R. and Srihari, S. N. (2000). On-Line and Off-Line Handwriting Recognition: A Comprehensive Survey. IEEE Transactions on Pattern Analysis and Machine Intelligence, 22(1):63-84.

Pollard, C. and Sag, I. A. (1994). Head-Driven Phrase Structure Grammar. University of Chicago Press and CSLI Publications, Chicago, Illinois.

Pree, W. (1999). In Building Application Frameworks: Object-Oriented Foundations of Framework Design, chapter Hot-Spot-Driven Development, pages 379-393. John Wiley \& Sons, Inc.

Pressman, R. S. (2002). Software Engineering - A Practitioner's Approach. McGraw-Hill, 5th edition.

R. R. Murphy (1996). Biological and Cognitive Foundations of Intelligent Data Fusion. IEEE Transactions on Systems, Man, and Cybernetics, 26:42-51.

SALT Forum (2002). Speech Application Language Tags (SALT) 1.0 Specification. Disponivel na Internet em http://www.saltforum.org. Acessado em 20/12/2006.

SALT Forum (2006). Speech Application Language Tags (SALT) - Technical White Paper. Disponível na Internet em http://www.saltforum.org. Acessado em 20/12/2006.

Schmidt, D. C. and Buschmann, F. (2003). Patterns, Frameworks, and Middleware: Their Synergistic Relationships. In ICSE '03: Proceedings of the 25th International Conference on Software Engineering, pages 694-704, Washington, DC, USA. IEEE Computer Society.

Serrano, M., Nigay, L., Demumieux, R., Descos, J., and Losquin, P. (2006). Multimodal interaction on mobile phones: development and evaluation using acicare. In MobileHCI 'O6: Proceedings of the 8th Conference on Human-computer Interaction with Mobile Devices and Services, pages 129-136, New York, NY, USA. ACM Press.

Sharma, R., Pavlovi, V. I., and Huang, T. S. (1998). Toward Multimodal Human-Computer Interface. Proceedings of the IEEE, 86(5):853-869.

Sun Microsystems (1996). Java Platform. Disponível na Internet em http://java.sun.com/downloads. Acessado em 20/09/2006.

Sun Microsystems (1998a). Java Media Framework. Disponivel na Internet em http://java.sun.com/products/java-media/jmf/index.jsp. Acessado em 30/08/2006.

Sun Microsystems (1998b). Java Speech API Grammar Format Specification. Disponível na Internet em http://java.sun.com/products/javamedia/speech/forDevelopers/JSGF/index.html. Acessado em 06/07/2006. 
Sun Microsystems (1998c). Java Speech API Specification. Disponível na Internet em http://java.sun.com/products/java-media/speech/forDevelopers/jsapi-doc/index.html. Acessado em 06/07/2006.

Sun Microsystems (1999). Java Speech API Markup Language Specification. Disponível na Internet em http://java.sun.com/products/javamedia/speech/forDevelopers/JSML/index.html. Acessado em 06/07/2006.

Sun Microsystems (2001). FreeTTS. Disponivel na Internet em http://freetts.sourceforge.net. Acessado em 30/08/2006.

Sun Microsystems (2004). Java Server Faces. Disponivel na Internet em http://java.sun.com/javaee/javaserverfaces. Acessado em 20/09/2006.

Taib, R. and Ruiz, N. (2005). Evaluating tangible objects for multimodal interaction design. In OZCHI '05: Proceedings of the 19th conference of the computer-human interaction special interest group (CHISIG) of Australia on Computer-human interaction, pages 1-4, Narrabundah, Australia, Australia. Computer-Human Interaction Special Interest Group (CHISIG) of Australia.

Taib, R. and Ruiz, N. (2006). Multimodal interaction styles for hypermedia adaptation. In IUI '06: Proceedings of the 11th international conference on Intelligent user interfaces, pages 351-353, New York, NY, USA. ACM Press.

Tse, E., Shen, C., Greenberg, S., and Forlines, C. (2006). Enabling interaction with single user applications through speech and gestures on a multi-user tabletop. In AVI '06: Proceedings of the working conference on Advanced visual interfaces, pages 336-343, New York, NY, USA. ACM Press.

W3C (1996). XML - Extensible Markup Language. Disponível na Internet em http:// www.w3c.org/XML. Acessado em 06/07/2006.

W3C (2000a). SRGS - Speech Recognition Grammar Specification. Disponível na Internet em http://www.w3.org/TR/speech-grammar. Acessado em 21/11/2006.

W3C (2000b). VoiceXML - Voice Extensible Markup Language. Disponível na Internet em http://www.w3.org/TR/voicexml20. Acessado em 30/08/2006.

W3C (2002a). Multimodal Interaction Framework. Disponível na Internet em http:// www.w3.org/TR/mmi-framework. Acessado em 06/07/2006.

W3C (2002b). XHTML+Voice Profile 1.0. Disponivel na Internet em http://www.w3.org/TR/ xhtml+voice. Acessado em 20/12/2006.

W3C (2003a). EMMA: Extensible MultiModal Annotation markup language. Disponível na Internet em http://www.w3.org/TR/emma. Acessado em 20/12/2006.

W3C (2003b). InkML - Ink Markup Language. Disponível na Internet em http://www.w3c.org/ TR/InkML. Acessado em 06/07/2006. 
Wang, K. (2002). SALT: An XML Application for Web-based Multimodal Dialog Management. In NLPXML 'O2: Proceedings of the 2nd Workshop on NLP and XML, pages 1-8, Morristown, NJ, USA. Association for Computational Linguistics.

Weiser, M. (1991). The computer for the 21st century. Scientific American, 265(3):94-104.

Westeyn, T., Brashear, H., Atrash, A., and Starner, T. (2003). Georgia Tech Gesture Toolkit: Supporting Experiments in Gesture Recognition. In Proceedings of the 5th international conference on Multimodal interfaces, pages 85-92. ACM Press.

Wikipedia (2006). Library (computing). Disponível na Internet em http://en.wikipedia.org/wiki/Library_(computing). Acessado em 20/12/2006.

Zhao, W., Chellappa, R., Phillips, P. J., and Rosenfeld, A. (2003). Face recognition: A literature survey. ACM Computing Surveys, 35(4):399-458. 